\title{
WORKBOOK TO ACCOMPANY
}

Bhemistr|

\section{and the}

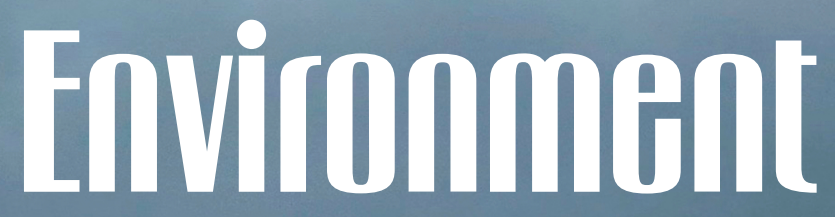

\section{A chemistry perspective for} discussion of environmental issues

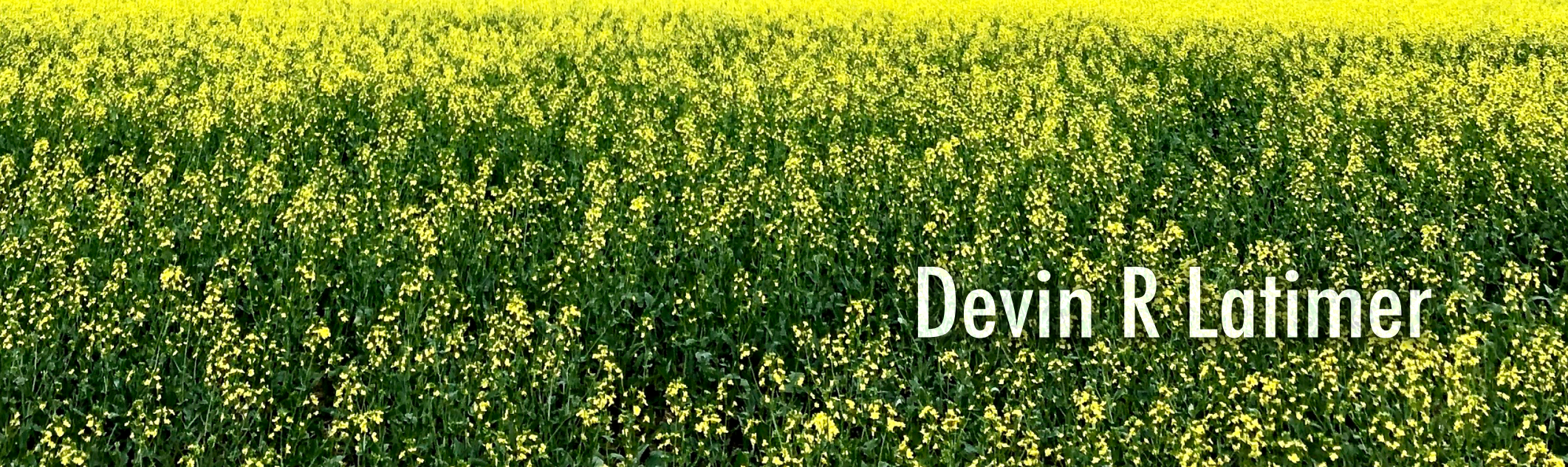


The following is a workbook of the Focus sections contained in Chemistry and the Environment by Devin R Latimer, which is licensed under a Creative Commons Attribution 4.0 International License, except where otherwise noted. Chemistry and the Environment by Devin R Latimer ( (C) August 21, 2020) was adapted from the OpenStax book Chemistry $2 e$ by Paul Flowers, Klaus Theopold, Richard Langley and William R. Robinson at OSCRiceUniversity (C) Jul 19, 2019 OpenStax) licensed under a Creative Commons Attribution License 4.0 license.

Cover photo by Steve Schlachter

Cover design by Keri Latimer 


\section{Workbook Contents}

Introductory Focus 1

Focus on Air 3

(Chemistry and the Environment page 363)

Focus on The Ozone Layer 8

(Chemistry and the Environment page 636)

Focus on Climate Change 27

(Chemistry and the Environment page 655)

Focus on Energy 45

(Chemistry and the Environment page 673)

Focus on Nuclear Energy

57

(Chemistry and the Environment page 1099)

Focus on Alternative Energy

(Chemistry and the Environment page 909)

Focus on Water Quality

(Chemistry and the Environment page 821)

Focus on Acid Precipitation

85

(Chemistry and the Environment page 876)

Focus on Polymers

90

(Chemistry and the Environment page 981) 


\section{Introductory Focus}

Drastic environmental change has often come during times of revolution - be it scientific, societal or ideological. This text offers a chemical background to support discussions of environmental issues of our times. In this, you will be introduced to the basics of chemistry and then we will use that information to focus on discussions involved in the following topics: Air Pollution, The Ozone Layer, Climate Change, Energy (Fossil Fuels, Nuclear Energy, Alternative Energy), Water Quality, Acid Precipitation and Polymers.

The figure below represents the trend in world population over the past 5000 years. Noteworthy are the bumps and dips in population over that time, but perhaps most striking is the sharp increase in population leading up to today at the far right end of the graph. Population continues to grow at the rate of approximately 1\% worldwide. It is an interesting exercise to refer to a site such as worldometers.info to see the world population as of today and then calculate $1 \%(0.01)$ of that number. Divide by 365 to get the daily population growth and you will see that human population is growing by approximately a quarter million people every day.

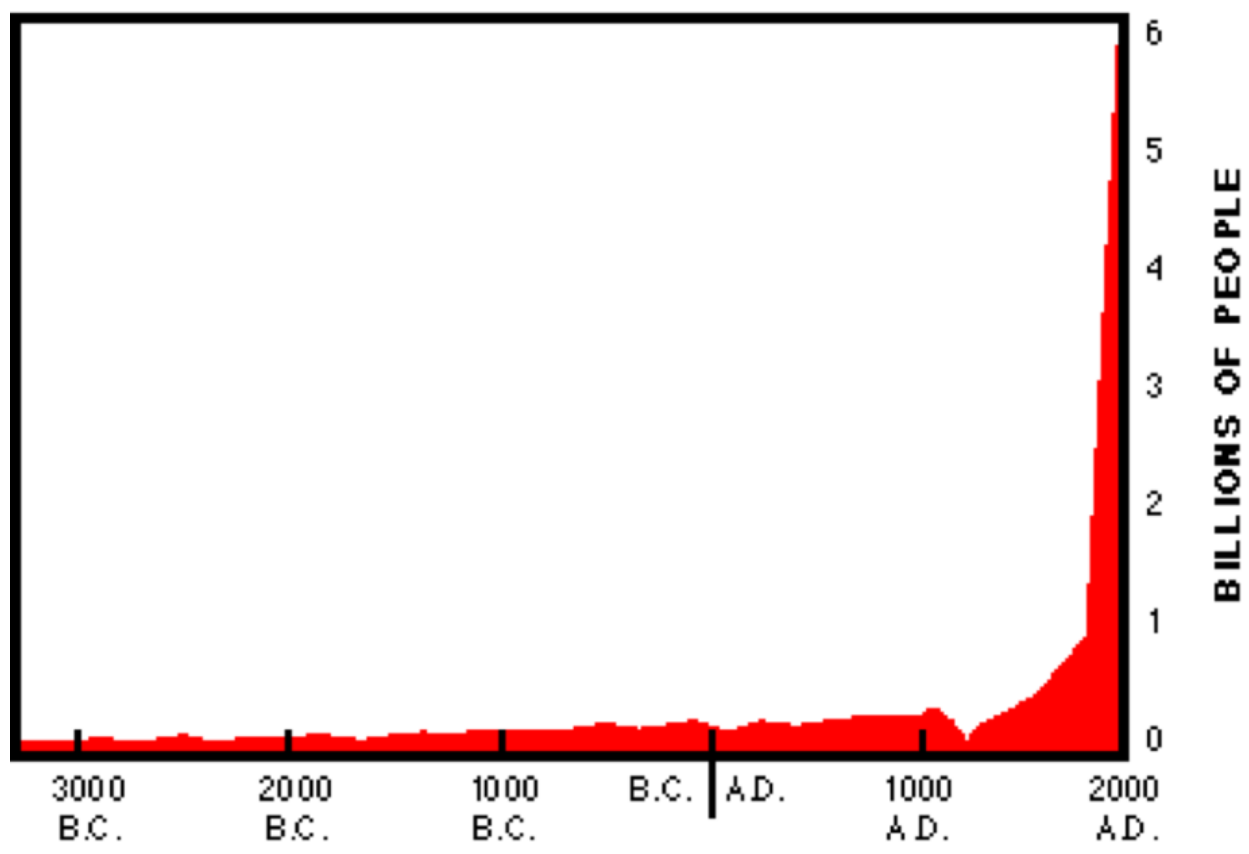


Likewise, our use of energy shows a large upsurge in the $20^{\text {th }}$ century that continues today with energy use growing at the rate of approximately $2 \%$.

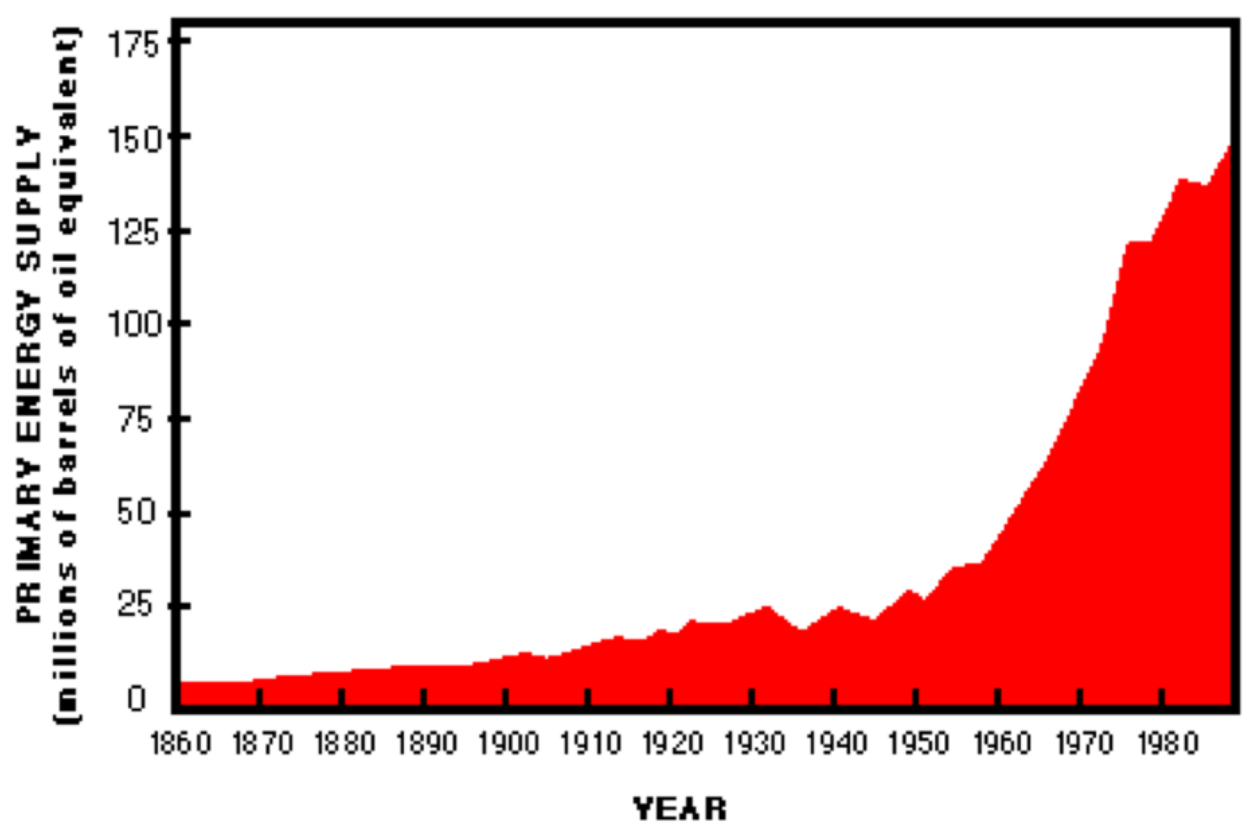

It is in this context that we begin the work-book style discussions ('Focus' sections) in this text. A staggering number of human beings using a staggering amount of energy and materials on a finite and complicated planet is having drastic environmental consequences. We deal with these consequences every day - some quite successfully, some less successfully. Studying the scientific principles involved in tandem with the debates involved with these issues is crucial in deciding on the best paths to move forward. 


\section{Focus on Air}

Some simple chemistry is now explored in the context of air and air pollution (ie. what we should be breathing $v s$ what we are breathing). This section deals with gaseous components of the atmosphere, and more specifically, components of the troposphere, the region of the atmosphere where earth's inhabitants live and breathe every day.

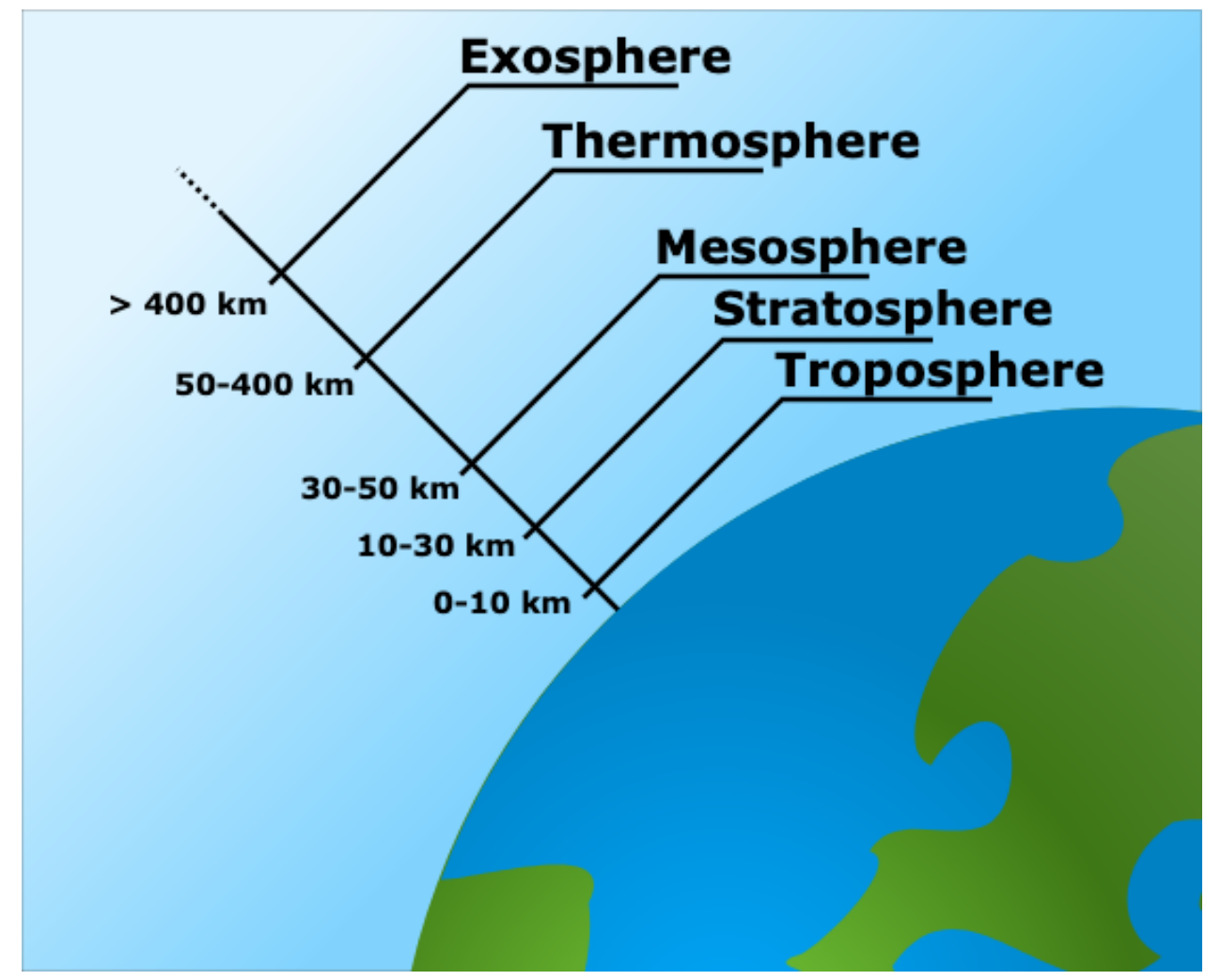

"File:Atmospheric Layers.svg" by Original by en:Bredk, converted to SVG by tiZom, globe borrowed from File:Earth clip art.svg is licensed under CC BY-SA 3.0

As seen in the following figure, air is mostly nitrogen, which is inert to us, and oxygen, which is important for respiration for all aerobic organisms. Argon and carbon dioxide make up $9 / 10$ of the remaining $1 \%$ of air molecules. Thus, 'pollution' is typically found in the remaining $0.1 \%$ of air. 


\section{The composition of dry air}

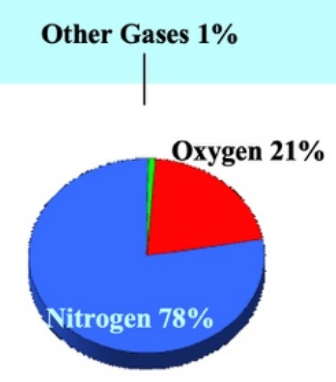

Refer to the information discussed in parts I-IV of this text and elaborate on the following focus boxes, solving the problems that appear. 


\section{The composition of dry air}

Other Gases $1 \%$

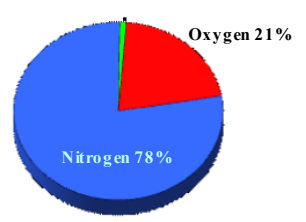

Major common air pollutants (small parts of the $1 \%$ )

- Carbon monoxide (oxygen delivery)

- Ozone (respiratory)

- Sulfur oxides (respiratory)

- Nitrogen oxides (respiratory)

\section{Atoms and Molecules}

- we will normally deal with them in terms of their chemical symbol

- examples:

Carbon $=\mathrm{C}$

Carbon Monoxide $=\mathrm{CO}$

Carbon Dioxide $=\mathrm{CO}_{2}$

Sulfur Oxides $=\mathrm{SO}_{\mathrm{x}}$

Nitrogen Oxide $=\mathrm{NO}_{\mathrm{x}}$ 


\section{chemistry}

- Chemical Reactions

reactants $\longrightarrow$ products

- Law of Conservation of Matter atoms on left $=$ atoms on right

\section{Coal $=$ carbon, trace sulfur}

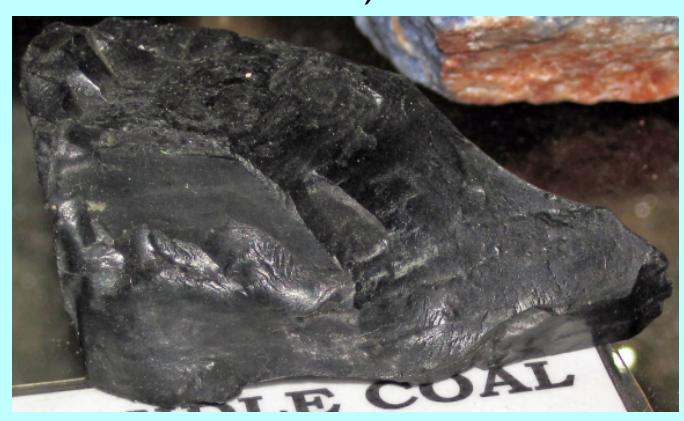

"Cannel coal (Tennessee, USA) 2" by James St. John is licensed under CC BY 2.0
-What is the balanced chemical reation for the combustion of solid carbon $\left(\mathrm{C}_{(\mathrm{s})}\right)$ with oxygen $\left(\mathrm{O}_{2(\mathrm{~g})}\right)$ to form carbon dioxide? 
- Show how these common air pollutants might be produced from the combustion of coal:

- Carbon Monoxide

- Sulfur Dioxide and Sulfur Trioxide

- Nitrogen Monoxide and Nitrogen Dioxide

- Write the balanced chemical reations for the combustion of methane $\left(\mathrm{CH}_{4}\right)$, ethane $\left(\mathrm{C}_{2} \mathrm{H}_{6}\right)$, ethanol $\left(\mathrm{C}_{2} \mathrm{H}_{5} \mathrm{OH}\right)$, and octane $\left(\mathrm{C}_{8} \mathrm{H}_{18}\right)$. Use chemical reactions to demonstrate the difference between the reaction to form carbon dioxide and the formation of carbon monoxide.

\section{Catalytic Converter}

Exhaust emission device that facilitates the conversion of toxic pollutants to less toxic substances.

Catalyst - a substance that increases the rate of a chemical reaction, but does not itself undergo permanent change.

Ex: Show the general reaction for the conversion of carbon monoxide and oxygen gas to carbon dioxide via a platinum catalyst. 


\section{Focus on The Ozone Layer}

Basic chemical structures, bond energies and the breaking of bonds by electromagnetic radiation is sufficient background to take an elementary look at a very important set of reactions taking place in another part of the atmosphere, the stratosphere.

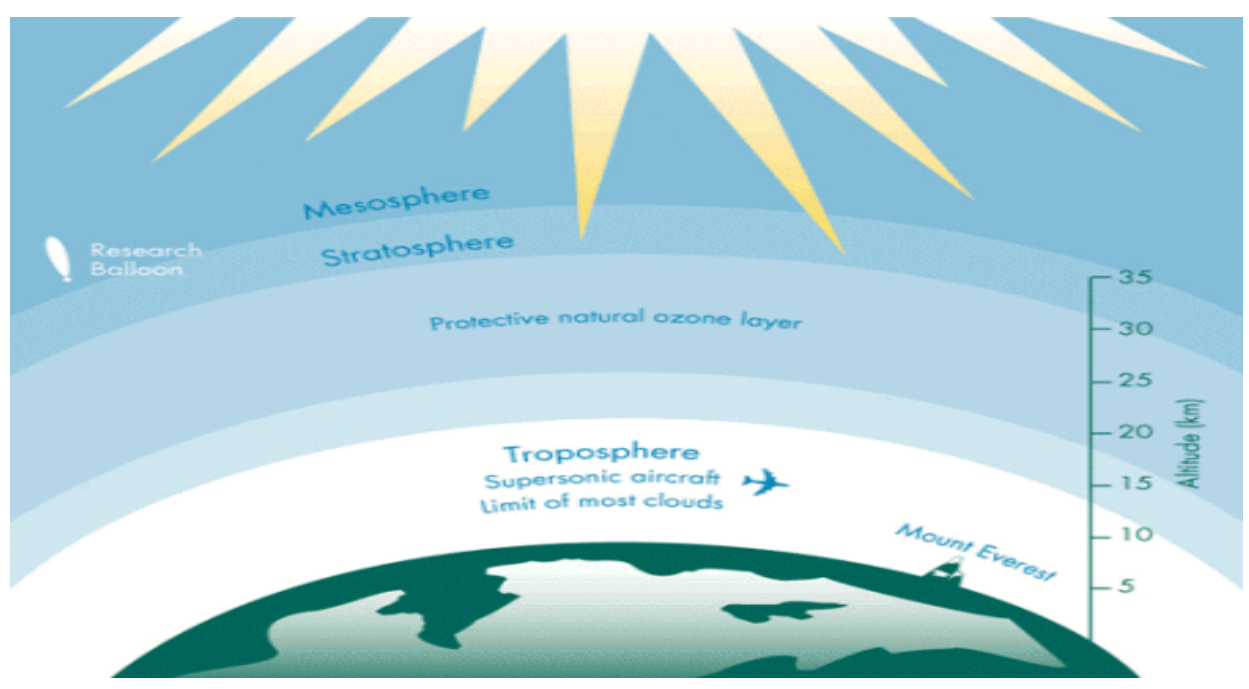

(C) Environment and Climate Change Canada. Layers of the Atmosphere. Government of Canada https://www.canada.ca/en/environment-climatechange/services/air-pollution/issues/ozone-layer/depletionimpacts/about.html

The four reactions of the Chapman cycle are key to protecting life on earth from harmful ultraviolet radiation. It was determined that a set of anthropogenic compounds were putting this protective ozone layer at risk. Refer to the information discussed in the previous Focus section as well as parts VI and VII of this text and elaborate on the following focus boxes, solving the problems that appear. Use the information to frame the story of the thinning ozone layer through the science and events. 

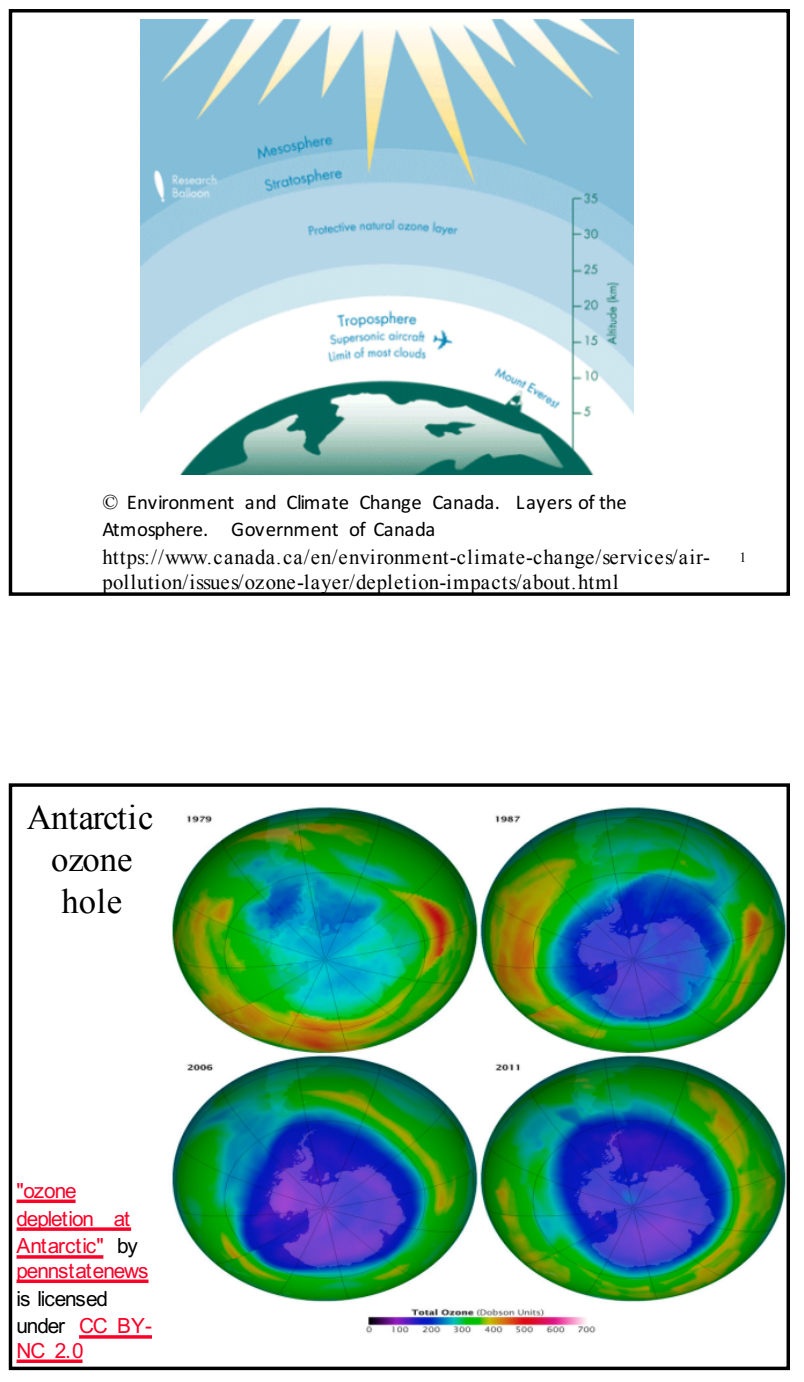

\section{Antarctic Ozone, July - September 2010}

- http://www.flickr.com/photos/gsfe/ 4995772362/

Animation provided by NASA/Goddard Space Flight Center. 


\section{Atomic Theory}

- matter is composed of discrete units called atoms, arranged in unique ways.

- However, atoms are also made up of smaller particles ...
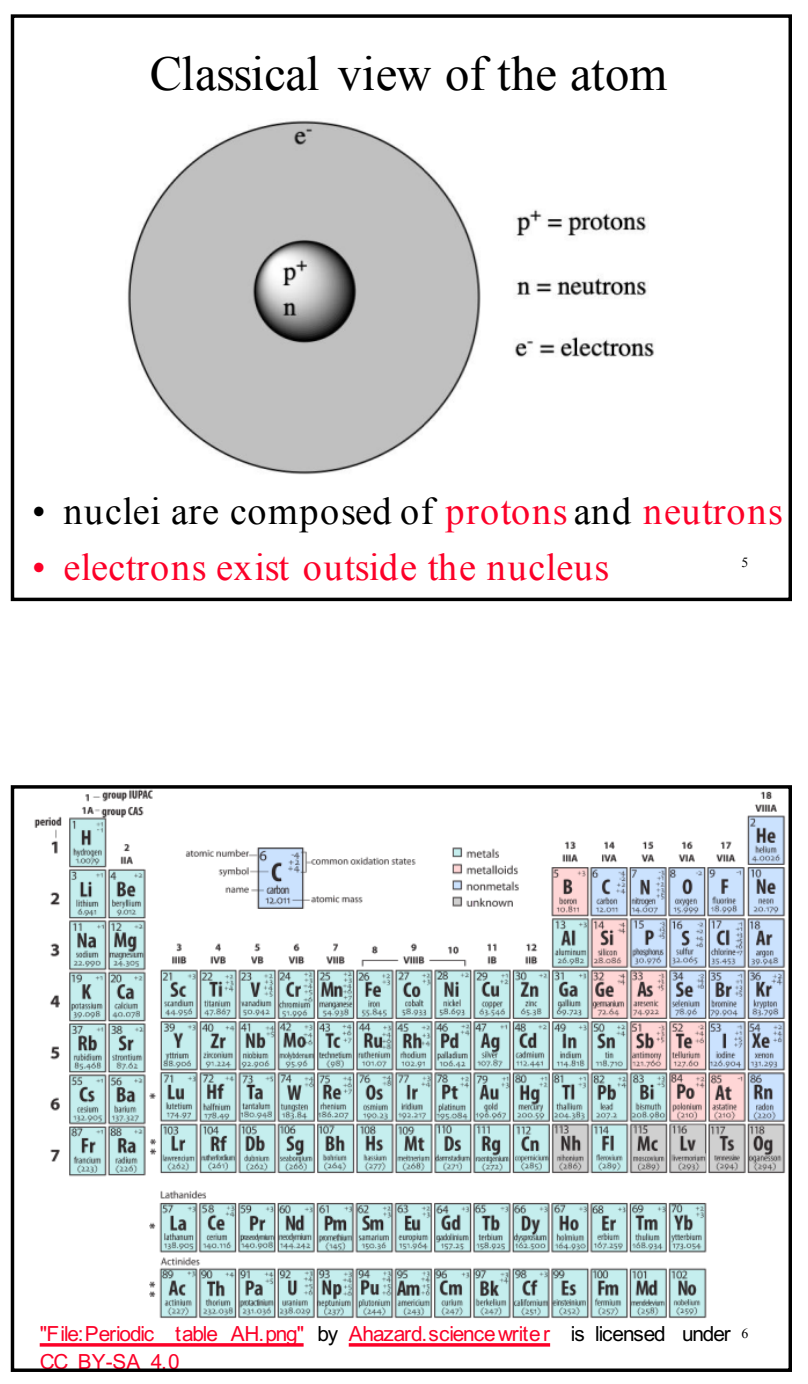


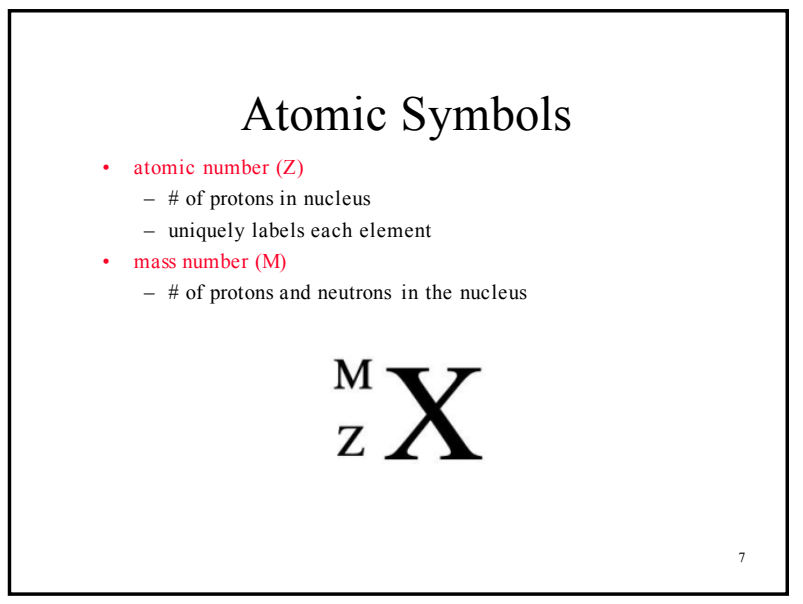

\begin{tabular}{|} 
What are the \# of protons and \\
neutrons in ${ }^{238} \mathrm{U}$ ? \\
- A. 238 protons, 92 neutrons \\
- B. 92 protons, 156 neutrons \\
- C. 92 protons, 146 neutrons \\
- D. 156 protons, 92 neutrons \\
- E. 146 protons, 92 neutrons \\
\end{tabular}

What are the \# of protons and neutrons in ${ }^{1} \mathrm{H}$ ? ${ }^{2} \mathrm{H}$ ? 
- isotopes: same Z, different M

- Ex: What is the number of protons and neutrons in the following isotopes?

$$
{ }_{1}^{1} \mathrm{H} \quad{ }_{1}^{2} \mathrm{H} \quad{ }_{1}^{3} \mathrm{H} \quad{ }^{12} \mathrm{C} \quad{ }^{13} \mathrm{C} \quad{ }^{14} \mathrm{C}
$$

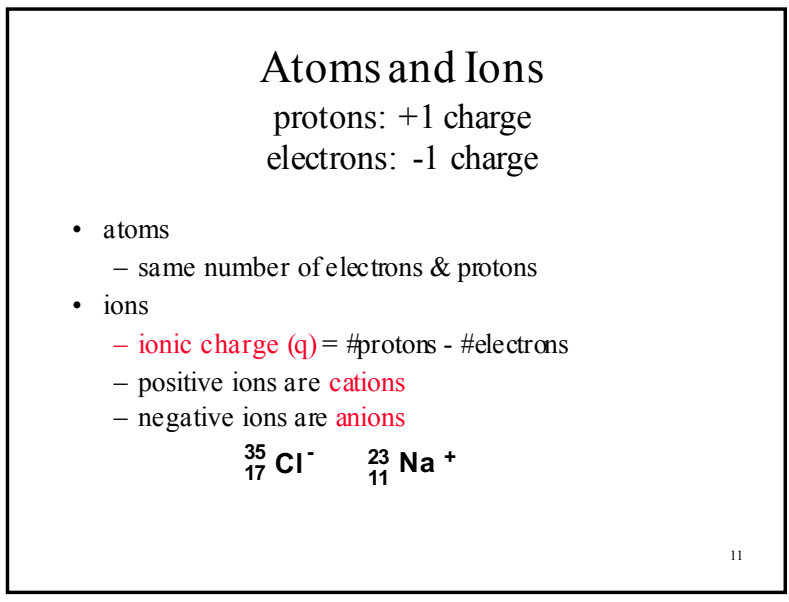

\section{What is the \# of protons, neutrons} and electrons in ${ }^{23} \mathrm{Na}^{+}$

- A. 23 protons, 23 neutrons, 11 electrons

- B. 12 protons, 11 neutrons, 11 electrons

- C. 11 protons, 11 neutrons, 12 electrons

-D. 11 protons, 12 neutrons, 12 electrons

- E. 11 protons, 12 neutrons, 10 electrons 
What is the \# of protons, neutrons and electrons in ${ }^{74} \mathrm{Se}^{2-}$

-A. 74 protons, 34 neutrons, 32 electrons

- B. 34 protons, 40 neutrons, 36 electrons

- C. 40 protons, 74 neutrons, 42 electrons

- D. 34 protons, 40 neutrons, 40 electrons

- E. 32 protons, 34 neutrons, 74 electrons

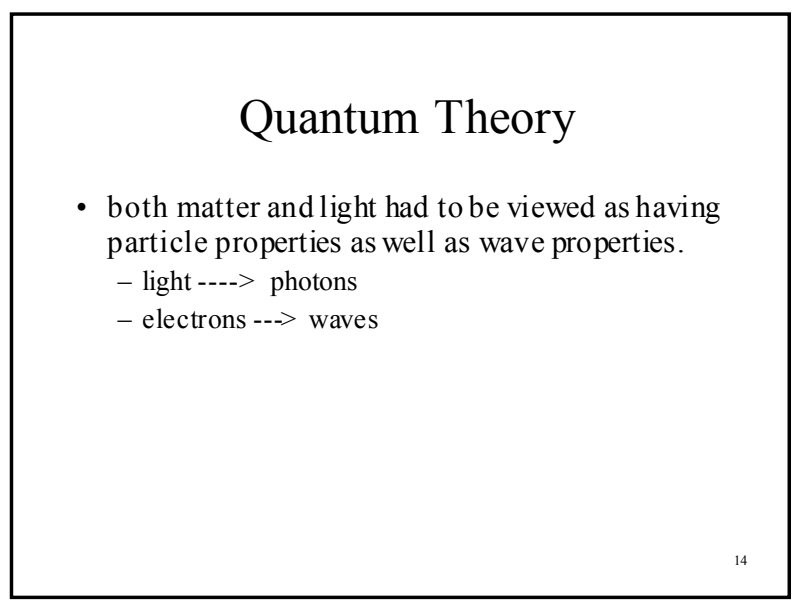

\section{Classical view of the $\mathrm{H}$ atom}

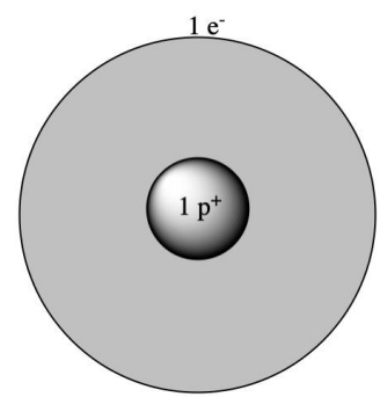




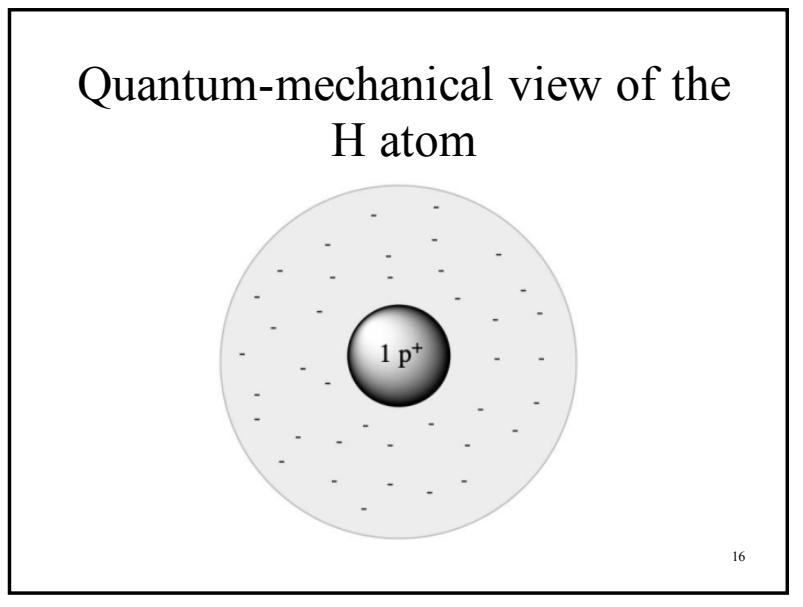

Quantum theory: electrons do not exist in any well-defined area of space and have only certain 'allowed' energy levels. These energy levels have a maximum capacity for electrons.

Exercise: Determine the electron configurations for the first 18 elements $(\mathrm{z}=1$ to $\mathrm{z}=18)$.

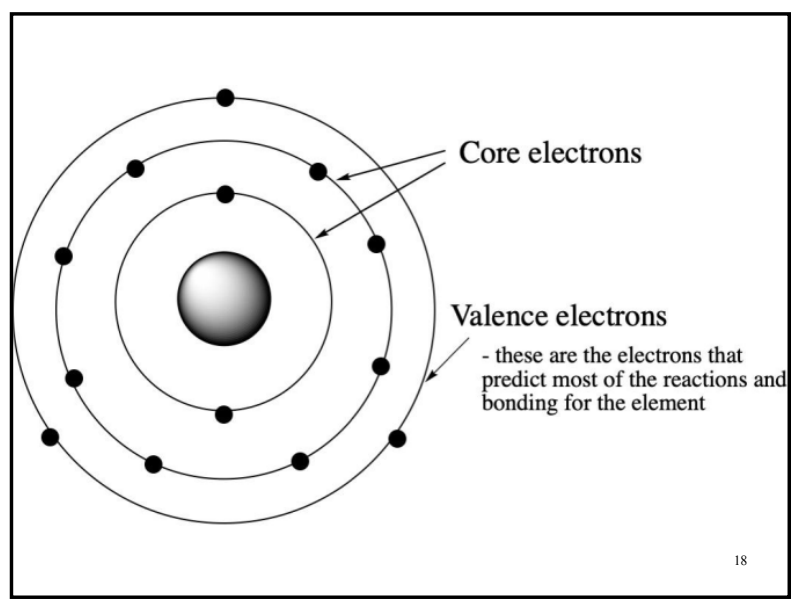




\section{Note: periodic table}

- Most periodic tables are labelled such that group A numbers refer to the number of valence electrons.

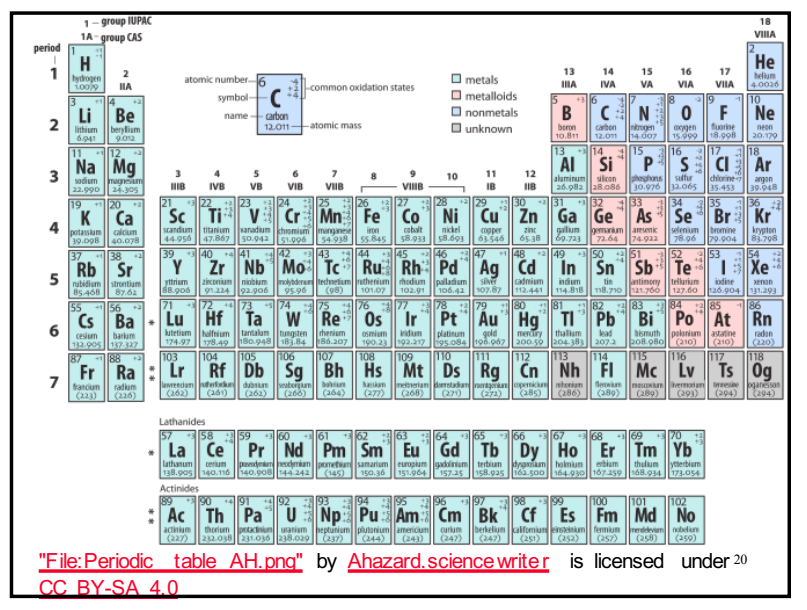

\section{How many valence electrons does} a neutral oxygen atom have?

- (a) 2

- $\underline{\text { (b) }} 6$

- $\underline{\text { (c) }} 8$

- $\underline{\text { (d) }} 16$

- (e) 32 


\section{How many electrons does a neutral fluorine atom have?}

- (a) 9

- $\underline{\text { (b) }} 8$

- (c) 7

- $\underline{\text { (d) } 6}$

- (e) 5

\section{Lewis Structures}

- Draw the atomic symbol

- Determine the number of valence electrons for the element

- Place 1 electron at a time in each of 4 spaces around the atomic symbol

- Each space can hold 2 electrons

- Ex: Draw the Lewis structures for the first 18 elements $(Z=1$ to $Z=18$ ).

\section{Noble Gases - Group VIIIA}

-The noble gases, noted for their stability, share a common 'closed shell' electron configuration.

-All of the noble gases have 8 valence electrons (except for helium which has 2). 


\section{Lewis Structures of Molecules}

- many elements will form molecules based on the closed shell rule.

- atoms will

- gain or lose e- (ionic compounds)

- share e- (covalent compounds)

\section{Covalent examples - Draw the}

Lewis structures for the following molecules:

$\begin{array}{llllll}\mathrm{H}_{2} & \mathrm{~F}_{2} & \mathrm{CH}_{4} & \mathrm{CCl}_{4} & \mathrm{NH}_{3} & \mathrm{H}_{2} \mathrm{~S}\end{array}$

$\begin{array}{lll}\mathrm{O}_{2} & \mathrm{CO}_{2} & \mathrm{CO}\end{array}$

\section{Covalent Bonds}

- The first covalent bond formed between two elements is between orbitals that are in the direction of the bond. These are known as $\boldsymbol{\sigma}$ bonds.

- Any further bonding that occurs is between orbitals that are at right angles to the direction of the bond. These are known as $\pi$ bonds. 


\section{Bond Length/Bond Strength}

- The greater the number of bonds (pairs of electrons) between two particular atoms in a molecule, the closer the two atoms will be to each other and the stronger the bond will be.

for example, it takes more energy to break the $\mathrm{CO}$ bond in carbon monoxide than it does to break the $\mathrm{CO}$ bond in carbon dioxide

Draw the Lewis structures
(including all resonance
structures) of ozone $\left(\mathrm{O}_{3}\right.$, one $\mathrm{O}$ is
central to the other two $)$
- the electron pair forming the $\pi$ bond is
'delocalized' over the three oxygen atoms,
as opposed to being 'localized' between two
atoms like the $\boldsymbol{\sigma}$ bonds are.

\section{Ozone}

- has two equivalent O-O bonds and their properties are intermediate between that normally found for a $\mathrm{O}-\mathrm{O}$ single bond and that normally found for an $\mathrm{O}-\mathrm{O}$ double bond. 


\section{Example}

Draw all of the resonance structures of the Nitrate ion, $\mathrm{NO}_{3}{ }^{-}$

\section{Electromagnetic Radiation}

\section{(Light)}

- A form of energy (photons) that exhibit wave-like behavior as they travel through space. The energy can be characterized by:

- wavelength: the distance between peaks where the level of the field is the same. The longer the wavelength, the lower the energy of the light.

- frequency: how many waves pass a given point in a given amount of time. The higher the frequency, the higher the energy of the light.

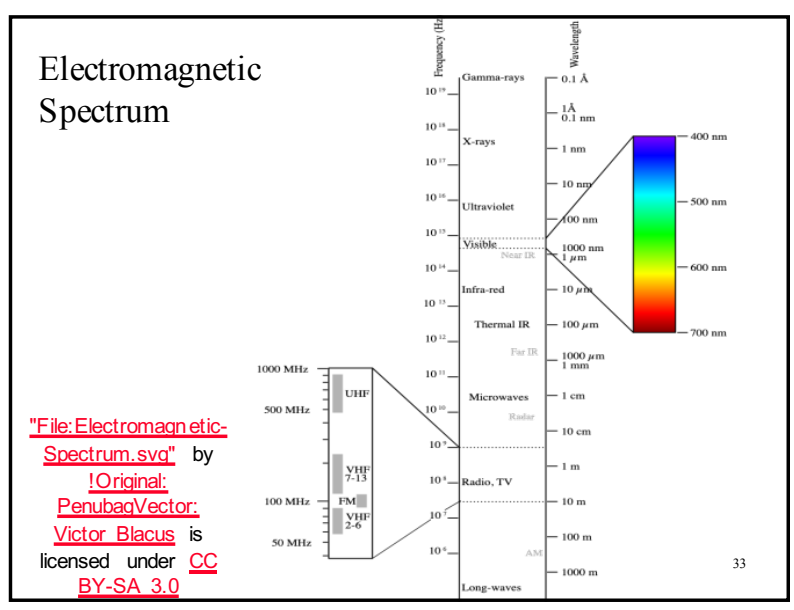




\section{FM radio wave at $3 \mathrm{~m}\left(1 \times 10^{8} \mathrm{~Hz}\right)$}

- The photons have an energy that our bodies are unable to detect unless it is fed through a receiver and converted into sound.
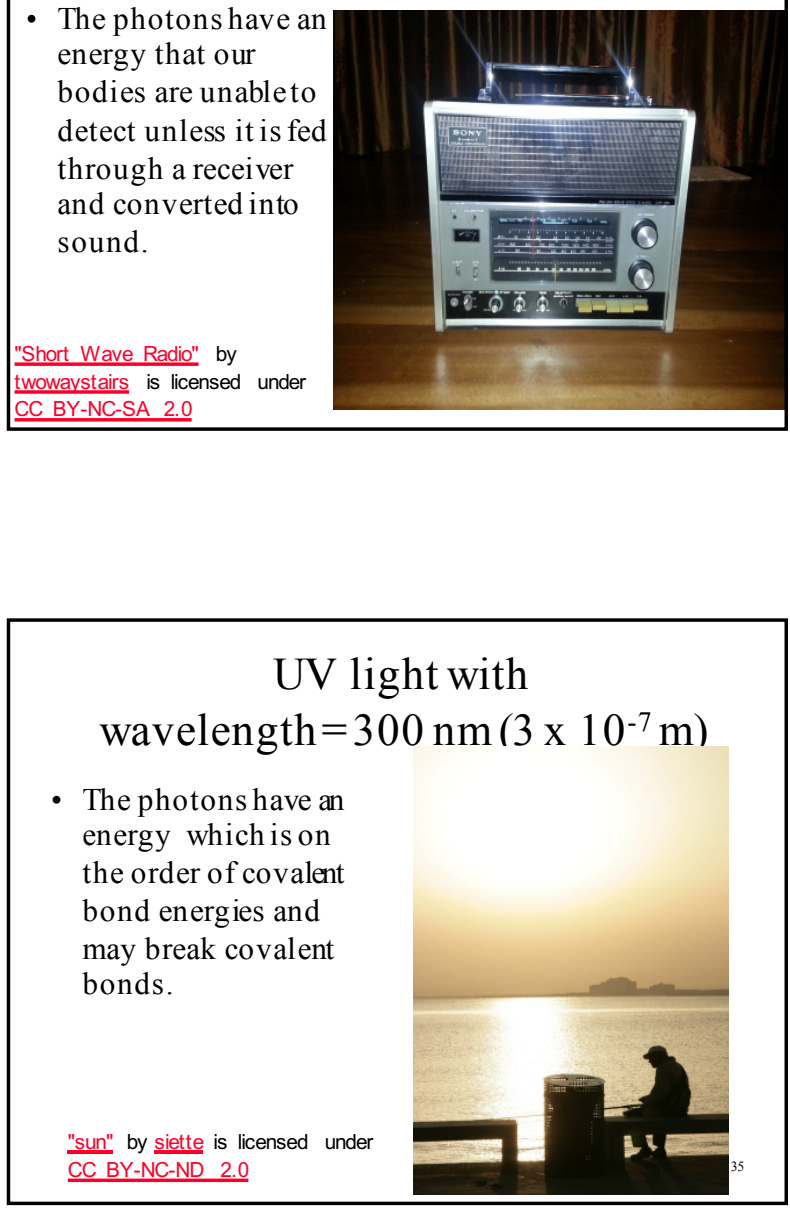

\section{Stratospheric Ozone: Its Formation and Fate}

- each day, 300,000 tons of ozone are created and destroyed in the four reactions of the Chapman Cycle. The constant creation and destruction of ozone results in a steady state (constant amount) of the compound. 


\section{Chapman cycle}

- Sketch the reactions of the Chapman cycle and demonstrate how certain frequencies of the sun's UV light are filtered out in the stratosphere.

- Identify any 'free radicals'- an unstable chemical species with an unpaired electron.

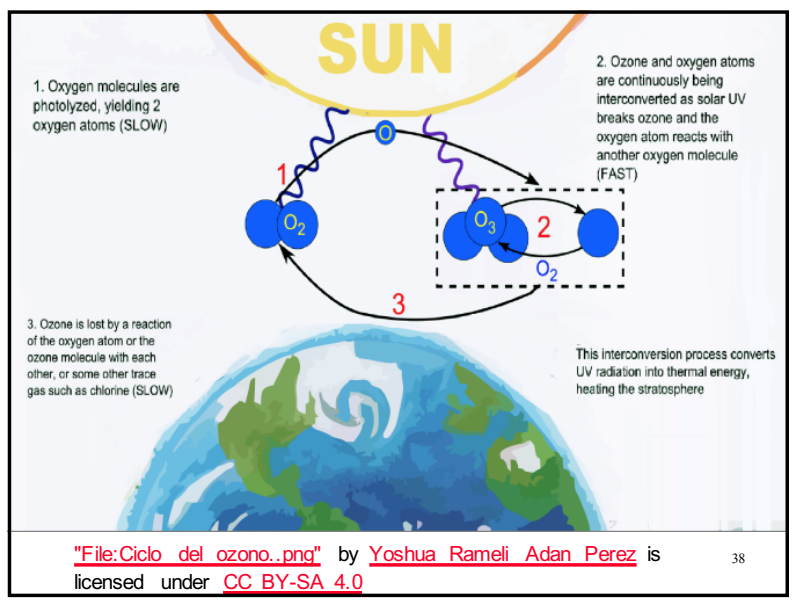

Elaborate on this graph. Why is there less intensity of electromagnetic radiation of lower wavelengths at the surface of the earth?

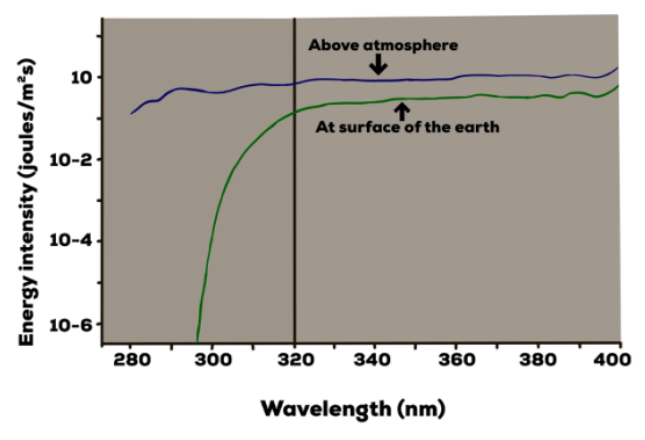

39 
Elaborate on this graph. Why is biological sensitivity higher for electromagnetic radiation of lower wavelengths?

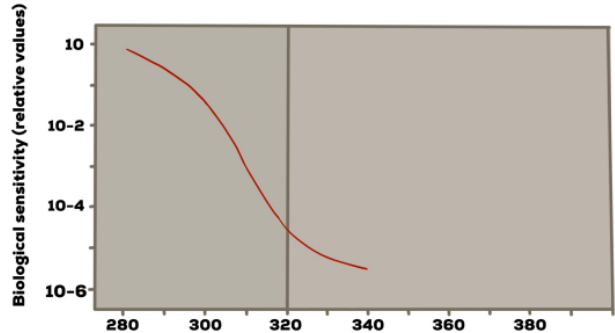

Wavelength (nm)

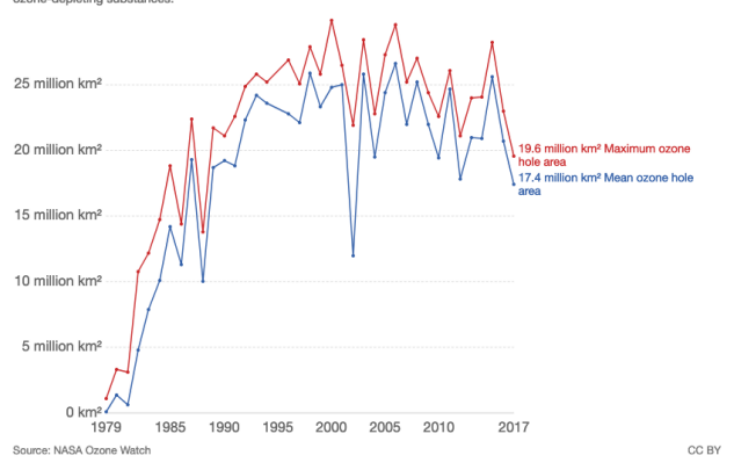

"File:Antarctic ozone hole area, OWID.svg" by Our World In Data is 41 licensed under CC BY 3.0

\section{Chlorofluorocarbons}

- anthropogenic chemicals introduced as a safe alternative to the relatively unsafe substances used in refrigeration.

- Ex: $\mathrm{CF}_{2} \mathrm{Cl}_{2}$

$$
\text { heat }+\mathrm{CF}_{2} \mathrm{Cl}_{2}(\mathrm{i}) \rightarrow \mathrm{CF}_{2} \mathrm{Cl}_{2(\mathrm{~g})}
$$

- Due in part to their inertness, they soon found many other uses. 


\section{Chlorofluorocarbons}

- Their inertness is due to the great strength of the $\mathrm{C}-\mathrm{F}$ and $\mathrm{C}-\mathrm{Cl}$ bonds. However, rather than remaining harmless in the troposphere, they eventually find their way up to the stratosphere where they react with high energy electromagnetic radiation and $\mathrm{Cl}$ radicals are released.

Show the reaction sequence that demonstrates catalytic destruction of ozone by chlorine radicals

- one $\mathrm{Cl}$ radical can break down over 100,000 ozone molecules before it is removed from this stratospheric cycle.

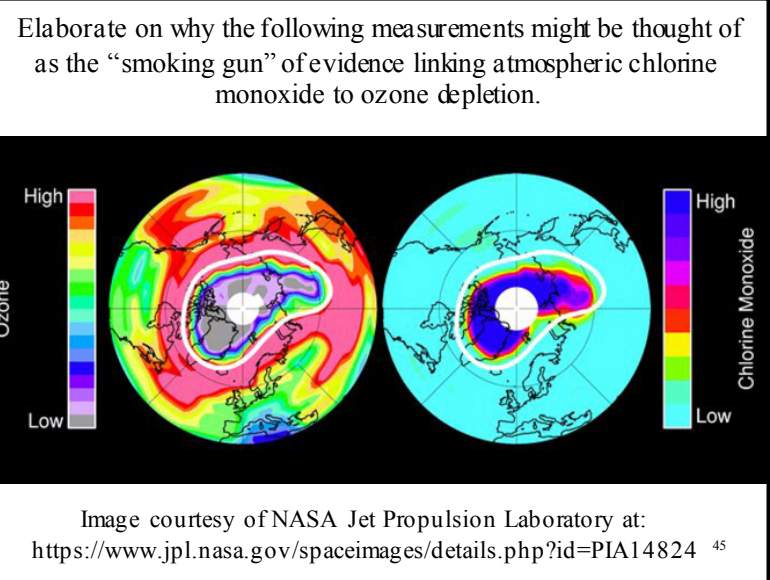


Antarctic Ozone, July - September 2010

- http://www.flickr.com/photos/gsfc/4995772 $\underline{362 /}$

Animation provided by NASA Goddard Space Flight Center.

\section{Antarctic Winter/Spring}

- Extreme cold of winter (-90 C) freezes atmospheric water into stratospheric clouds of ice crystals. Also condenses other species

- Otherwise safe molecules can be converted to more reactive species. When the sun comes out, the break down of these species may release chlorine radicals.

\section{7 - Montreal Protocol}

- Phas eout of production and use of certain CFC's, development of new compounds.

- Continually being refined, new compounds being added to ban (HCFC's).

- Ex. 2005: $\mathrm{CH}_{3} \mathrm{Br}$ phaseout begins.

- Ex. 2013/2015: HCFC's phaseout begins.

- Many CFC's have a lifetime of $\sim 100$ years,

however, some levelling off of effective $[\mathrm{Cl}]$ and

$[\mathrm{Br}]$ has been observed. 
Ozone-depleting substance emissions

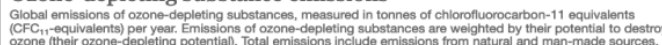

1.4 million tonnes

1.2 million tonnes

1 million tonnes

1 million tonnes

800,000 tonnes

600,000 tonnes

400,000 tonnes

200,000 tonnes

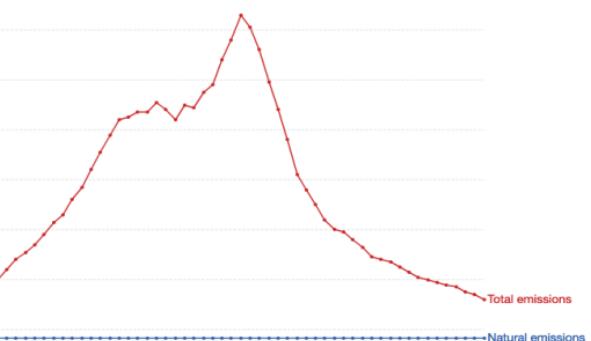

0 tonnes -

1970

1980

$1990-2000$

2014

Source: Hegalin of al. (2014). Twonty quoostons and answors about the ozone layer: 2014 update.

"File:Ozone-depleting substance emissions, OWID.svg" by Our World In Data is licensed under CC BY 3.0

Equivalent stratospheric chorine (ESC) concentrations

Equivalent stratospheric chloric (ESC) concentrations with projections to 2100 based on chemistry-climate model
ESC concentrations are measured relative to levels in 1960 (1960 0 ) and measured as the global average, and

egional average. Figures represent the mean across a number of model inns; model projections have notable

60

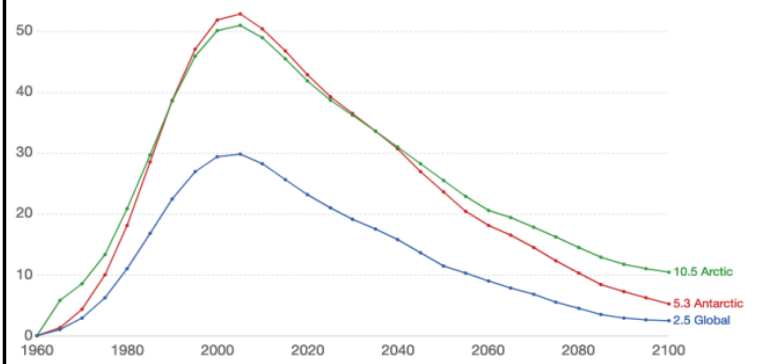

Source: Hegglin et al. (2014). Twenty questions and answers about the orone layer; 2014 update

"File:Equivalent stratospheric chorine (ESC) concentrations OWID.svg" by Our World In Data is licensed under CC BY 3.0
Excess skin cancer cases due to ozone depletion, United States

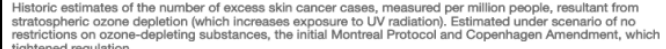

resstrictions on ozone-depleting substancess, the intial Montreal Protocol and Copenhagen Amendment, which
tightened regulation.

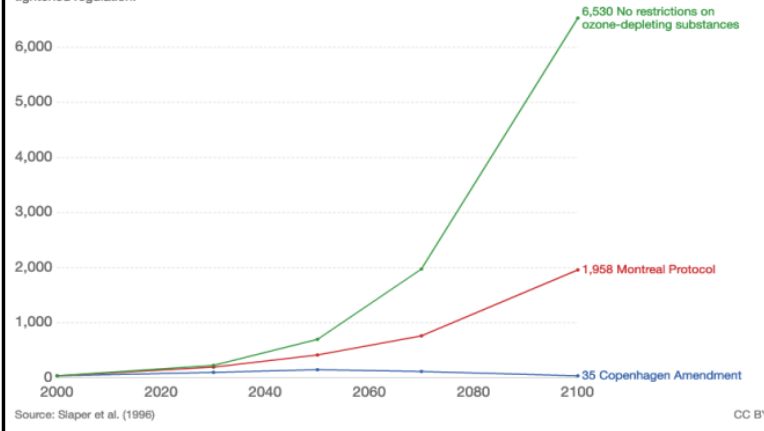
Souroe: Slaper of al. (1996)

"File:Excess skin cancer cases due to ozone depletion, OWID.svg" by Our World In Data is licensed under CC BY 3.0 


\section{Ozone Watch}

https://earthobservatory.nasa.gov/features/vid eos/the-ozone-hole

Video provided by NASA/Goddard Space Flight Center.

\section{Summary - Ozone/CFC's}

- Chapman cycle

- Potentially catastrophic series of events.

- 'Smoking gun' of evidence.

- Montreal Protocol, and subsequent refinements.

- Substitutes were (are) available.

- Economic setback (but not devastating).

- The ozone 'holes' are shrinking 


\section{Focus on Climate Change}

Molecular shape, polarity and a further look at the interaction of electromagnetic radiation and matter enable one to understand the fundamentals of the greenhouse effect.

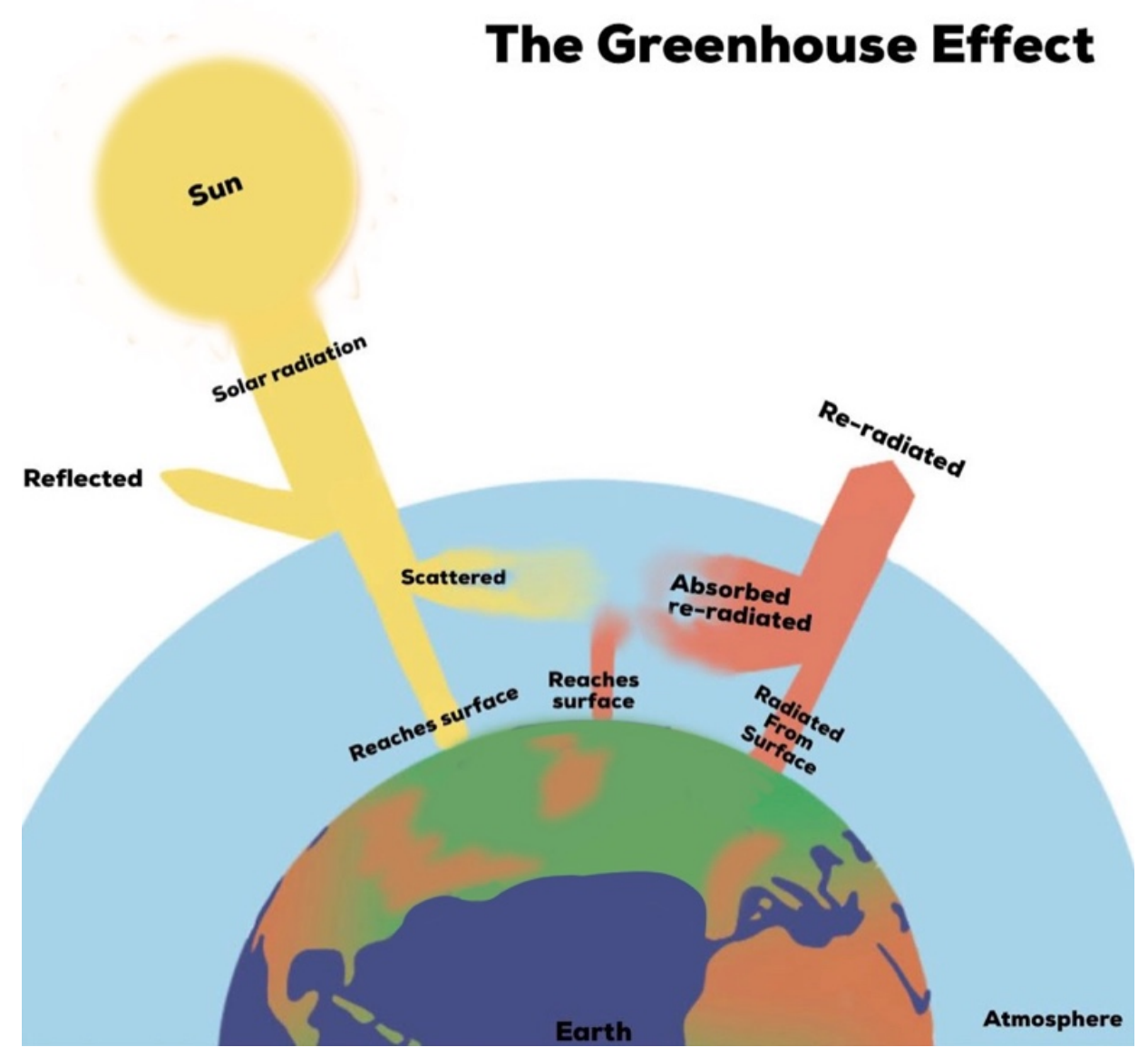

When the suns energy warms the atmosphere and surface of the earth, much of that heat is re-radiated back out into the atmosphere. Molecules in the atmosphere absorb some of that released heat and then re-release it, warming the atmosphere and surface of the earth further. Without this natural greenhouse effect, the earth's average global temperature would be approximately $-18{ }^{\circ} \mathrm{C}$, but instead it is $+15{ }^{\circ} \mathrm{C}$. This $33{ }^{\circ} \mathrm{C}$ temperature difference is crucial to the way that life and society have evolved and a stable average temperature is thought to be an important metric for many climate related issues such as weather and sea levels. 
Anthropogenic release of extra greenhouse gases is being blamed for a measurable increase in recent global temperatures.

Refer to the information discussed in the previous Focus section and elaborate on the following focus boxes, solving the problems that appear. Use the information to frame the story of the climate change debate to where it stands today. It is quite useful to compare the story to that of the ozone layer. 

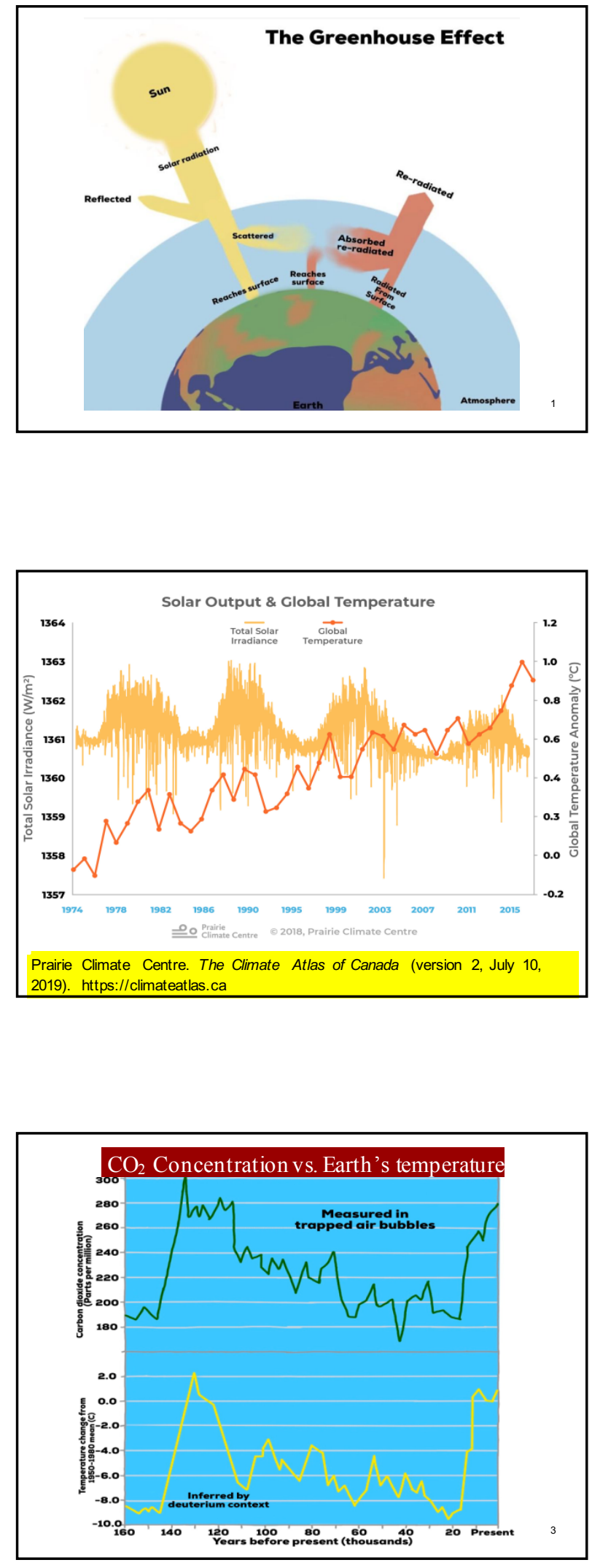

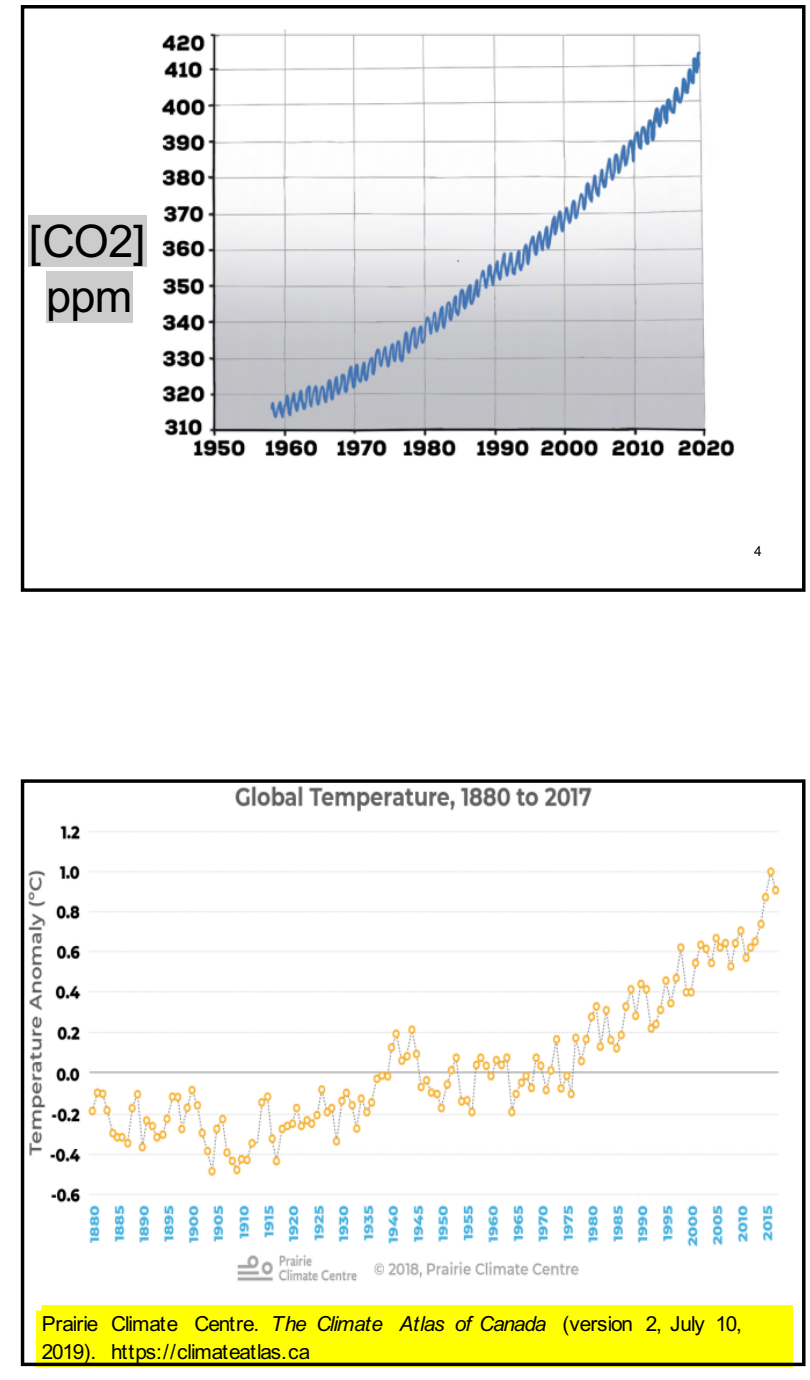

\section{Climate Atlas $-1^{\circ} \mathrm{C}$ and its impacts}

- https://climateatlas.ca/video/one-degreeand-its-impacts

Rebroadcast with permission of the Climate Atlas, Prairie Climate Centre

https://climateatlas.ca/ 


\section{Galileo Movement Australia- Axe the Tax}

- https://www.youtube.com/watch?t=7\&v=B C114geSTP8

Rebroadcast with permission of the Galileo Movement Australia

http://www.galileom ov ement.com.aul

\section{Molecular Shape}

- The 3-dimensional positions of bonded atoms in the molecule with respect to a central atom.

- Valence Shell Electron Pair Repulsion (VSEPR)

\section{non-bonding electrons}

- VSEPR predicts the positions of all electrons around a central atom (electron pair geometry).

- Molecular geometry involves the 3dimensional positions of atoms only.

- Further, lone pairs of electrons take up more room than bonding pairs of electrons. 
Ex: Determine the molecular shape of the following molecules.

ie. consider the central atom and determine the number of 'groups of electrons' (symmetry number, SN), then determine the molecular shape.
$\mathrm{Ex}: \mathrm{CO}_{2}$
$\mathrm{Ex}: \mathrm{H}_{2} \mathrm{CO}$
$\mathrm{Ex}: \mathrm{CH}_{4}$

$\mathrm{Ex}: \mathrm{CF}_{2} \mathrm{Cl}_{2}$

$\mathrm{Ex}: \mathrm{NH}_{3}$

Ex: $\mathrm{H}_{2} \mathrm{~S}$

\begin{tabular}{|lll|}
\hline $\begin{array}{l}\text { Electron } \\
\text { groups }\end{array}$ & Examples & Shape \\
4 groups of \\
bonding \\
electrons \\
$\begin{array}{l}3 \text { bonding, } \\
1 \text { non-bonding }\end{array}$ & & \\
2 bonding, & & pyramidal \\
2 non-bonding & & \\
& & bent \\
& & \\
\end{tabular}

\section{What is the shape of the $\mathrm{H}_{2} \mathrm{~S}$ molecule?}

- A. Linear

- B. Triangular planar

- C. Tetrahedral

- D. Triangular pyramid

- E. Bent 
What is the shape of the $\mathrm{CHF}_{3}$ molecule?

- A. Linear

- B. Triangular planar

- C. Tetrahedral

- D. Triangular pyramid

- E. Bent

What is the shape of the $\mathrm{SO}_{3}$ molecule ( $\mathrm{S}$ is central)?

- A. Linear

- B. Triangular planar

- C. Tetrahedral

- D. Triangular pyramid

- E. Bent

\section{What is the shape of the $\mathrm{NF}_{3}$ molecule?}

- A. Linear

- B. Triangular planar

- C. Tetrahedral

- D. Triangular pyramid

- E. Bent 


\section{Bond Polarity}

- when two different atoms form a bond, one attracts the shared pair of electrons more strongly than the other.

- the displacement of the bonding pair causes a partially positive charge on one atom and a partially negative on the other.

- The bond is said to have electric poles and be a polarbond.

\section{Molecular Polarity}

- In a polar molecule, electron density accumulates toward one side of the molecule.

- Ex: Is the $\mathrm{CO}_{2}$ molecule polar? What about $\mathrm{H}_{2} \mathrm{O}$ ?

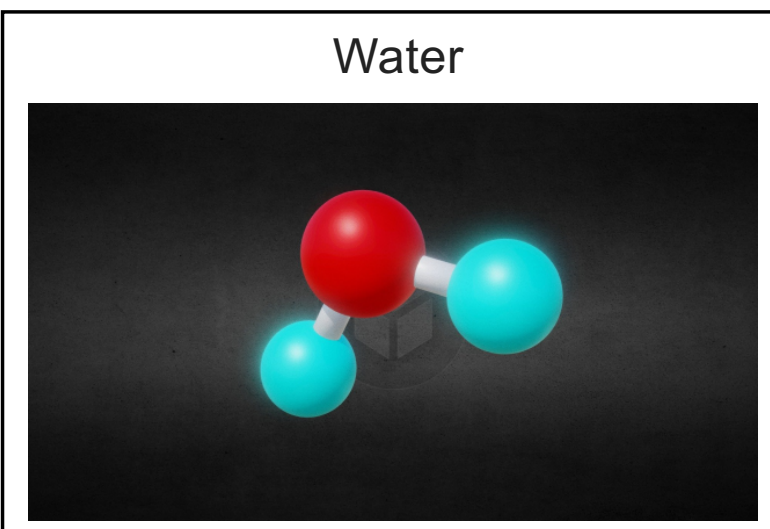


Is the $\mathrm{CHF}_{3}$ molecule polar?

- A. yes

- B. no

- C. Not enough information given

\section{Is the $\mathrm{F}_{2}$ molecule polar?}

- A. yes

- B. no

- C. Not enough information given

Is the $\mathrm{SO}_{3}$ molecule ( $\mathrm{S}$ is central) polar?

- A. yes

- B. no

- C. Not enough information given 


\section{Is the $\mathrm{Cl}_{2} \mathrm{O}$ molecule polar?}

- A. yes

- B. no

- C. Not enough information given

\section{Vibrational States of Molecules}

Based on its molecular geometry, a molecule's bonds are able to undergo certain vibrations. These are known as its 'fundamental modes of vibration'.

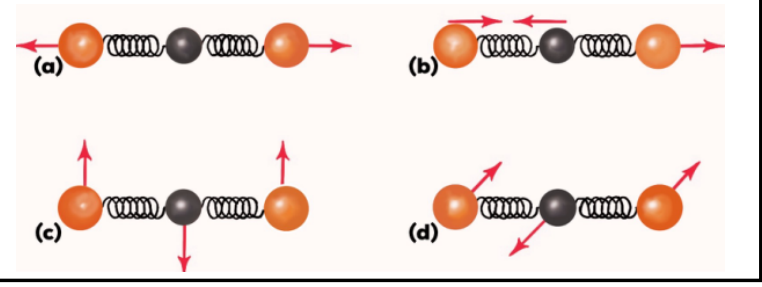

- Like electronic states, there are vibrational states which occur at certain 'fixed' or 'quantized' energy levels.

- Infrared radiation - is not of sufficient energy to break bonds (as in UV/ozone) but can be energetic enough to cause an increase in the amplitude of the 'vibrating'.

- The amount of energy that is absorbed depends on the type of vibration as well as the change in dipole moment as the bonded atoms vibrate. 

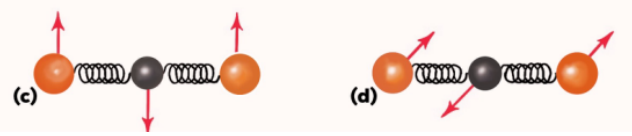

Molecular vibrations in $\mathrm{CO}_{2}$. Each spring represents a $\mathrm{C}=\mathrm{O}$ bond.

(a) = no change in dipole moment - no IR absorption.

$(\mathbf{b}, \mathbf{c}, \mathbf{d})=$ these vibrations have a net change in dipole, so absorption/emission of IR can accompany a vibrational state transition.

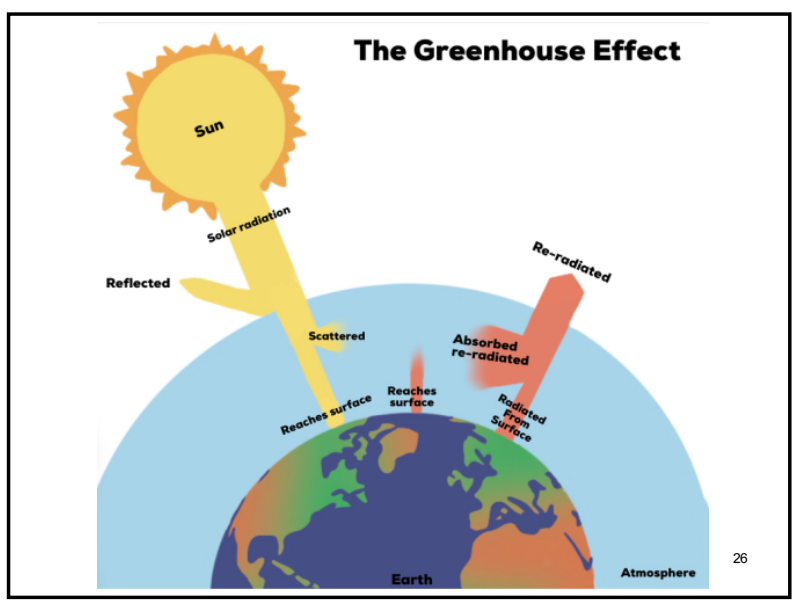

Choose all of the molecules which can absorb infrared radiation?

- A. $\mathrm{N}_{2}$

- B. $\mathrm{O}_{2}$

- C. $\mathrm{Ar}$

- D. $\mathrm{CO}_{2}$

- D. $\mathrm{CH}_{4}$ 


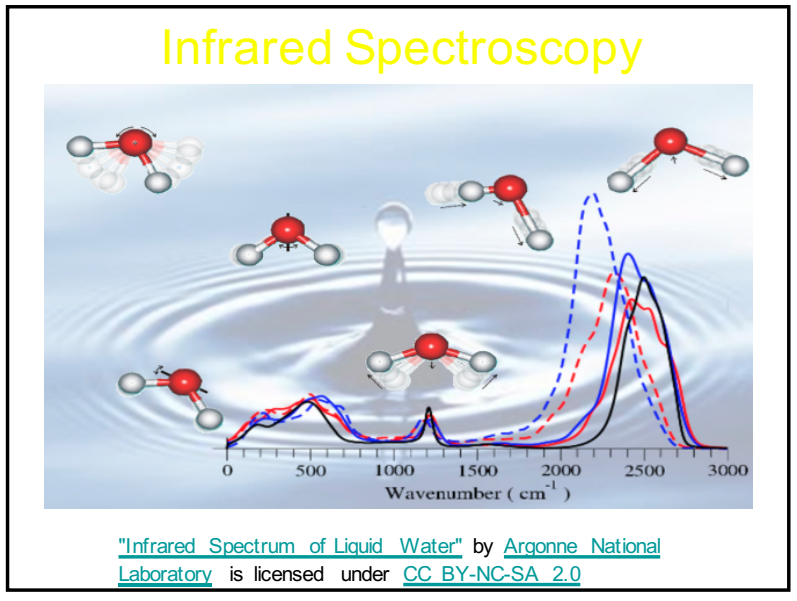

\section{Note: The Composition of Dry Air}

In addition to the pie chart below, 0.9 of the " $1 \%$ other gases" is argon. Thus, what percentage of dry air contains greenhouse gases?
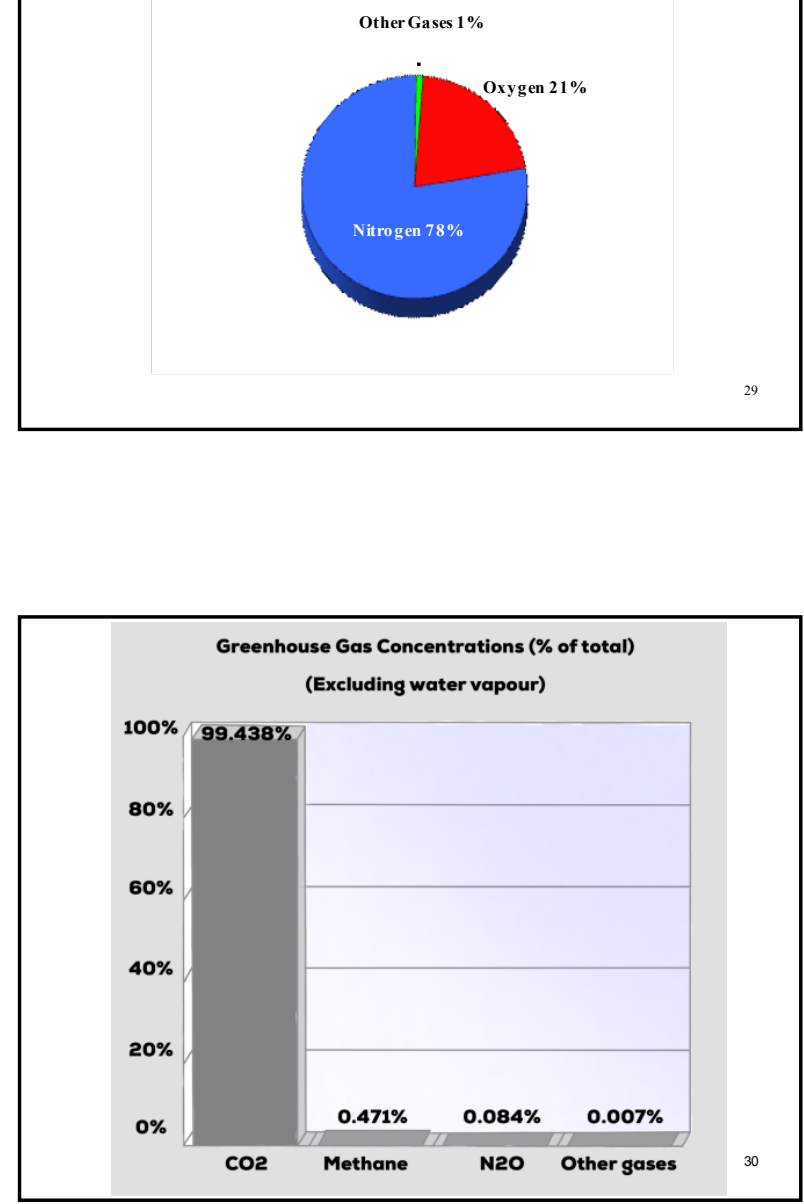
Global Warming Potential (GWP) represents the relative contribution of a molecule of an atmospheric gas to global warming.

Compound Name

$\mathrm{CO}_{2} \quad$ carbon

carbon
dioxide

methane

nitrous

oxide

CFC-12 anthropogenic sources

fossil fuel combustion,

deforestation

fossil fuel production, livestock

combustion, fertilizers

refrigeration, aerosols
GWP

1

21

310

8100
Not considering average atmospheric lifetimes, which of the following would you expect to have the greatest global warming potential?

- A. $\mathrm{N}_{2}$

- B. $\mathrm{CH}_{2} \mathrm{~F}_{2}$

- C. $\mathrm{CO}_{2}$

- D. $\mathrm{CH}_{4}$

- E. $\mathrm{F}_{2}$
Not considering average atmospheric lifetimes, which of the following would you expect to have the greatest global warming potential?

- A. $\mathrm{CO}_{2}$

- B. $\mathrm{CH}_{3} \mathrm{~F}$

- C. $\mathrm{N}_{2}$

-D. $\mathrm{CH}_{4}$

- E. $\mathrm{CCl}_{2} \mathrm{~F}_{2}$ 
Compare the effectiveness of CFC-12 as a ghg to that of $\mathrm{CO}_{2}$ : multiply GWP by concentration.

\begin{tabular}{|lllcc} 
Compound & Name & anthropogenic sources & GWP & $\begin{array}{c}2020 \text { atmospheric } \\
\text { concentration }\end{array}$ \\
$\mathrm{CO}_{2}$ & $\begin{array}{l}\text { carbon } \\
\text { dioxide }\end{array}$ & $\begin{array}{l}\text { fossil fuel combustion, } \\
\text { deforestation }\end{array}$ & 1 & $427 \mathrm{ppm}$ \\
$\mathrm{CH}_{4}$ & methane & $\begin{array}{l}\text { fossil fuel production, } \\
\text { livestock }\end{array}$ & 21 & $1875 \mathrm{ppb}$ \\
$\mathrm{N}_{2} \mathrm{O}$ & $\begin{array}{l}\text { nitrous } \\
\text { oxide }\end{array}$ & combustion, fertilizers & 310 & $332 \mathrm{ppb}$ \\
$\mathrm{CCl}_{2} \mathrm{~F}_{2}$ & $\mathrm{CFC}-12$ & refrigeration, aerosols & 8100 & $498 \mathrm{ppt}$ \\
& & & &
\end{tabular}
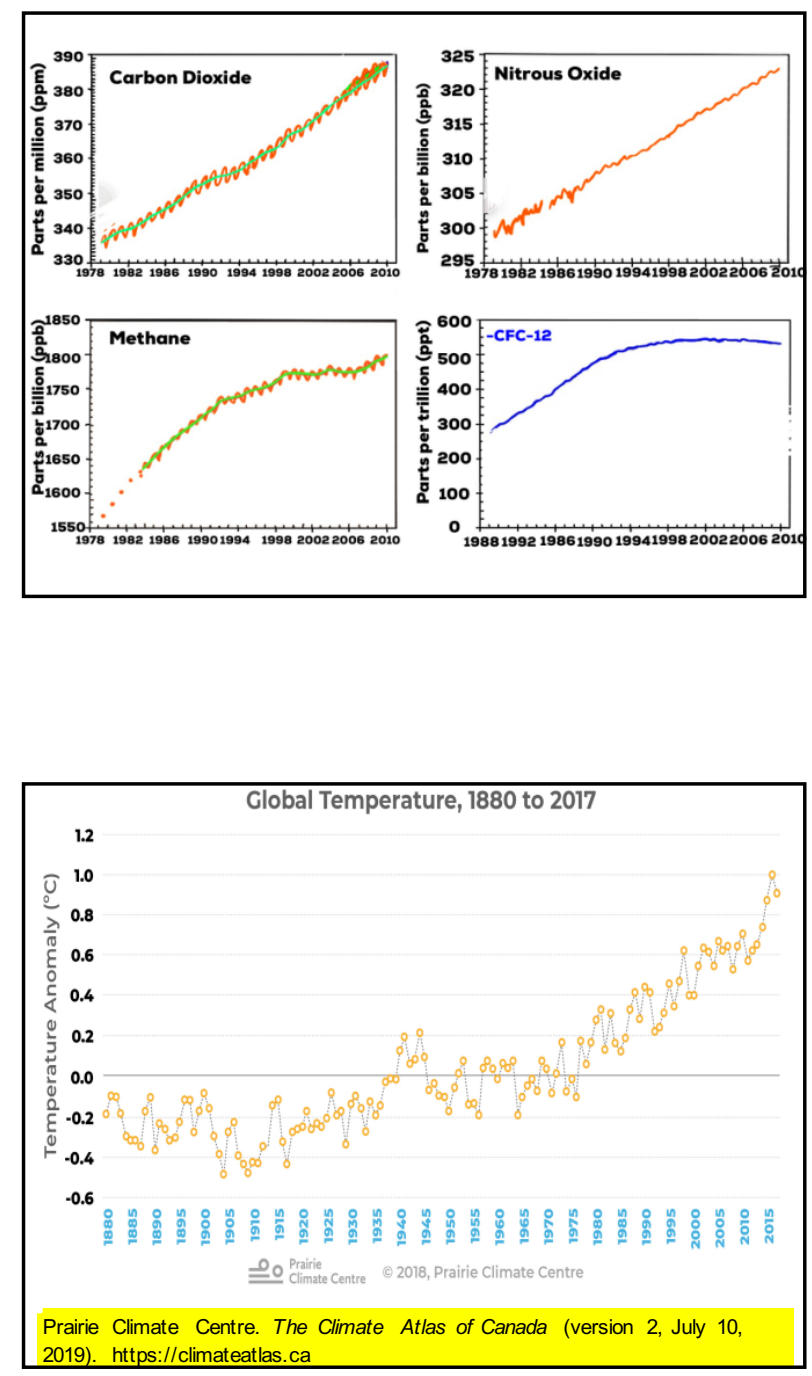

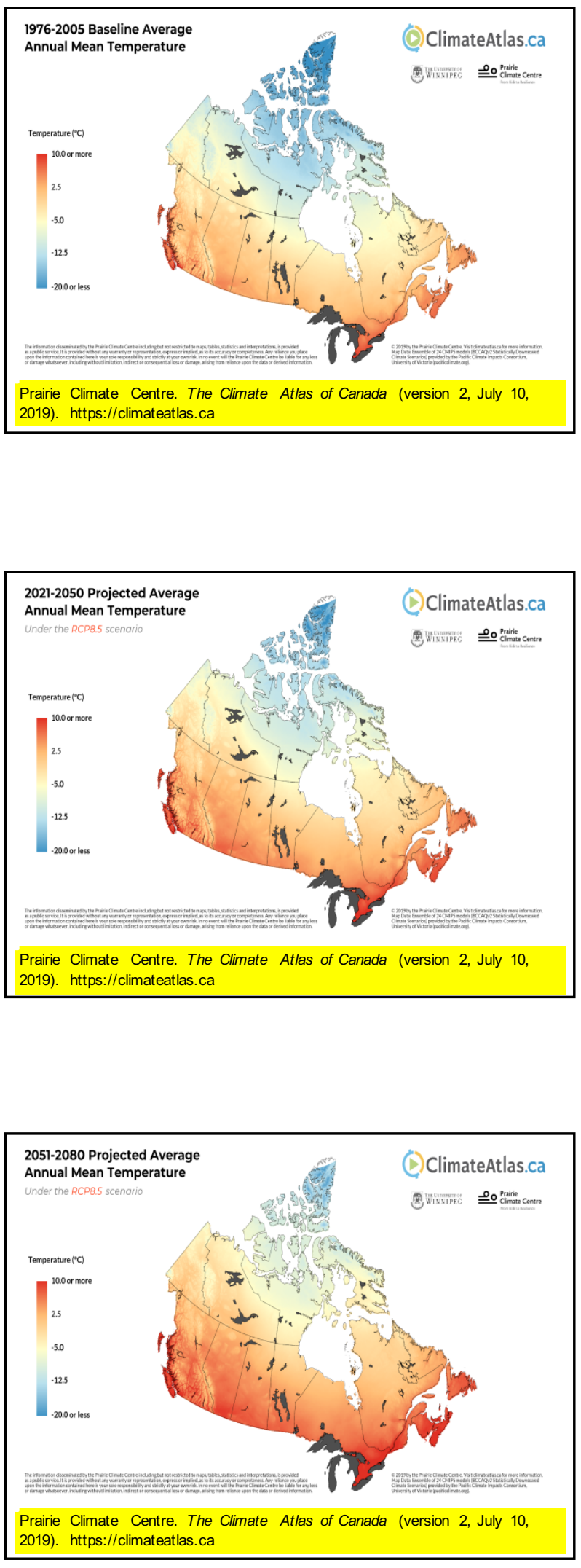

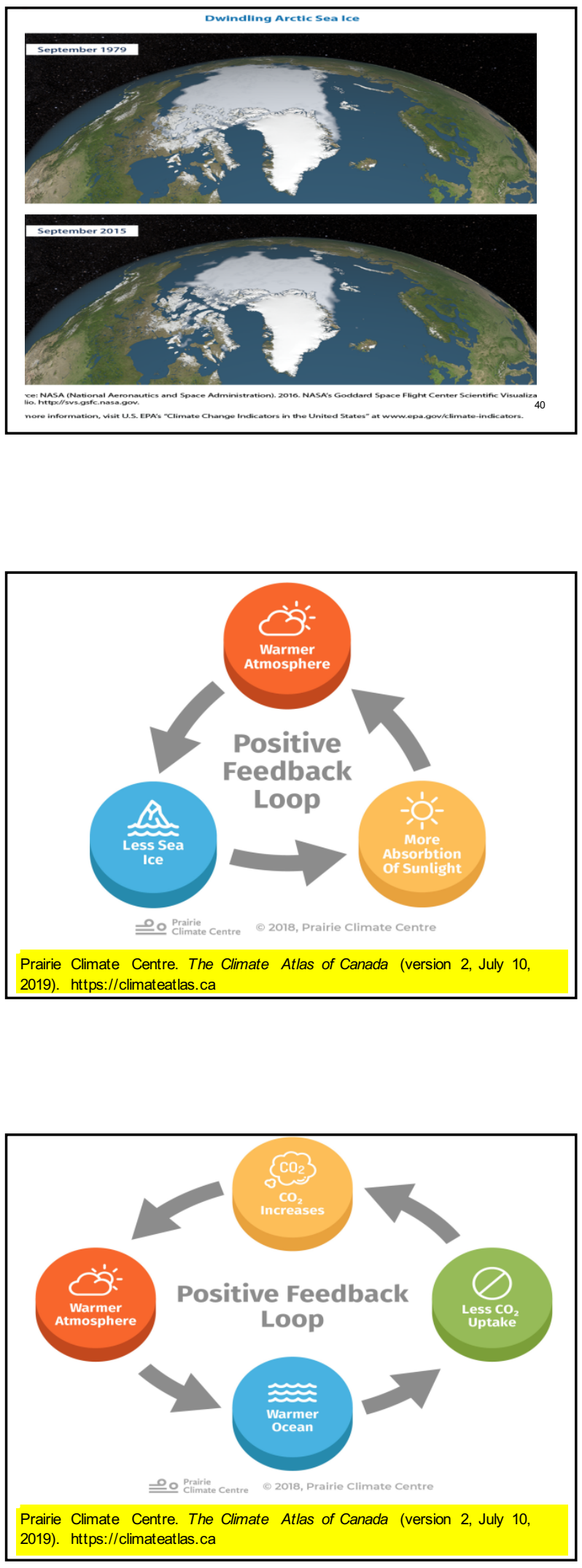


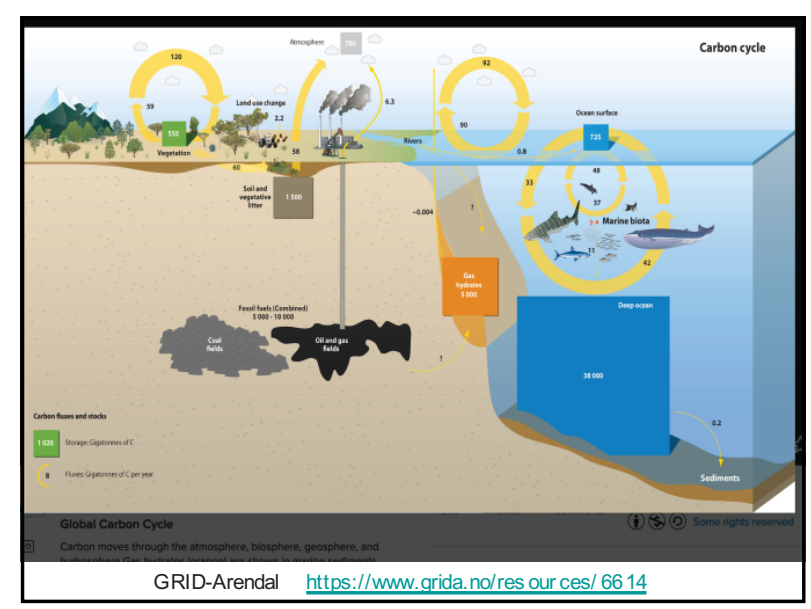

\section{Intergovernmental Panel on Climate Change (IPCC) 1988}

Kyoto Protocol - 1997

- IPCC certified the scientific basis of the greenhouse effect.

-Emission targets set to reduce emis sions of six greenhouse gases from 1990 levels.

$\left(\mathrm{CO}_{2}, \mathrm{CH}_{4}, \mathrm{~N}_{2} \mathrm{O}, \mathrm{HFC}\right.$ 's, PFC's, and $\left.\mathrm{SF}_{6}\right)$

-U.S.A. did not ratify

- Many members such as Canada did not meet targets. Canada has since withdrawn. 


\section{Kyoto successors}

- 'Washington Declaration' - 16 February 2007

- Copenhagen 2009

- Cancun 2010

- South Africa 2011

- Qatar/South Korea 2012 (COP 18)

- Warsaw, 2013

- UN Climate Summit, 2014

- Paris, 2016

\section{Remember: Ozone/CFC's}

\section{summary}

- Potentially catastrophic series of events.

- Smoking gun.

- Substitutes were (are) available.

- Economic setback (but not devastating).

- Montreal Protocol, and current refinements.

\section{Compare: Climate change summary}

- Scientific events.

- Smoking gun?

- Substitutes available?

- Economic setback?

- Government, industry, personal action? Protocols? 


\section{Focus on Energy}

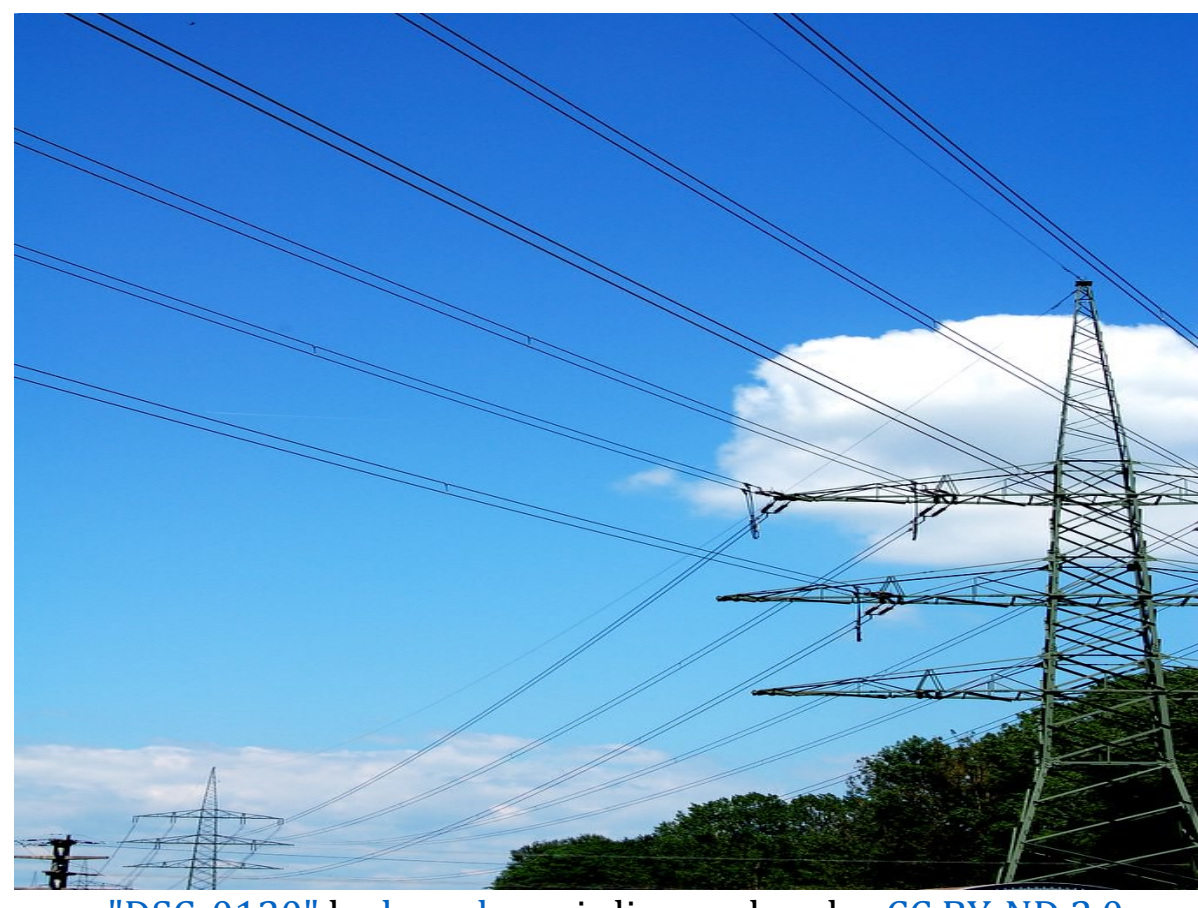

"DSC_0120" by berndnow is licensed under CC BY-ND 2.0

What is energy? Where does the abundance of energy electricity, gasoline, natural gas, etc. - that people have available today come from? Since the industrial revolution began in the $18^{\text {th }}$ century, humankind have discovered a multitude of energy sources to help power our society. The average life expectancy has been extended and the world's population has grown, while our use of external energy sources has continued to grow even faster. With that, there have been rewards, consequences and challenges along the way.

Refer to the information discussed in the previous Focus section as well as Part V of this text and elaborate on the following focus boxes, solving any problems that appear. Make note of the important role that 'fossil' fuels have played and continue to play in meeting our energy demands. In order to determine the best route to meeting our future energy needs, one must understand the benefits and challenges of the processes that are currently in use. 


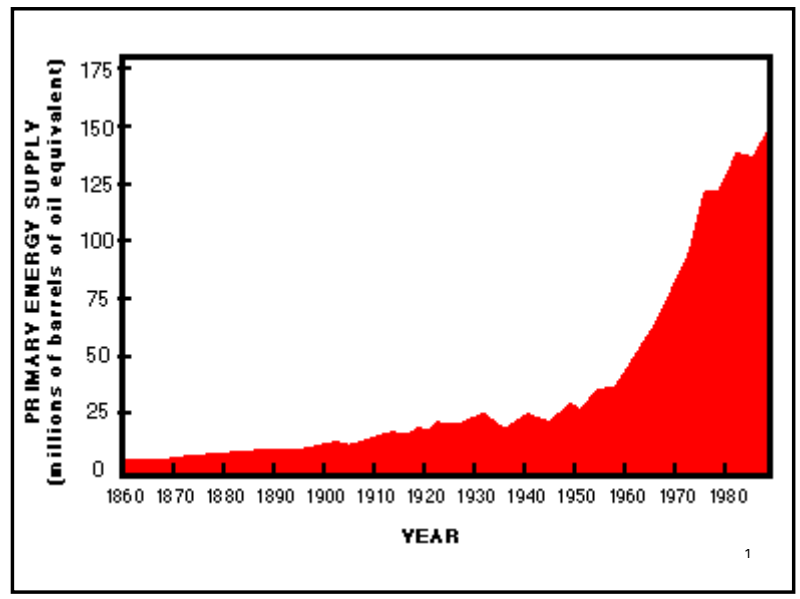

\section{Energy}

Energy can be defined as the capacity to supply heat or do work. One type of work $(w)$ is the process of causing matter to move against an opposing force.

\section{Two types of energy associated} with objects can be defined

potential energy - the energy an object has because of its relative position, composition, or condition.

kinetic energy - the energy that an object possesses because of its motion.

Label the following hydroelectric dam with (i) potential energy, (ii) kinetic energy, (iii) work. 


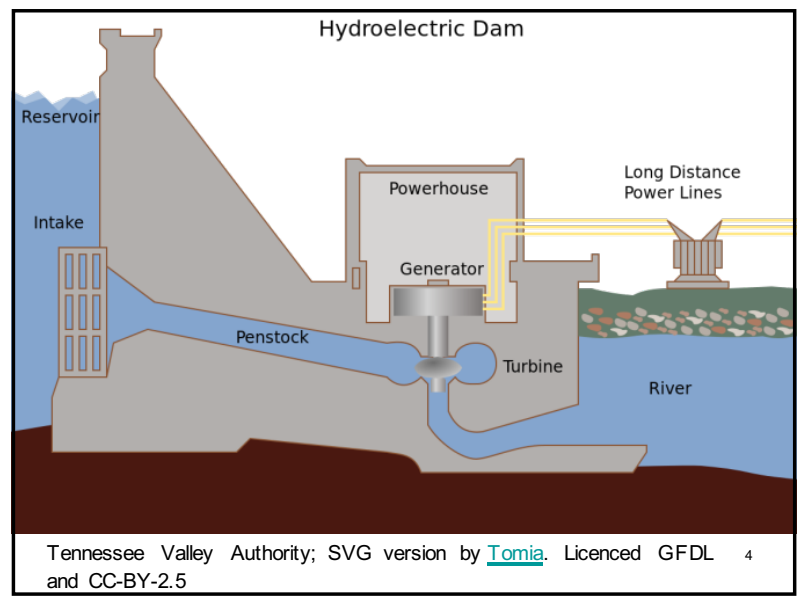

\section{Some sources of Energy}

- Hydro Reservoirs

- Chemical Bonds

- Nuclear Transformations

- Solar Power

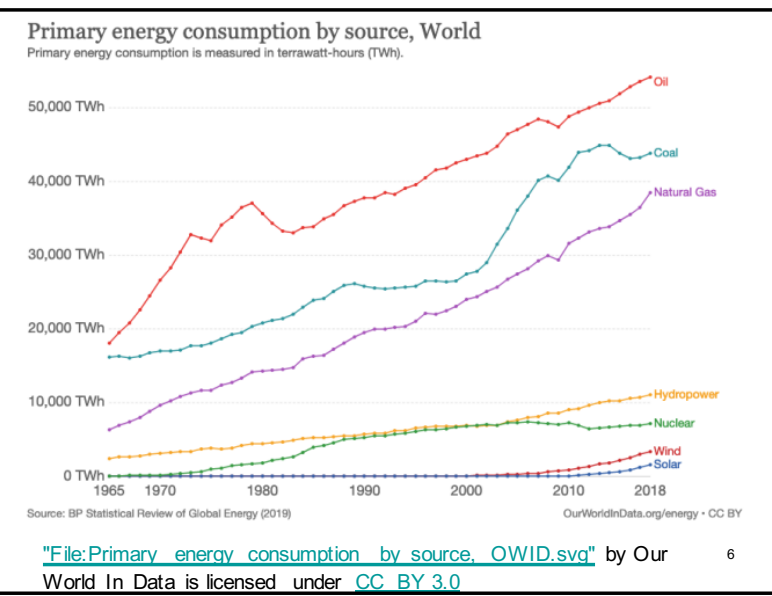




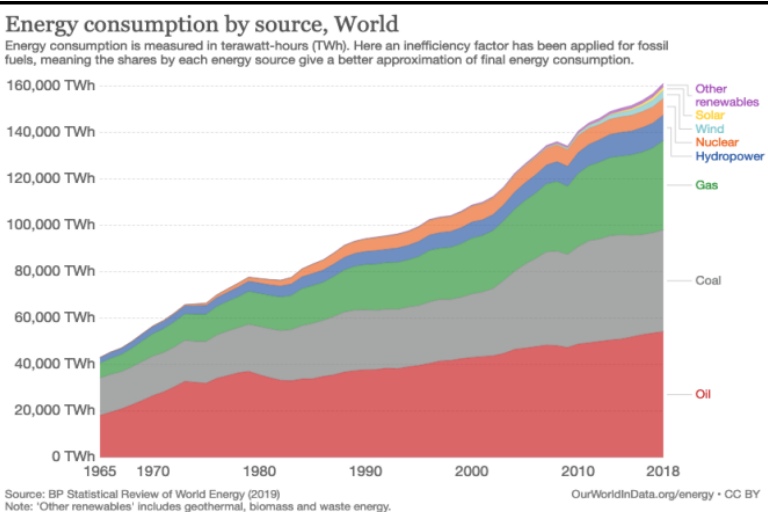

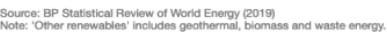

"File:Energy consumption by source, OWID.svg" by Our World 7 In Data is licensed under CC BY 3.0
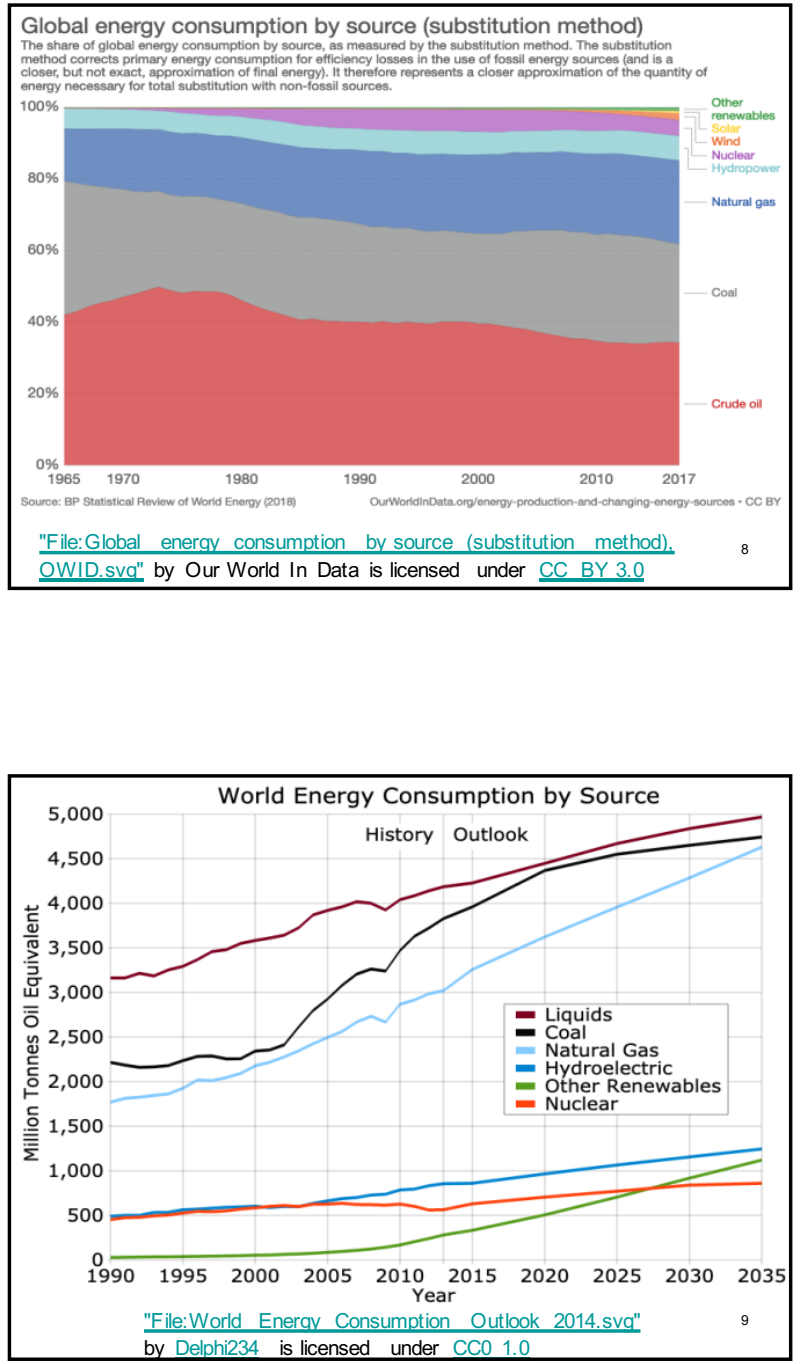


\section{Chemical Bond Energy}

The rearrangement of atoms in chemical reactions... breaking bonds and forming new bonds... may require energy, or it may release energy.

Bond energy - is the amount of energy that is required to break a chemical bond. Thus, it is also the amount of energy that is released when that same chemical bond is formed.

Exothermic - releases energy

Endothermic - requires energy

Show the balanced reaction

for the combustion of hydrogen and determine the energy change for the reaction (per mole of $\mathrm{H}_{2}$ combusted as well as per gram of $\mathrm{H}_{2}$ combusted). Is this energy absorbed or released by the reaction? 


\begin{tabular}{lll}
\multicolumn{3}{l}{ Average Bond Lengths and Bond Energies for Some Common Bonds } \\
Bond & Bond Length $(\AA)$ & Bond Energy (kJ/mol) \\
$\mathrm{C}-\mathrm{C}$ & 1.54 & 345 \\
$\mathrm{C}=\mathrm{C}$ & 1.34 & 611 \\
$\mathrm{C} \equiv \mathrm{C}$ & 1.20 & 837 \\
$\mathrm{C}-\mathrm{N}$ & 1.43 & 290 \\
$\mathrm{C}=\mathrm{N}$ & 1.38 & 615 \\
$\mathrm{C} \equiv \mathrm{N}$ & 1.16 & 891 \\
$\mathrm{C}-\mathrm{O}$ & 1.43 & 350 \\
$\mathrm{C}=\mathrm{O}$ & 1.23 & 741 \\
$\mathrm{C} \equiv \mathrm{O}$ & 1.13 & 1080 \\
\hline
\end{tabular}

\begin{tabular}{|c|c|c|c|c|c|}
\hline \multicolumn{6}{|c|}{ Bond Energies (kJ/mol) } \\
\hline Bond & Bond Energy & Bond & Bond Energy & Bond & Bond Energy \\
\hline $\mathrm{H}-\mathrm{H}$ & 436 & C-S & 260 & $\mathrm{~F}-\mathrm{Cl}$ & 255 \\
\hline $\mathrm{H}-\mathrm{C}$ & 415 & $\mathrm{C}-\mathrm{Cl}$ & 330 & $\mathrm{~F}-\mathrm{Br}$ & 235 \\
\hline $\mathrm{H}-\mathrm{N}$ & 390 & $\mathrm{C}-\mathrm{Br}$ & 275 & $\mathrm{Si}-\mathrm{Si}$ & 230 \\
\hline $\mathrm{H}-\mathrm{O}$ & 464 & C-I & 240 & Si-P & 215 \\
\hline $\mathrm{H}-\mathrm{F}$ & 569 & $\mathrm{~N}-\mathrm{N}$ & 160 & $\mathrm{Si}-\mathrm{S}$ & 225 \\
\hline $\mathrm{H}-\mathrm{Si}$ & 395 & $\mathrm{~N}=\mathrm{N}$ & 418 & $\mathrm{Si}-\mathrm{Cl}$ & 359 \\
\hline H-P & 320 & $\mathrm{~N} \equiv \mathrm{N}$ & 946 & $\mathrm{Si}-\mathrm{Br}$ & 290 \\
\hline $\mathrm{H}-\mathrm{S}$ & 340 & $\mathrm{~N}-\mathrm{O}$ & 200 & $\mathrm{Si}-\mathrm{I}$ & 215 \\
\hline $\mathrm{H}-\mathrm{Cl}$ & 432 & $\mathrm{~N}-\mathrm{F}$ & 270 & P-P & 215 \\
\hline $\mathrm{H}-\mathrm{Br}$ & 370 & $\mathrm{~N}-\mathrm{P}$ & 210 & P-S & 230 \\
\hline $\mathrm{H}-\mathrm{I}$ & 295 & $\mathrm{~N}-\mathrm{Cl}$ & 200 & $\mathrm{P}-\mathrm{Cl}$ & 330 \\
\hline $\mathrm{C}-\mathrm{C}$ & 345 & $\mathrm{~N}-\mathrm{Br}$ & 245 & $\mathrm{P}-\mathrm{Br}$ & 270 \\
\hline
\end{tabular}

\begin{tabular}{|c|c|c|c|}
\hline $\mathrm{C}-\mathrm{C}$ & 345 & $\mathrm{~N}-\mathrm{Br} 245$ & $\mathrm{P}-\mathrm{Br} 270$ \\
\hline $\mathrm{C}=\mathrm{C}$ & 611 & O-O 140 & P-I 215 \\
\hline $\mathrm{C} \equiv \mathrm{C}$ & 837 & $\mathrm{O}=\mathrm{O} \quad 498$ & S-S $\quad 215$ \\
\hline $\mathrm{C}-\mathrm{N}$ & 290 & O-F 160 & $\mathrm{~S}-\mathrm{Cl} 250$ \\
\hline $\mathrm{C}=\mathrm{N}$ & 615 & O-Si 370 & $\mathrm{~S}-\mathrm{Br} 215$ \\
\hline $\mathrm{C} \equiv \mathrm{N}$ & 891 & O-P 350 & $\mathrm{Cl}-\mathrm{Cl} 243$ \\
\hline $\mathrm{C}-\mathrm{O}$ & 350 & O-Cl 205 & $\mathrm{Cl}-\mathrm{Br} 220$ \\
\hline $\mathrm{C}=\mathrm{O}$ & 741 & O-I 200 & Cl-I 210 \\
\hline $\mathrm{C} \equiv \mathrm{O}$ & 1080 & $\mathrm{~F}-\mathrm{F} \quad 160$ & $\mathrm{Br}-\mathrm{Br} 190$ \\
\hline $\mathrm{C}-\mathrm{F}$ & 439 & F-Si 540 & $\mathrm{Br}-\mathrm{I} \quad 180$ \\
\hline $\mathrm{C}-\mathrm{Si}$ & 360 & F-P 489 & I-I \\
\hline $\mathrm{C}-\mathrm{P}$ & 265 & F-S 285 & \\
\hline
\end{tabular}




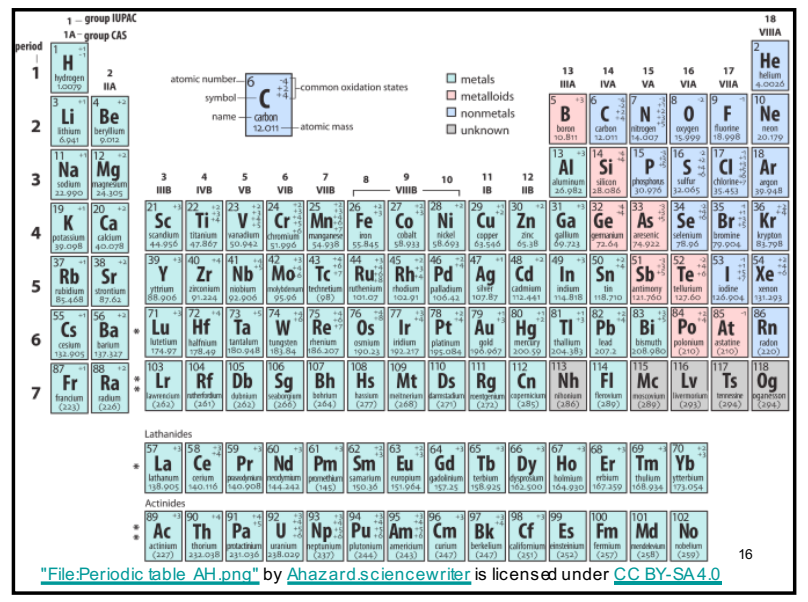

What is the approximate energy change associated with the combustion of methane (per mole of $\mathrm{CH}_{4}$ combusted as well as per gram of $\mathrm{CH}_{4}$ combusted)? Is this energy absorbed or released by the reaction? Do the same determination for ethane $\left(\mathrm{C}_{2} \mathrm{H}_{6}\right)$

\section{Coal}

- $\sim \mathrm{C}_{135} \mathrm{H}_{96} \mathrm{O}_{9} \mathrm{NS}$

- $85 \%$ Carbon

- $30 \mathrm{~kJ}$ per gram

- solid

- various grades

- there's lots of it. ( 400 years) 


\section{http://www.worldometers.info/}

- Energy at:

http://uww. worldometers.info/

\section{Petroleum}

- Various Hydrocarbons

- $48 \mathrm{~kJ}$ per gram

- liquid

- must first be refined (distillation)

- value captures/conversions

- there's less known reserves ( $<50$ years) and it's becoming harder to extract ("peak oil")

- 'Where oil is' vs. Where oil is used'

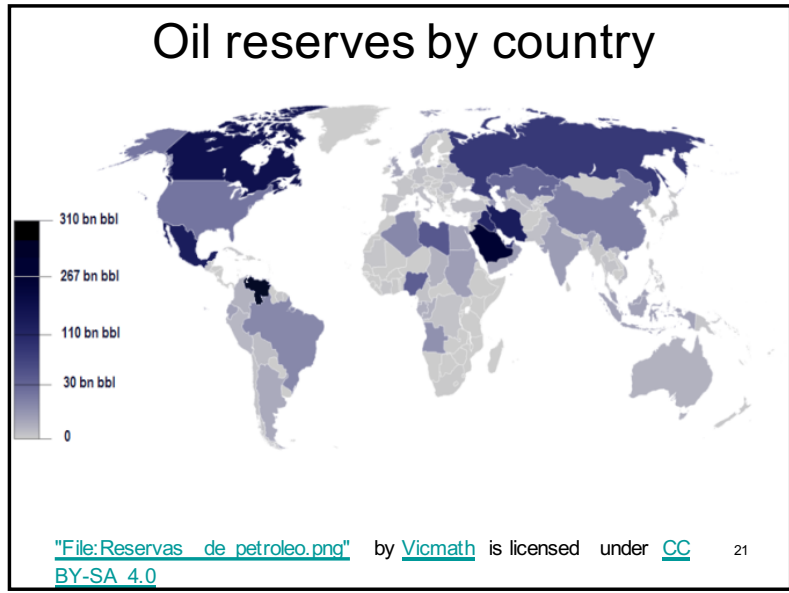




\section{Gasoline additives}

\section{- Tetraethyl lead}

- - used to be added to gasoline to minimize premature firing.

- - Pb would be released to the environment

- - Pb interferes with the function of certain enzymes

Elimination of octane enhancing tetraethyl lead (TEL) created a need to find substitutes.

MTBE (methyl tertiary-butyl ether)

Due to groundwater contamination concerns, MTBE is now banned in the U.S., Canada and Japan.

Ethanol (ethyl alcohol)

\section{Natural Gas}

- $\mathrm{C}_{1}-\mathrm{C}_{4}$ hydrocarbons

- gas

- approximately $55 \mathrm{~kJ}$ per gram

- Approximately 150 years remain of known reserves 


\section{Biomass}

- Wood

- Biodiesel

- Ethanol

- Show the balanced chemical reaction for the combustion of ethanol $\left(\mathrm{CH}_{3} \mathrm{CH}_{2} \mathrm{OH}\right)$. Calculate the energy change per mole and per gram of ethanol combusted.

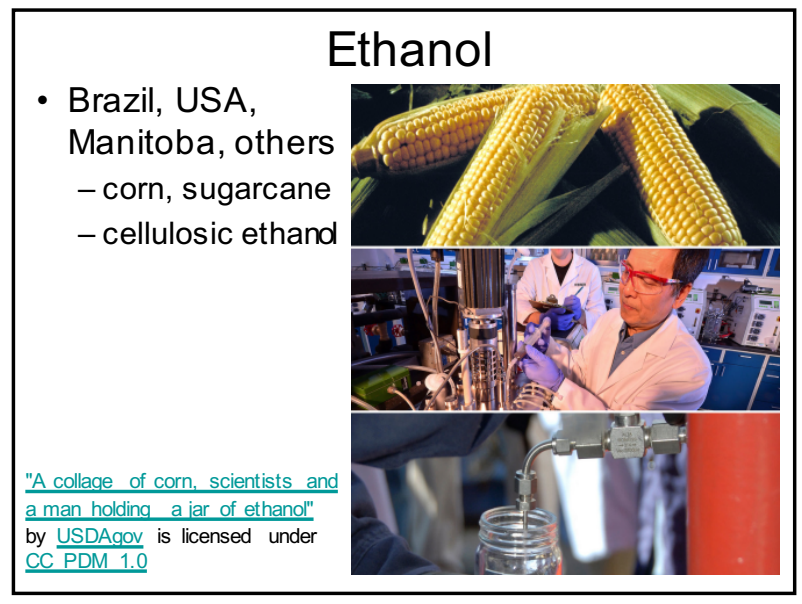

\section{Alternative Combustibles}

- For example:

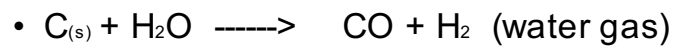

--> Fisher-Tropsch synthesis of gasoline (Fe or Co catalyst) 


\section{Biogas}

- The ferment of animal and vegetable wastes

- $60 \%$ methane

\section{Garbage}

- More than $1 / 3$ is directly combustible, as little as $10 \%$ of the original volume may end up as landfill

- Japan, Germany, US

\section{Fossil Fuels, Biofuels - Photosynthesis}

- Note: the energy in all fossil fuels and biofuels originates from the same place chlorophyll in plants captures solar energy and converts $\mathrm{CO}_{2}$ and $\mathrm{H}_{2} \mathrm{O}$ into carbohydrates, essentially storing the energy in the chemical bonds of the new molecule.

- $6 \mathrm{CO}_{2}+6 \mathrm{H}_{2} \mathrm{O}+$ sunlight $\Rightarrow \mathrm{C}_{6} \mathrm{H}_{12} \mathrm{O}_{6}+6 \underset{30}{\mathrm{O}_{2}}$ 
Fossil Fuels - the reasons for Conservation and Alternatives

- Pollution

- Climate Change

- Finite Resources - 'Peak oil'

- Political consequences

- Are practically non-renewable. Now is the time to ensure we have this important energy and feedstock source (for chemical synthesis) for the future. 


\section{Focus on Nuclear Energy}

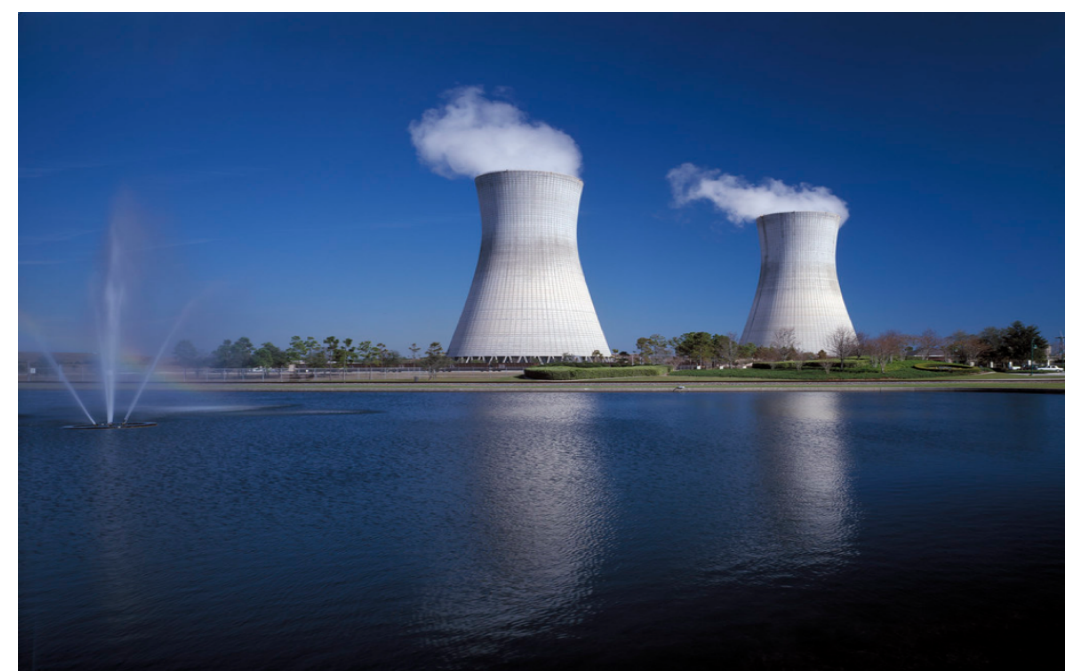

"Cooling towers" by US Department of State is licensed under CC BY-NC 2.0

When nuclear energy came into the mainstream in the 1950's, it was envisioned, by then chairman of the U.S. Atomic Energy Commission Lewis L Strauss, to be such a cheap and powerful source of energy that "our children would enjoy in their homes electrical energy too cheap to meter." While some countries like France have since adopted and developed 'nuclear' as the primary source of energy for electricity generation, in most countries the development of nuclear power has slowed considerably. While the energy potential might remain, accidents and other complications have led to considerable costs and political opposition to the development of nuclear power programs.

Refer to the information discussed in the previous Focus section as well as Part XIV of this text and elaborate on the following focus boxes, solving any problems that appear. While learning the basics of balanced nuclear reactions and radioactivity, make note of important distinctions between nuclear and other types of fuels in meeting our energy demands. In order to determine the best route to meeting our future energy needs, one must understand the benefits and challenges of the processes that are currently in use. 
Approximately $15 \%$ of the world's electricity is generated by nuclear power plants

\section{The Countries With The} Most Nuclear Reactors

Number of operational reactor units by country in 2019

United States $\frac{E}{7}$

France (D) 58

China 47

Russia 36

South Korea :०: 23

India 21

Canada ( +1$) \quad 18$

United Kingdom 米 15

Ukraine 15

Japan $\bullet \quad 9$

Source: World Nuclear Industry Status Report 2019

(c) $\odot \ominus$

Nuclear fission - the splitting of a large nucleus into smaller ones with the release of energy.

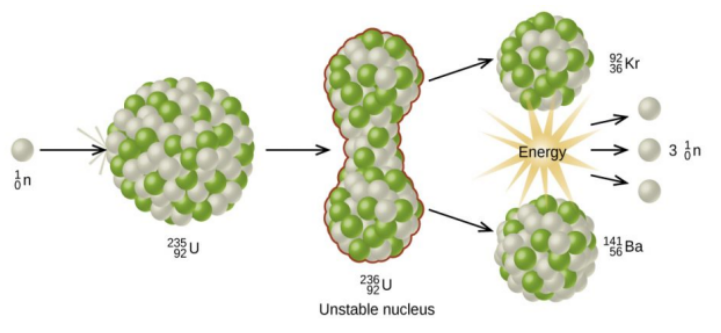

${ }_{92}^{235} \mathrm{U}+{ }_{1}^{0} \mathrm{n} \longrightarrow{ }_{92}^{236} \mathrm{U} \longrightarrow{ }_{36}^{141} \mathrm{Ba}+{ }_{36}^{92} \mathrm{Kr}+3{ }_{0}^{1} \mathrm{n}$

- Show the balanced nuclear reaction for U235 absorbing a neutron and undergoing fission to produce Ba-141, Kr-92 and neutrons. 
Energy is released because the sum of the masses of these fragments is less than the original mass, and this missing mass (about 0.1 percent of the original mass of U-235) has been converted into energy according to Einstein's equation:

$\mathrm{E}=\mathrm{mc}^{2}$

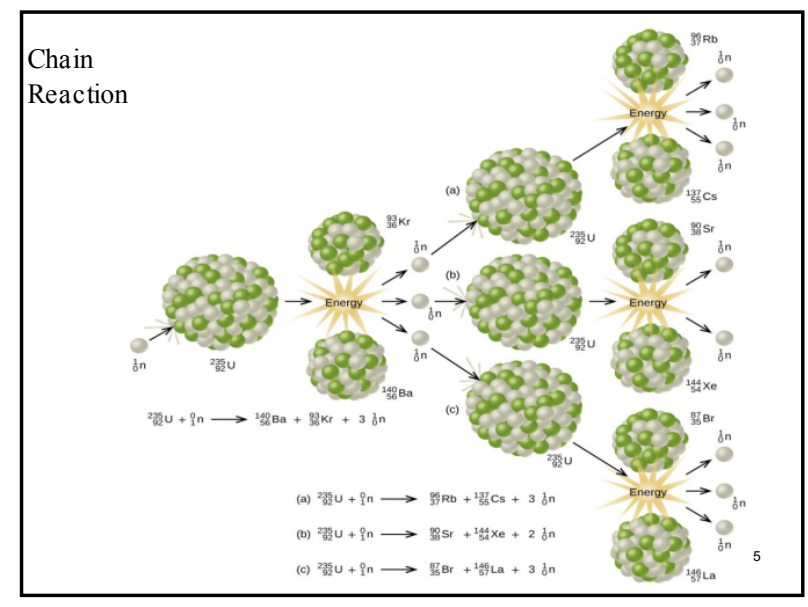

$$
\text { Using } \mathrm{E}=\mathrm{mc}^{2}
$$

Ex: Calculate the amount of energy that is released when $1.0 \mathrm{~kg}$ of U-235 undergoes nuclear fission.

$0.1 \%$ of the mass is converted to energy 


\section{CANDU}

(CANada Deuterium Uranium) reactor

- natural U ---> UO

- ceramic pellets --> rods ---> bundles

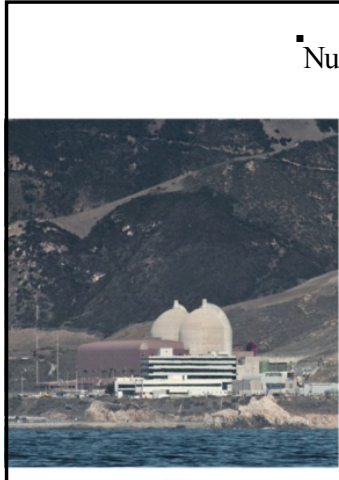

(a)
Nuclear Reactor

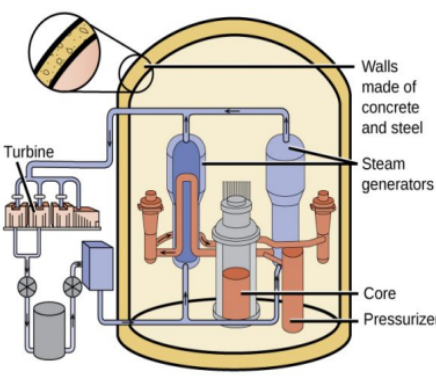

(b)

Chemistry and the Environment by Devin R. Latimer is licensed under ${ }_{8}$ a Creative Commons Attribution 4.0 International License

For equivalent energy production

- 3-400 tons coal

- emitting:

-1400 tons CO2

-12 tons SOx

-4 tons NOx

- Expensive and becoming more so
- one CANDU bundle

- no C, S or $\mathrm{N}$ oxides emitted into air

- Postulated to potentially be a very cheap source of energy 
Could a nuclear power plant undergo a nuclear explosion?

Power plant (controlled fission)

$=0.7-5 \%$ U-235

Nuclear explosion (critical mass)

$=90 \%$ U-235

Sub-critical mass

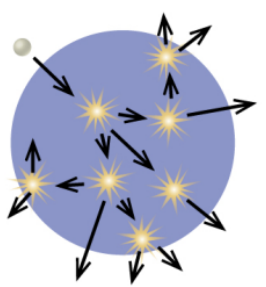

(a)

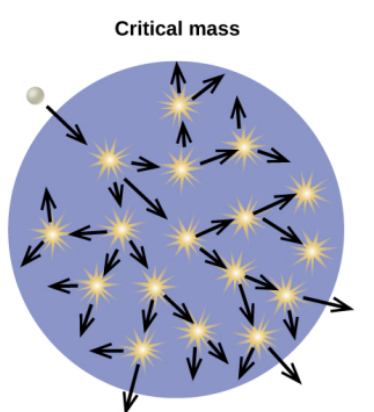

(b)

Chemistry and the Environment by Devin R. Latimer is licensed under 11 a Creative Commons Attribution 4.0 International License

Could nuclear power plant fuel be used to make weapons? 
The isotopes U-235 and U-238 behave essentially the same in all chemical reactions, so the separation/purification of either of these isotopes is extremely difficult.

However, plutonium is a much more likely candidate. Show the balanced nuclear reaction of how U-238 absorbing neutrons can create $\mathrm{Pu}-239$ via the release of beta particles.

\section{Accidents/Waste}

Large amounts of radioactivity can be very dangerous.

Radioactivity - the spontaneous emission of radiation by certain elements

\begin{tabular}{|c|c|c|c|}
\hline Type & Nuclear equation & Representation & $\begin{array}{c}\text { Change in } \\
\text { masslatomic numbers }\end{array}$ \\
\hline Alpha decay & ${ }_{Z}^{A} X \quad{ }_{2}^{4} \mathrm{He}+{ }_{\mathrm{Z}}^{\mathrm{A}-4}-\frac{4}{2} \mathrm{Y}$ & 890 & $\begin{array}{l}\text { A: decrease by } 4 \\
\text { Z: decrease by } 2\end{array}$ \\
\hline Beta decay & ${ }_{z}^{A} X \quad-{ }_{-1}^{0} \mathrm{e}+z+{ }^{A} Y$ & 800 & $\begin{array}{l}\text { A: unchanged } \\
Z \text { increase by } 1\end{array}$ \\
\hline $\begin{array}{l}\text { Gamma } \\
\text { decay }\end{array}$ & $\delta \gamma+\frac{A}{2} Y$ & $(8,2) \stackrel{\downarrow}{\text { Excited nuclear state }}$ & $\begin{array}{l}\text { A: unchanged } \\
Z \text { : unchanged }\end{array}$ \\
\hline $\begin{array}{l}\text { Positron } \\
\text { emission }\end{array}$ & ${ }_{Z}^{A} X \quad{ }_{+1}^{0} e+Y-{ }_{1}^{A} Y$ & $\stackrel{\nabla}{\downarrow} \rightarrow 809$ & $\begin{array}{l}\text { A: unchanged } \\
\text { Z: decrease by } 1\end{array}$ \\
\hline $\begin{array}{l}\text { Electron } \\
\text { capture }\end{array}$ & ${ }_{Z}^{A} X \quad-i e+Y_{-1}^{A} Y$ & $8909 \longrightarrow \underset{x \text {-ray }{ }^{\prime} \rightarrow}{\longrightarrow} 8909$ & $\begin{array}{l}\text { A: unchanged } \\
\text { Z: decrease by } 1\end{array}$ \\
\hline
\end{tabular}



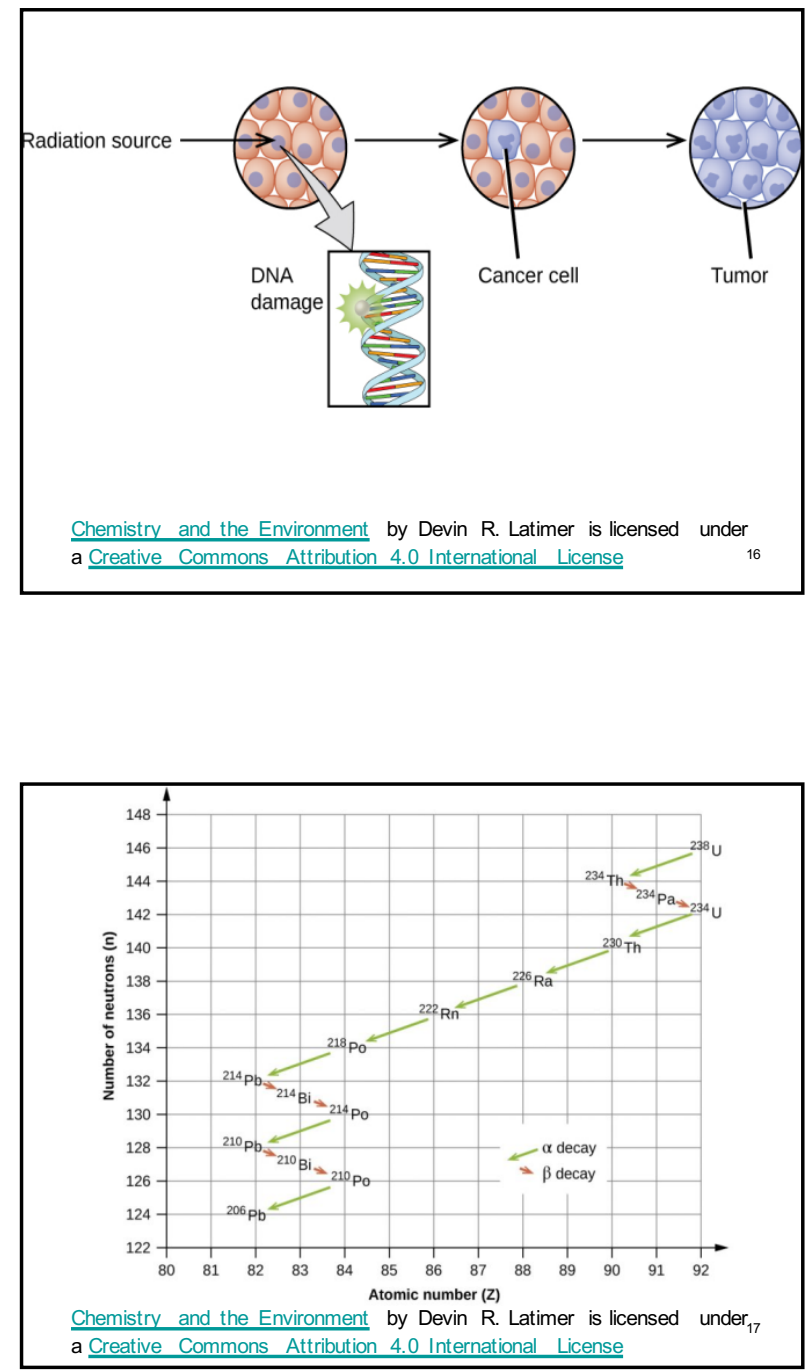

Half-life $\left(t_{1 / 2}\right)$ : the time required for a quantity to reduce to half of its initial value.

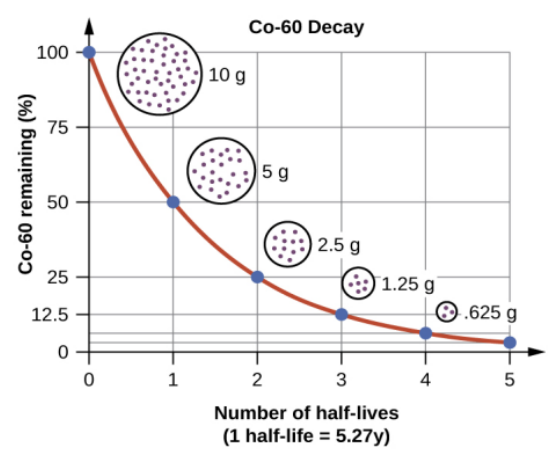

Chemistry and the Environment by Devin R. Latimer is licensed under18 a Creative Commons Attribution 4.0 International License 

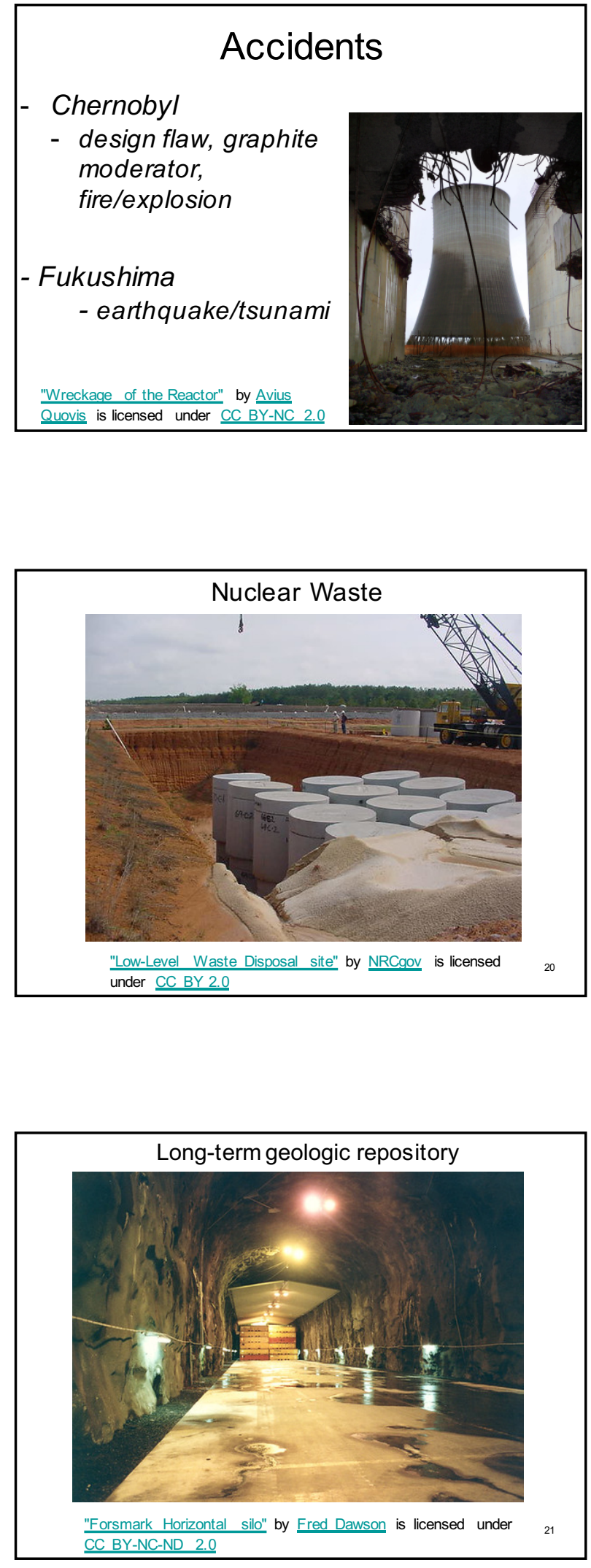


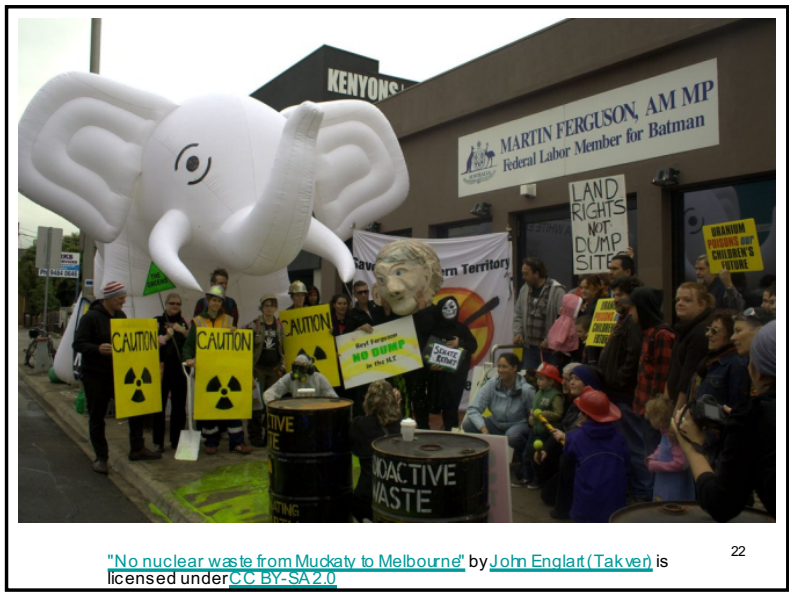

Spent Nuclear Fuel: A Trash Heap Deadly for 250,000 Years or a Renewable Energy Source?

- http://www.scientificamerican.com/article.c $\mathrm{fm}$ ? id=nuclear-waste-lethal-trash-orrenewable-energy-source

A sample of $10 \mathrm{Kg}$ of Thorium-234 is allowed to radioactively decay for

96.4 days. Approximately, how much Th-234 remains? [Th-234 $\mathrm{t}_{1 / 2}=24.1$ days]

- A. $7.5 \mathrm{Kg}$

- B. $5 \mathrm{Kg}$

- C. $2.5 \mathrm{Kg}$

-D. $1.25 \mathrm{Kg}$

- E. $0.625 \mathrm{Kg}$ 


\section{Carbon Dating}

- A sample of fossilized remains is found to contain $6 \%$ of the original (living organism)

${ }^{14} \mathrm{C}$. Approximately, how old are the remains? [C-14 $\mathrm{t}_{1 / 2}=5715$ years]

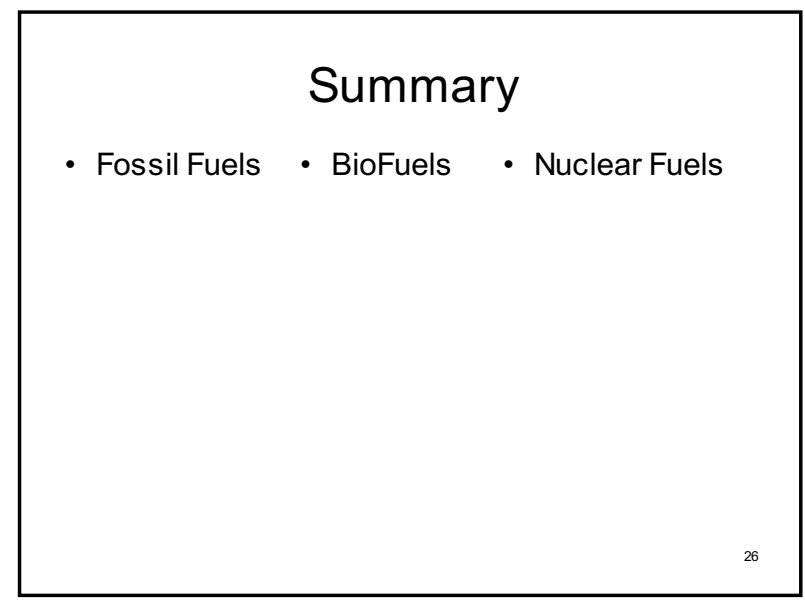




\section{Focus on Alternative Energy}

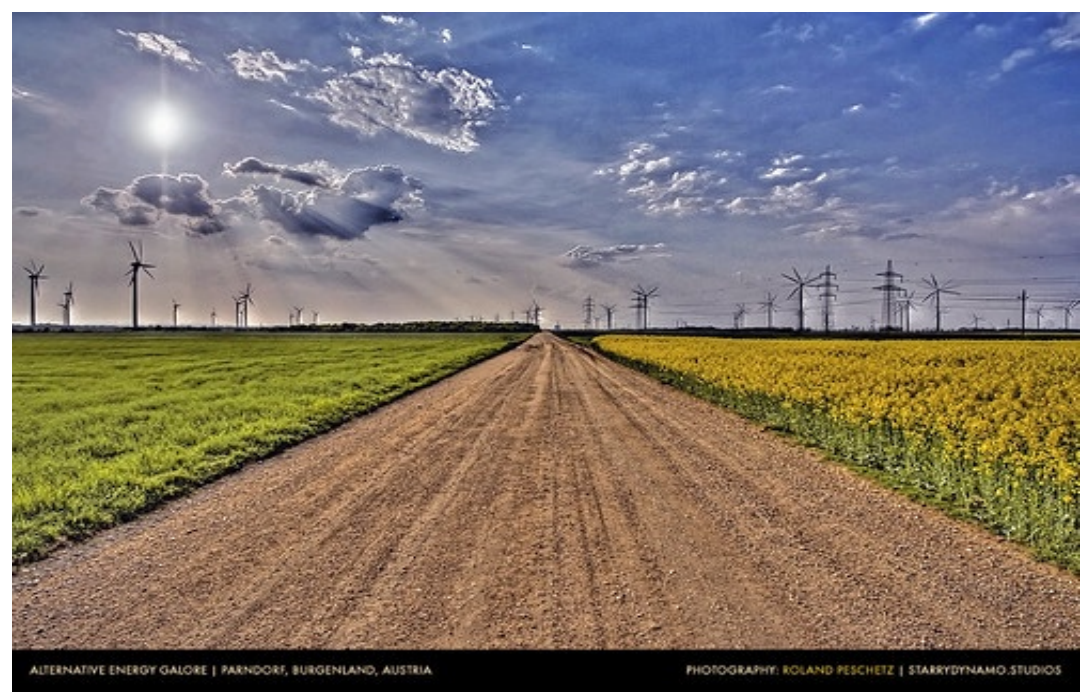

\section{"Alternative Energy Galore" by roliathBrickworx is} licensed under CC BY-NC 2.0

There are a multitude of what one might call 'alternative' sources of energy - biofuels, wind, solar, solar-thermal, hydroelectric, fuel cells - simply because they supply a small portion of the world's total energy needs. In this text, we introduced biofuels in the 'Focus on Energy' section as an alternative combustible to the fossil fuels that we spent much of that section on. In this section we will introduce a few other fuels but limit our discussion to hydroelectric power, batteries and hydrogen based power as they all have significant chemistry-based fundamentals at the level of this text.

Refer to the information discussed in the previous Focus section as well as Part XII of this text and elaborate on the following focus boxes, solving any problems that appear. While learning the basics of electrochemistry and using hydrogen as a fuel source, make note of important distinctions between this and other types of fuels in meeting our energy demands. One must understand the benefits and challenges of the processes that are currently in use and those being proposed to meet our future energy demands in order to decide on the best route for moving forward. 


\section{Solar Power}

- Direct Heat

- Wind

- Water - the hydrologic cycle.

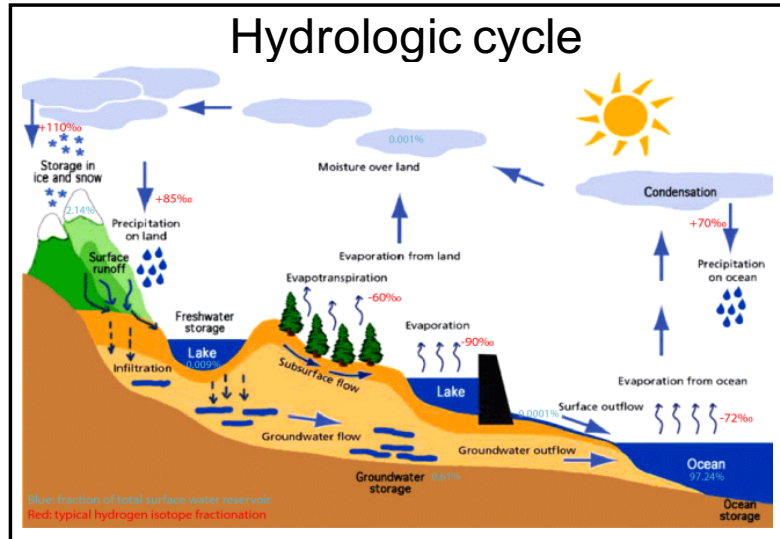

"File:F3 hydrological cycle.png" by Sunson08 is licensed under CC BY-SÅ 4.

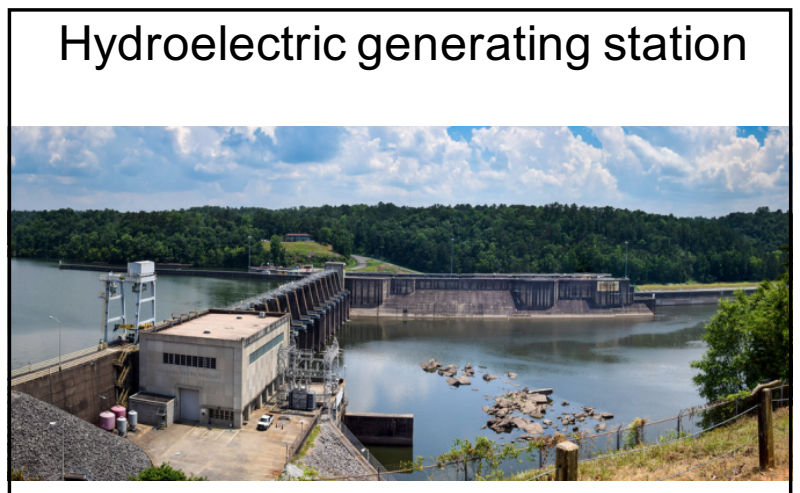

"Holt Dam Tuscaloosa" by petridish38 is licensed under CC BY-NC 2.03 

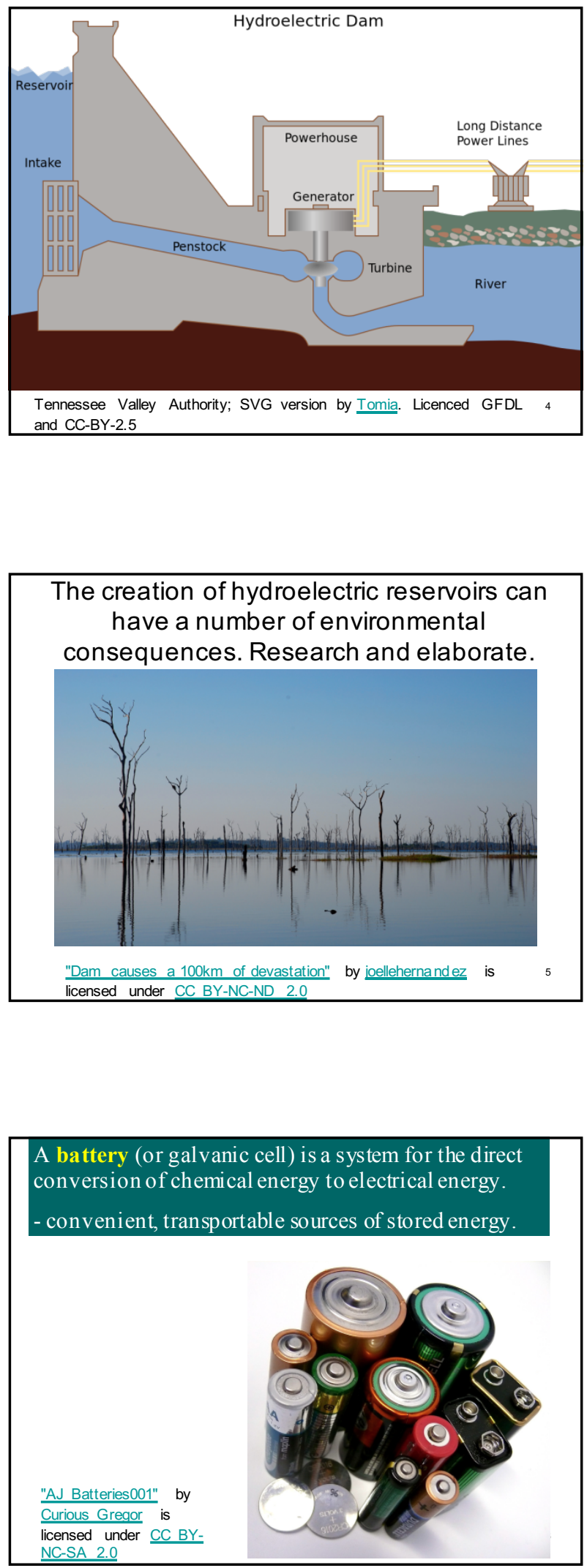


\section{Nickel-Cadmium battery}

- a redox reaction between cadmium and nickel. Show the full redox reaction and identify the species that is being oxidized and that which is being reduced.

\section{Fuel Cell}

- chemical reaction corresponding to hydrogen combustion but the energy is released as electricity.

- combustion:

$\mathrm{H}_{2(\mathrm{~g})}+1 / 2 \mathrm{O}_{2(\mathrm{~g})} \Rightarrow \mathrm{H}_{2} \mathrm{O}_{(1)}$ yields $143 \mathrm{~kJ} / \mathrm{g}$ and water

- fuel cell redox reaction: has the same overall reaction as combustion

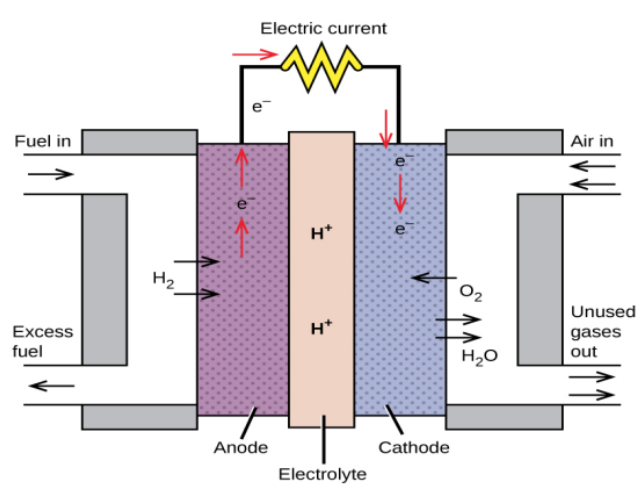

Chemistry and the Environment by Devin R. Latimer is licensed under $a_{9}$ Creative Commons Attribution 4.0 International License 
- Show the half-reactions and overall reaction involved in the release of energy from hydrogen in a fuel cell. Summarize how this compares with the combustion of hydrogen.

- To make the hydrogen economy a reality, where will we get the hydrogen?

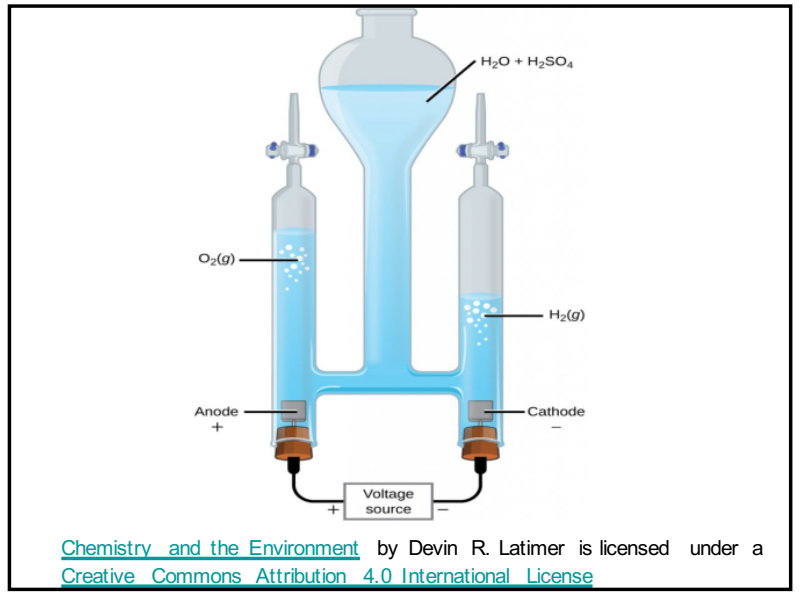

\section{Photovoltaics - involves the flow of electrons} directly from the impact of the sun.

- normally using semiconductors

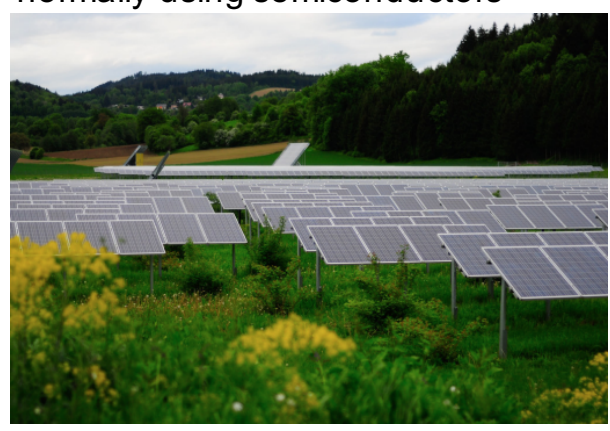


Solar Thermal - concentration of heat energy directly from the sun for use in heating or electricity generation

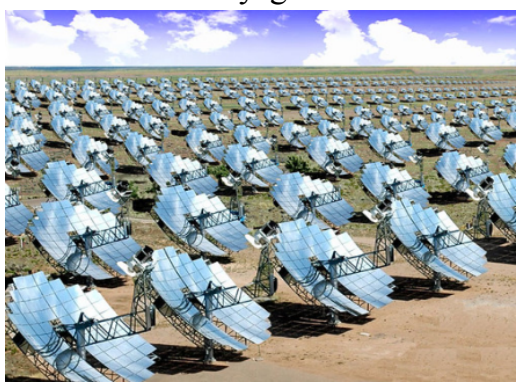

"Solar Thermal" by International Rivers is licensed under $\underline{\text { CC }}{ }_{13}$ BY-NC-SA 2.0

\section{Fusion}

- of nuclei can produce massive amounts of energy.

- What is the fusion reaction involved in the sun? What are the conditions necessary for this reaction? Do you think this is a feasible route to power in the future?

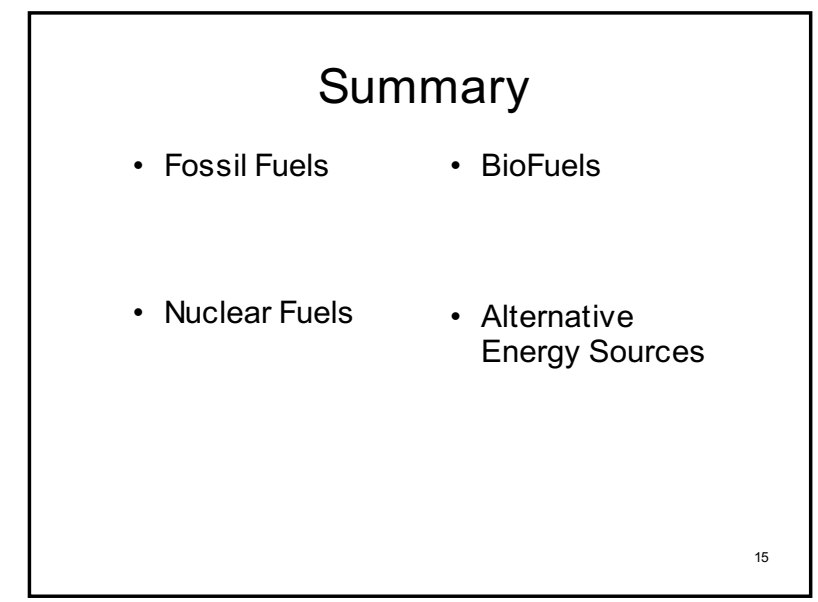




\section{Focus on Water Quality}

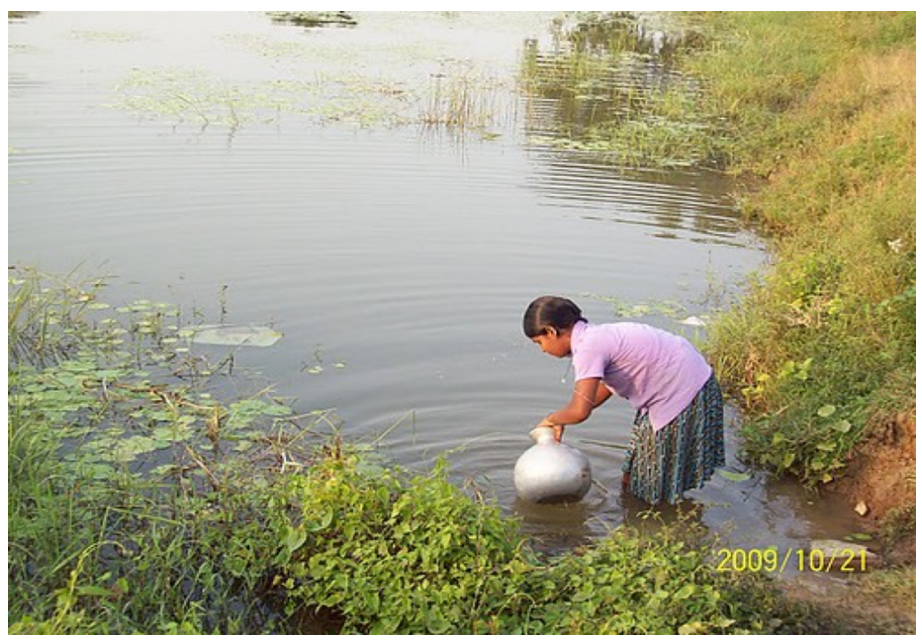

"Safe Drinking Water Supply and Sanitation Project for Puri district" by India Water Portal is licensed under CC BY-NC-SA 2.0

Water - one of the most important and plentiful resources on earth, yet it's availability and quality are lacking to many around the globe. From droughts to pollution, the lack of clean water is a question of health, and ultimately, survival, for millions of people. Water is known to chemists as the 'universal solvent' and in this section the role of solutes and solvents are examined in terms of interactions between molecules to give a glimpse of the field of environmental fate modelling - the prediction of where a chemical might end up in the environment. In order to make a proper assessment of a compound in the environment, there are a number of other factors that must be examined, such as persistence and toxicity, full discussions of which are beyond the scope of this text.

Refer to the information discussed in the previous Focus section as well as Part VIII and IX of this text and elaborate on the following focus boxes, solving any problems that appear. While the field is very complicated, a general ability to approximate the relative solubility of a compound and do rudimentary calculations in concentration terms can provide an important resource for the examination of contaminants in the aqueous environment. 


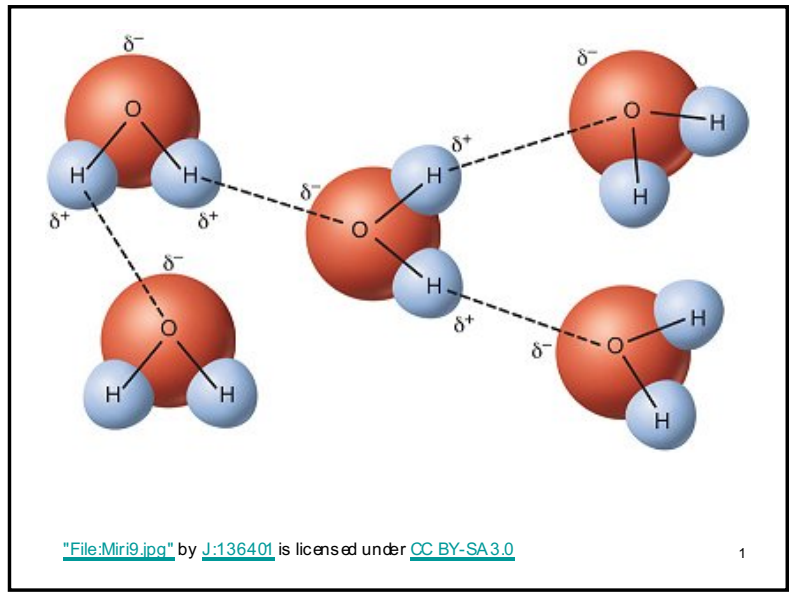

\begin{tabular}{l} 
Hydrogen bond \\
- an especially strong intermolecular force \\
between an electronegative element \\
(such as $\mathrm{N}, \mathrm{O}$ or a halogen) and a \\
hydrogen that is covalently bound to an \\
electronegative element (such as $\mathrm{N}, \mathrm{O}$ or \\
a halogen). \\
Demonstrate the dominant intermolecular \\
in the following solutions. Does the \\
solution have hydrogen bonding? \\
(i) $\mathrm{H}_{2} \mathrm{O}$, (ii) $\mathrm{NH}_{3}$, (iii) $\mathrm{CH}_{3}-\mathrm{O}-\mathrm{CH}_{3}$, \\
(iv) $\mathrm{NH}_{3}$ in $\mathrm{CH}_{3}-\mathrm{O}-\mathrm{CH}_{3}$. \\
\hline
\end{tabular}

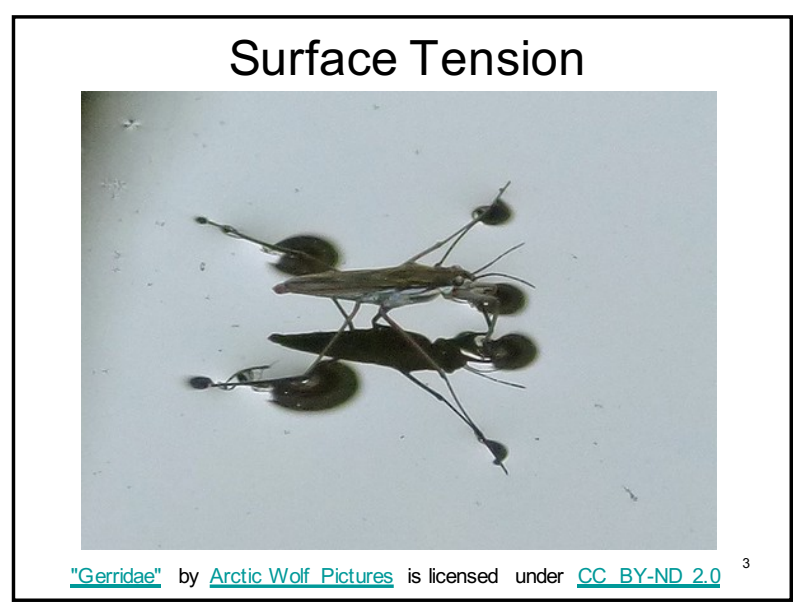




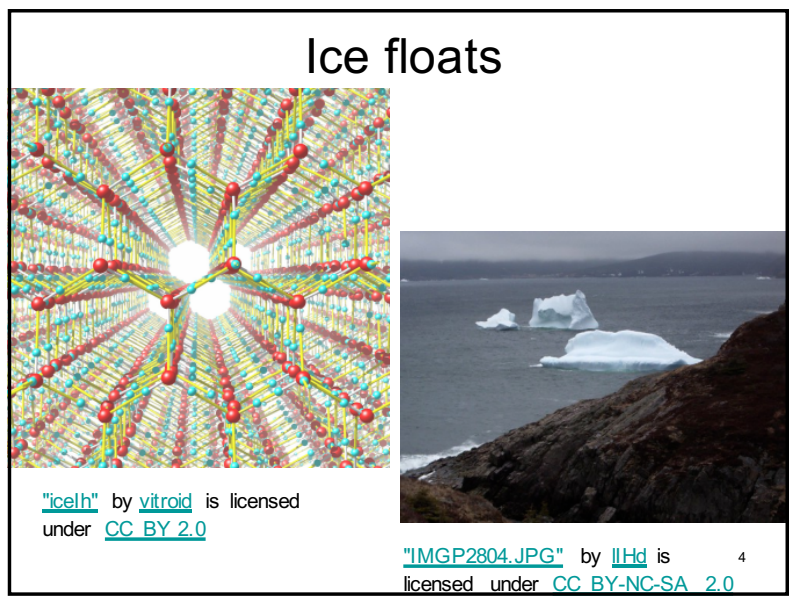

\section{ion}

- an atom or group of atoms that has lost or gained one or more electrons so that it is no longer electrically neutral

- Will form based on the 'stable' electron configuration of the noble gases (Group 8)

- ex: show the reaction of elemental potassium and elemental chlorine to form potassium chloride

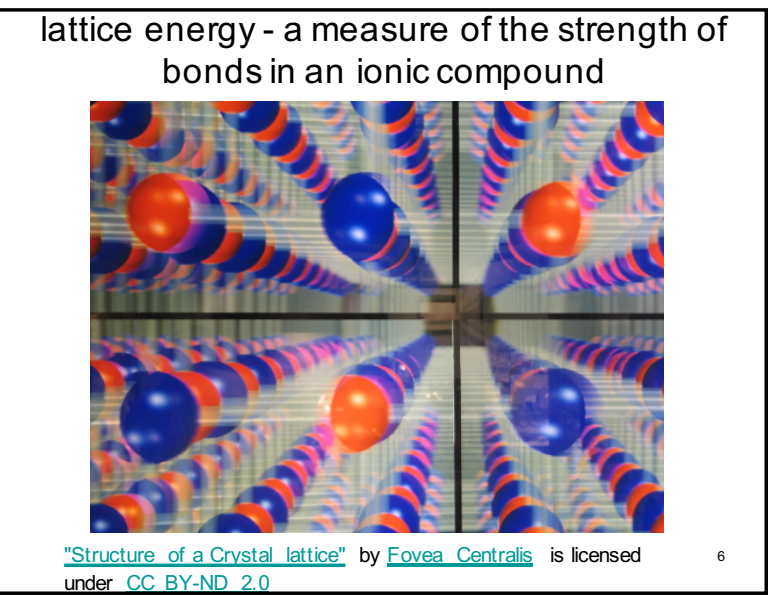




\section{Second Law of Thermodynamics}

Spontaneous processes involve an increase in the entropy (a measure of the disorder of the system) of the universe.

Show the reaction for the dissolution of solid $\mathrm{KCl}$ in water and summarize the interactions that must be overcome and the interactions that result after the dissolution.

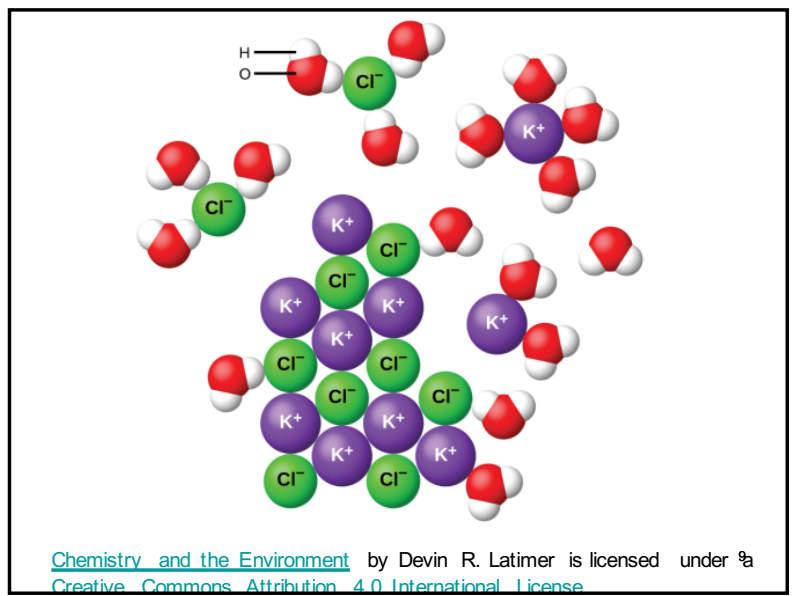


Now consider the following mixtures.

How soluble will they be in one another?

$\mathrm{CH}_{3} \mathrm{CH}_{2} \mathrm{CH}_{2} \mathrm{CH}_{2} \mathrm{CH}_{3}$

$\mathrm{H}_{2} \mathrm{O}$

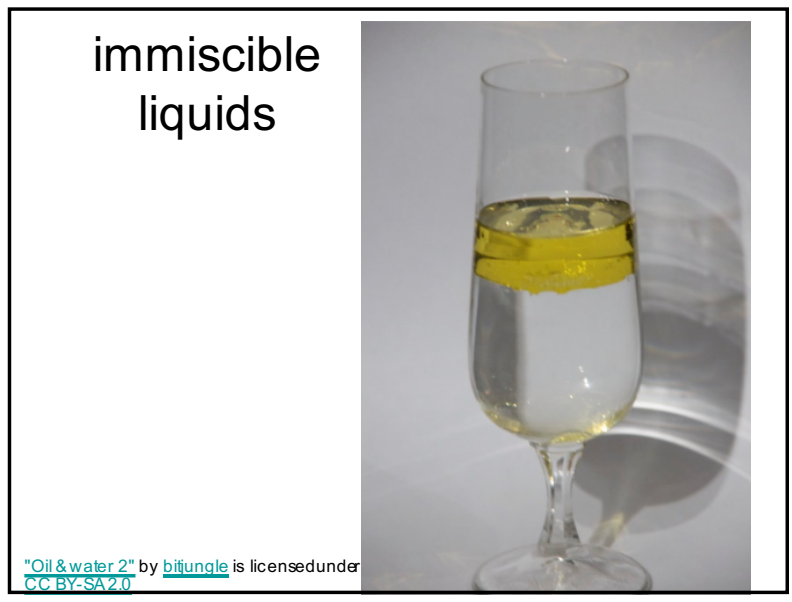

\section{$\mathrm{CH}_{3} \mathrm{CH}_{2} \mathrm{CH}_{2} \mathrm{CH}_{2} \mathrm{CH}_{3}$}

$+$

$\mathrm{CH}_{3} \mathrm{CH}_{2} \mathrm{CH}_{2} \mathrm{CH}_{3}$ 


\section{"Like dissolves like"}

- Polar (hydrophilic) compounds normally dissolve other polar compounds, while non-polar

(hydrophobic) dissolve non-polar.

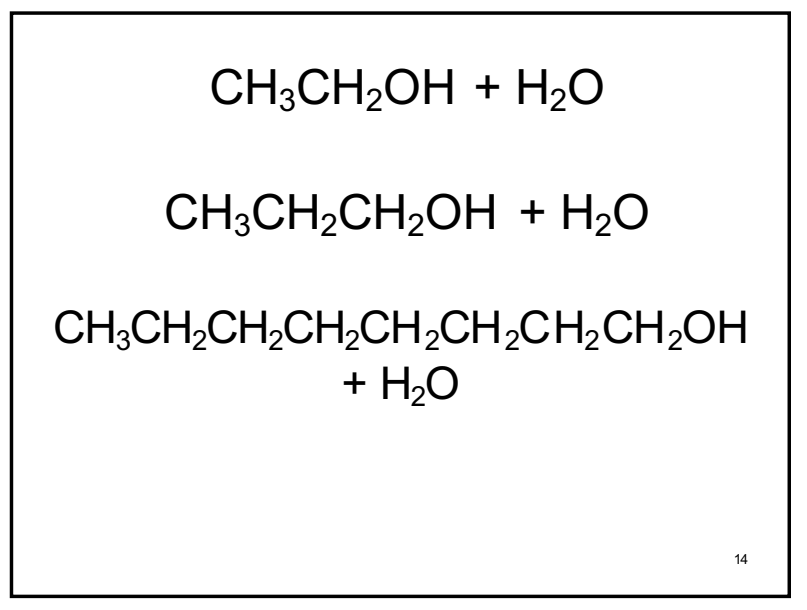

\section{$\mathrm{CH}_{3} \mathrm{CH}_{2} \mathrm{CH}_{2} \mathrm{CH}_{2} \mathrm{CH}_{2} \mathrm{CH}_{2} \mathrm{CH}_{2} \mathrm{CH}_{2} \mathrm{OH}$$$
+\mathrm{H}_{2} \mathrm{O}
$$

- Now, estimate/measure the differential solubility of a compound between these two solvents.

$\mathrm{K}_{\text {ow }}$ : octanol-water partition coefficient.

Environmental fate modelling 


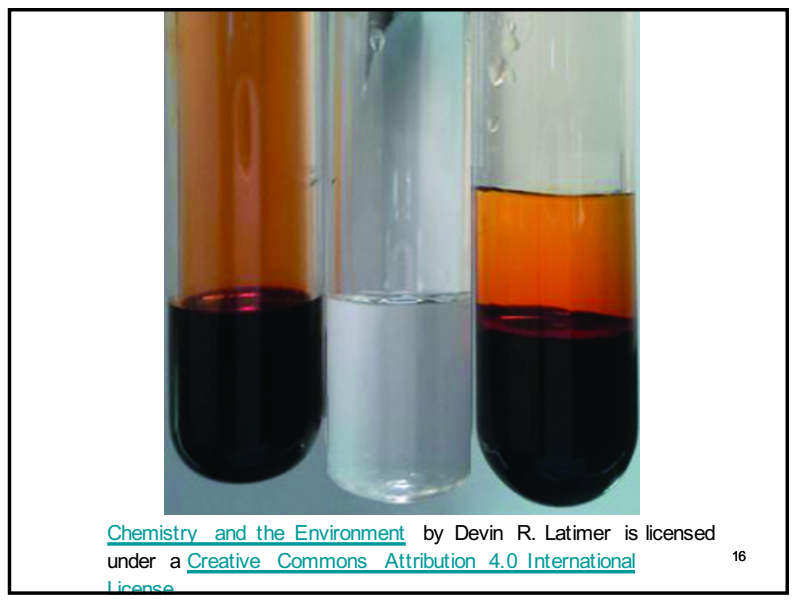

Would you expect $\mathrm{MgCl} 2$ to be more
soluble in water or the long chain
hydrocarbon,
$\mathrm{CH}_{3} \mathrm{CH}_{2} \mathrm{CH}_{2} \mathrm{CH}_{2} \mathrm{CH}_{2} \mathrm{CH}_{2} \mathrm{CH}_{2} \mathrm{CH}_{2} \mathrm{OH}$ ?
- A. Water
- B. $\mathrm{CH}_{3} \mathrm{CH}_{2} \mathrm{CH}_{2} \mathrm{CH}_{2} \mathrm{CH}_{2} \mathrm{CH}_{2} \mathrm{CH}_{2} \mathrm{CH}_{2} \mathrm{OH}$
- C. Equal solubility.

\section{Would you expect}

$\mathrm{CH}_{3} \mathrm{CH}_{2} \mathrm{CH}_{2} \mathrm{CH}_{2} \mathrm{CH}_{2} \mathrm{CH}_{2} \mathrm{CH}_{2} \mathrm{CH}_{2} \mathrm{Cl}$ to be more soluble in water or the long chain hydrocarbon, $\mathrm{CH}_{3} \mathrm{CH}_{2} \mathrm{CH}_{2} \mathrm{CH}_{2} \mathrm{CH}_{2} \mathrm{CH}_{2} \mathrm{CH}_{2} \mathrm{CH}_{2} \mathrm{OH}$ ?

- A. Water

- B. $\mathrm{CH}_{3} \mathrm{CH}_{2} \mathrm{CH}_{2} \mathrm{CH}_{2} \mathrm{CH}_{2} \mathrm{CH}_{2} \mathrm{CH}_{2} \mathrm{CH}_{2} \mathrm{OH}$

- C. Equal solubility. 
Compared to $\mathrm{CH}_{3} \mathrm{CH}_{2} \mathrm{OH}$, what would you expect the solubility properties of $\mathrm{CH}_{3} \mathrm{CH}_{2} \mathrm{CH}_{2} \mathrm{CH}_{2} \mathrm{OH}$ to be?

- A. More soluble in octanol, less soluble in water and organic matter.

- B. Less soluble in octanol, more soluble in water and organic matter.

- C. More soluble in octanol and organic matter, less soluble in water.

- D. Less soluble in octanol and organic matter, less soluble in water.

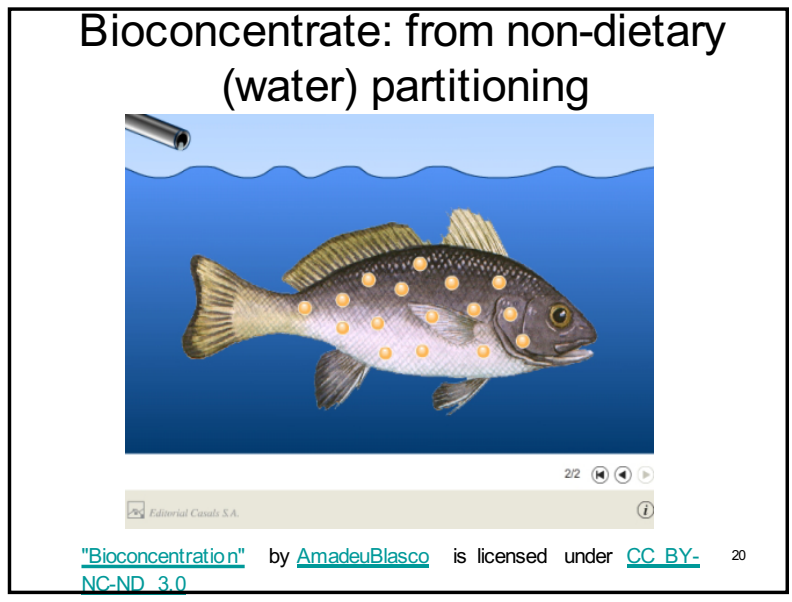

Biomagnify: concentration up the foodchain

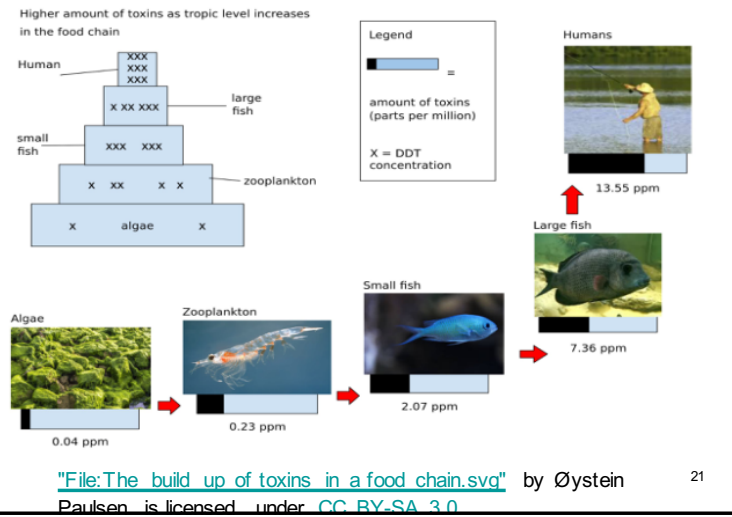



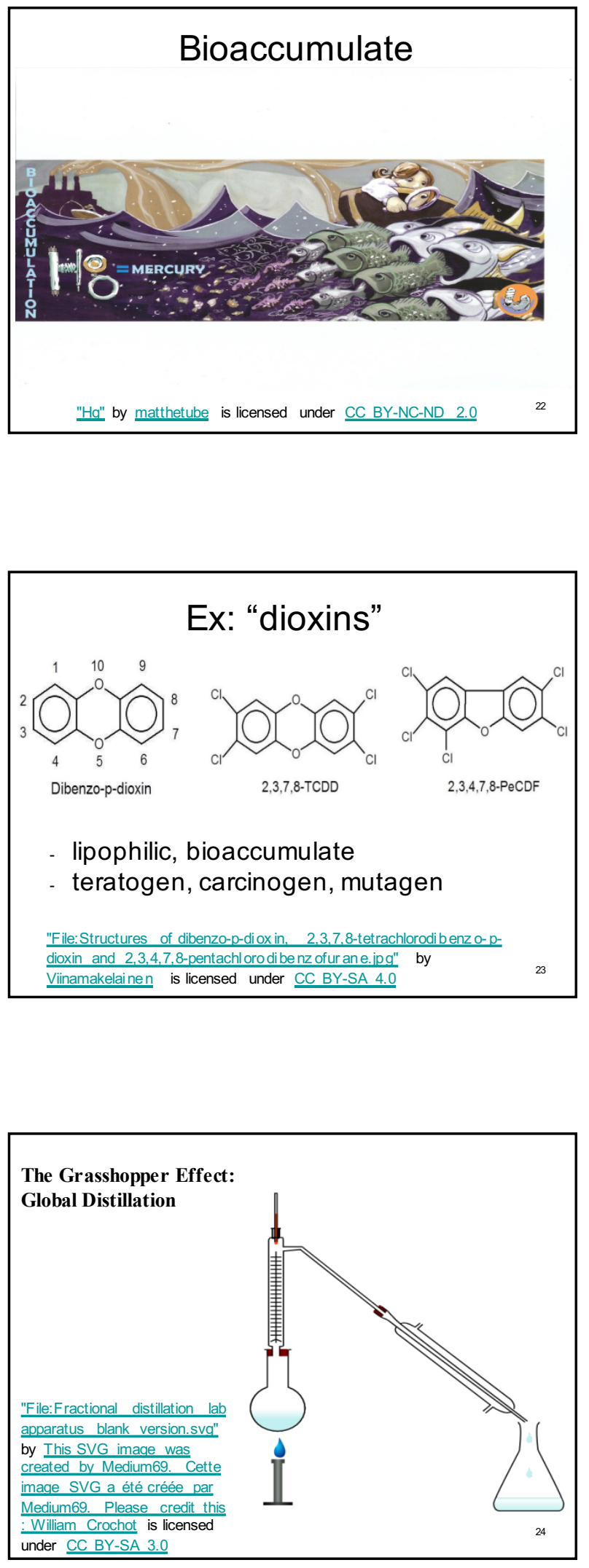


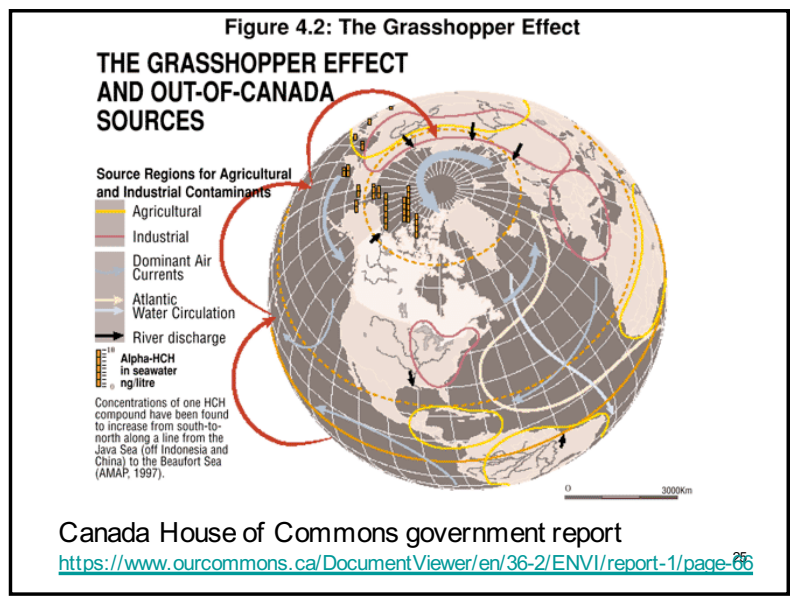

\begin{tabular}{|c|}
\hline Concentration Terms \\
Mass $\%=[$ mass solute/mass solution] x 100 \\
Molarity = moles solute/L of solution \\
Ex: What is the concentration (in mass \% \\
and $M$ ) of the resulting solution when you \\
add 5 grams of NaOH to 95 mL of water? \\
\end{tabular}

\begin{tabular}{|l|}
\hline Concentration Terms \\
Parts per hundred (percent) \\
$1 \mathrm{~g}$ of $\mathrm{NaCl}$ as part of $100 \mathrm{~g}$ of solution is a $1 \% \mathrm{NaCl}$ solution \\
1 in $100=1$ in $1 \times 10^{2}$ \\
Parts per million (ppm) \\
1 part solute in $1,000,000$ parts solvent $=1$ in $1 \times 10^{6}$ \\
Parts per billion (ppb) \\
1 part solute in $1,000,000,000$ parts solvent $=1$ in $1 \times 10^{9}$ \\
Ex: The maximum contaminant level [MCL] for dioxin in drinking \\
water is set at $3 \times 10^{8}$ ppm. A sample of drinking water is found to \\
contain $2 \times 10^{-4}$ ppb. Is the sample of water safe to drink? \\
\end{tabular}




\section{The $1 \%$}

- For example, present carbon dioxide concentrations in air 0.040 \%

- $\mathrm{Q}$ - if the indoor $\mathrm{CO}_{2}$ concentration in a building is measured at $4002 \mathrm{ppm}$, would this be considered normal?

- ie. What is the $0.040 \%$ concentration expressed as ppm?

\section{The $1 \%$}

- For example, carbon dioxide $=0.040 \%$ or $400 \mathrm{ppm}$.

So, the measurement of $4002 \mathrm{ppm}$ is 10 times the normal tropospheric $\left[\mathrm{CO}_{2}\right]$. (most likely, more outside air would need to be introduced to the building)

- The permissible upper limit for concern for ground level carbon monoxide is given as $0.009 \mathrm{ppt}$. A researcher finds the level in Winnipeg one day to be measuring at $6 \mathrm{ppm}$. What is the measured value in ppt and is this permissible?

-A. $0.06 \mathrm{ppt}$, this is not permissible

-B. $0.06 \mathrm{ppt}$, this is permissible

-C. $0.006 \mathrm{ppt}$, this is not permissible

-D. $0.006 \mathrm{ppt}$, this is permissible

-E. $0.0006 \mathrm{ppt}$, this not permissible 
- The permissible upperlimit for ground level ozone is $0.12 \mathrm{ppm}$. A researcher finds the level in Toronto one day to be measuring at $580 \mathrm{ppb}$. What is the measured value in ppm and is this of concern?

-A. $58 \mathrm{ppm}$, this is of concern

-B. $0.00058 \mathrm{ppm}$, this is of no concern

-C. $0.58 \mathrm{ppm}$, this is of concern

-D. $58 \mathrm{ppm}$, this is of no concern

-E. $0.58 \mathrm{ppm}$, this is of no concern. 


\section{Focus on Acid Precipitation}

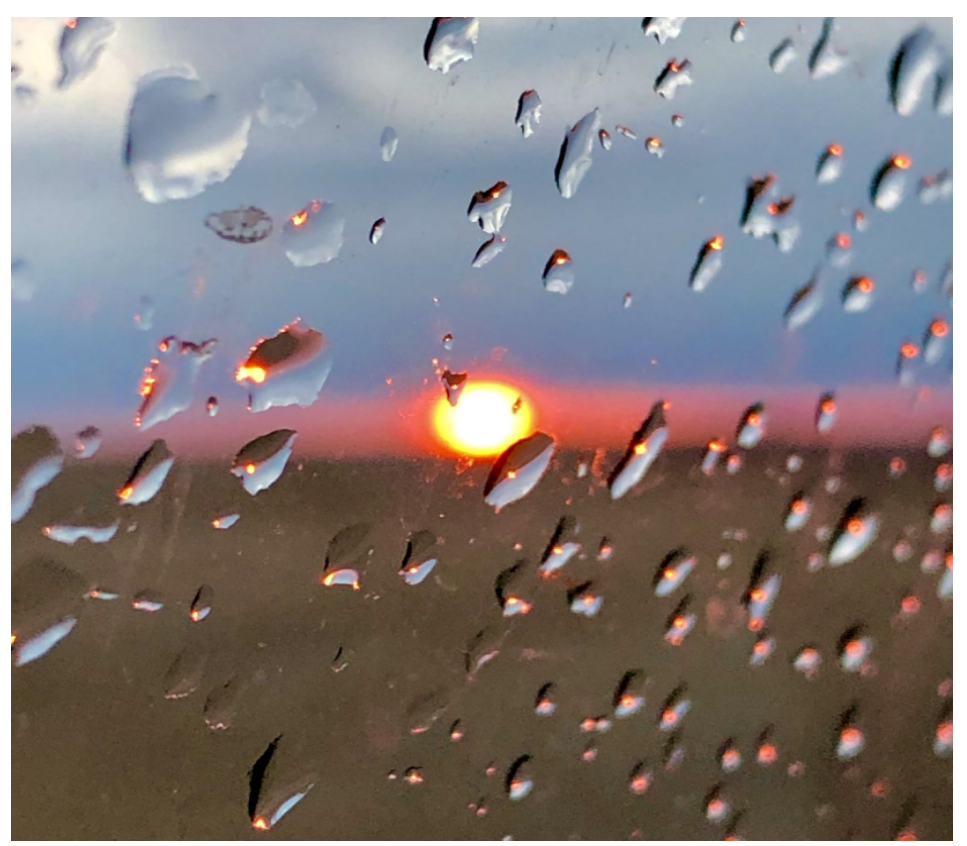

Photo by Steve Schlachter reproduced with permission

At many times, in many places, lakes and forests can experience a surge in acidity causing an unhealthy environment whereby the fish and trees in that ecosystem will die. What is an acid? Where does this extra acidity in the environment come from? Why are some places more prone to acidity than others? In many cases, it seems that the source of the acidity is found in one area, while the environmental effects of the acidity are observed in another. In this section, acids and bases will be introduced in the context of this 'extra acidity' and the source of what is referred to as 'acid precipitation' will be traced. While understanding whole ecosystems is quite complicated, a decent foundation in acidbase chemistry and the calculations involved with a number such as $\mathrm{pH}$ can enable a person to understand the data involved and take part in the discussions required to solve the problem.

Refer to the information discussed in the previous Focus section as well as Part XI of this text and elaborate on the following focus boxes, solving any problems that appear. 
One way to define an acid is as a substance that releases hydrogen ions, $\mathrm{H}^{+}$, in aqueous solution.

Since the hydrogen ion has no electron, and only one proton (hence the positive charge), the

hydrogen ion sometimes is referred to as a proton.

Example:

$$
\mathrm{HCl}(g) \stackrel{\mathrm{H}_{2} \mathrm{O}}{\longrightarrow} \underset{\text { (a proton) }}{\mathrm{H}^{+}(a q)}+\mathrm{Cl}^{-}(a q)
$$

However, in aqueous solution, the $\mathrm{H}^{+}$will be associated with a water molecule to form the hydronium ion, $\mathrm{H}_{3} \mathrm{O}^{+}$

One way to define a base is as a substance that releases hydroxide ions, $\mathrm{OH}$, in aqueous solution.

Show how each of these produce hydroxide in water:

$\mathrm{NaOH}$

$\mathrm{NH}_{3}$
When acids and bases react with each other, it is called a neutralization reaction.

$$
\mathrm{HCl}(a q)+\mathrm{NaOH}(a q) \longrightarrow \mathrm{NaCl}(a q)+\mathrm{H}_{2} \mathrm{O}(\text { () }
$$

In neutralization reactions, hydrogen ions from an acid combine with the hydroxide ions from a base to form molecules of water.

The other product is a salt (an ionic compound) and will often be dissolved in the aqueous solution. 


\section{$\mathrm{pH}$ and $\mathrm{pOH}$}

a measure of the concentration of $\mathrm{H}_{3} \mathrm{O}^{+}$

$(\mathrm{pH})$ and $\mathrm{OH}^{-}(\mathrm{pOH})$ in solution.

$$
\begin{aligned}
& \mathrm{pH}=-\log \left[\mathrm{H}_{3} \mathrm{O}^{+}\right] \\
& \mathrm{pOH}=-\log \left[\mathrm{OH}^{-}\right] \\
& \mathrm{pH}+\mathrm{pOH}=14
\end{aligned}
$$

What is the $\mathrm{pH}$ of a solution with $\left[\mathrm{H}_{3} \mathrm{O}^{+}\right]=1.0 \times 10^{-7} \mathrm{M}$ ? What is the $\mathrm{pOH}$

What is the $\mathrm{pH}$ of a solution with $\left[\mathrm{H}_{3} \mathrm{O}^{+}\right]=2.0 \times 10^{-6} \mathrm{M}$ ? What is the $\mathrm{pOH}$

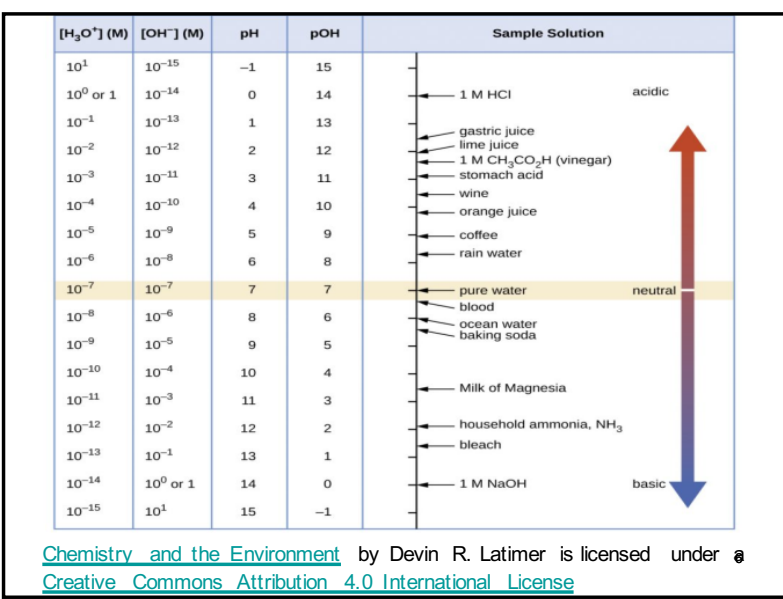


Pure water has a $\mathrm{pH}$ of 7.0, while normal rain has a $\mathrm{pH}$ of around 5.7 because of dissolved $\mathrm{CO}_{2}$. Show how the dissolution of $\mathrm{CO}_{2}$ in water produces carbonic acid $\mathrm{H}_{2} \mathrm{CO}_{3}$ which then reacts with water to produce hydronium ions.

But acid precipitation can have very low $\mathrm{pH}$ values

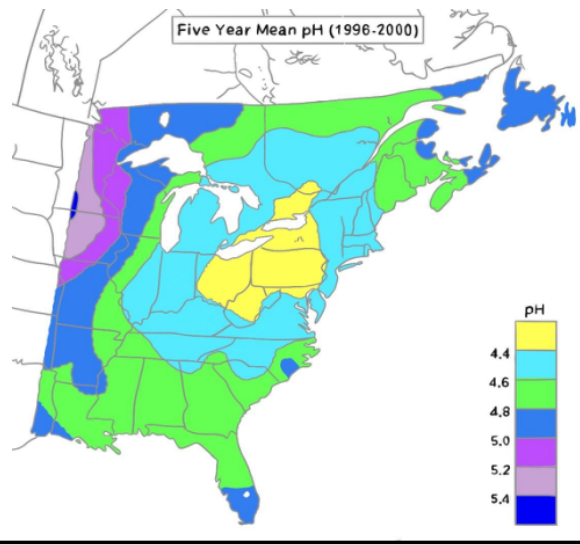

Remember: Because the $\mathrm{pH}$ scale is logarithmic, 1 unit of $\mathrm{pH}$ is a difference of 10 times in the amount of acidity.

Analysis of rain for specific compounds has indicated that the primary components responsible for the extra acidity are the oxides of sulfur and nitrogen. Explain, using chemical reactions, how the combustion of coal can lead to oxides of sulfur and nitrogen, and to acidic aqueous solutions. 
Acidic precipitation damages forests, aquatic life, monuments

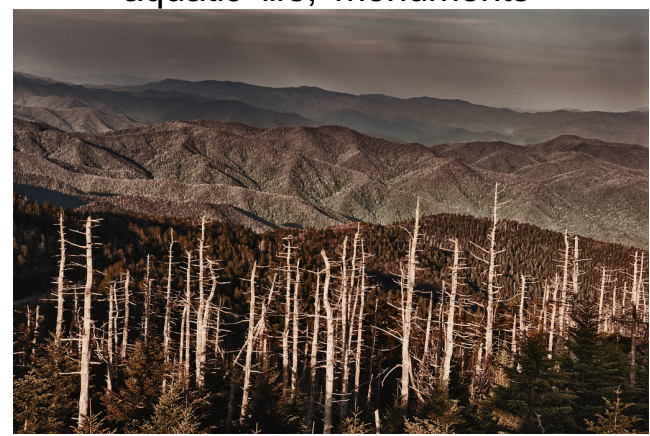

Smokey Mountain National Park - Acid Rain on Top" by You want it darker is licensed under CC BY-NC-ND 2.0

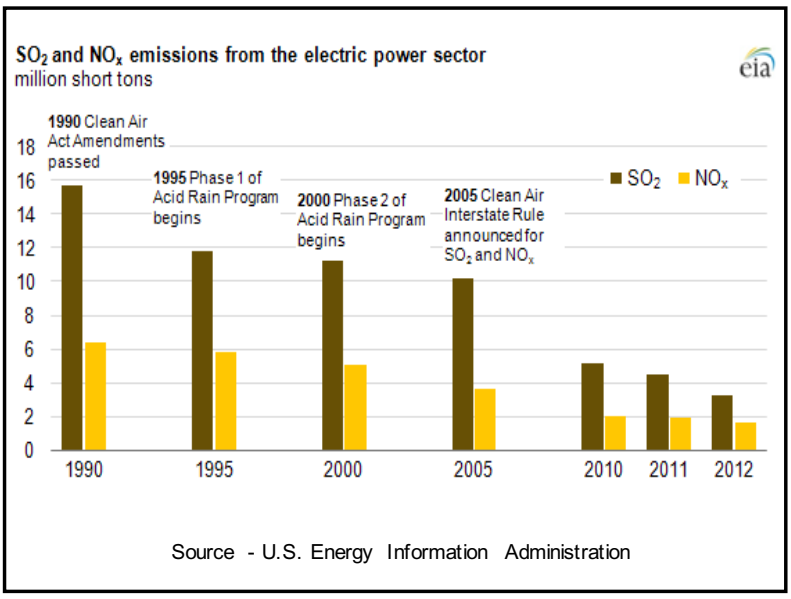

BBC - The bittersweet story of how we stopped acid rain (ELA)

https://www. bbc.com/future/article/20190823-canlessons-from-acid-rain-help-stop-climate-change 


\section{Focus on Polymers}

Synthetic polymers were developed in the early $20^{\text {th }}$ century, and since that time have become ubiquitous in our world. The clothing, the helmet and the goggles on the people riding these snowmobiles and, indeed, even the material that makes up the housing of the snowmobiles, are all synthetic polymers.

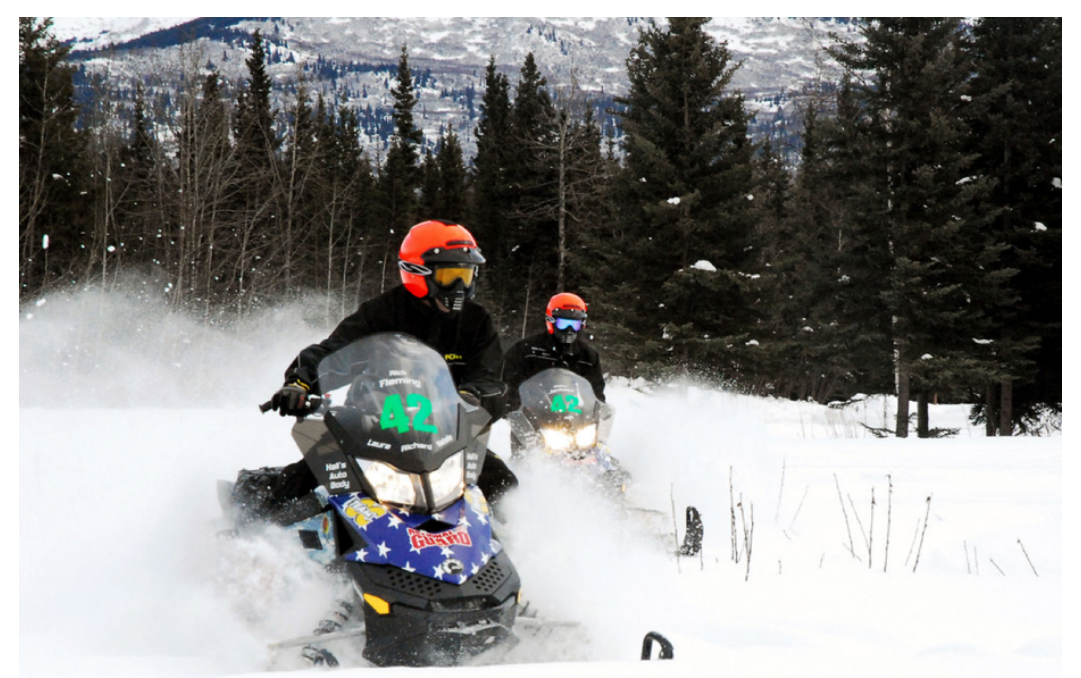

"Alaska National Guard Iron Dog snowmobile race, Camp Denali, Alaska" by The U.S. Army is licensed under CC BY 2.0

The computers we work on, our cell phones and much of the furniture around us all have a large number of different polymers involved in them. The success of these materials, however, is a double-edged sword - their variety continues to provide us with amazing and useful materials, but the fact that they are cheap, vast and persistent is also causing a unique environmental catastrophe. In this section, the basic reactions involved in producing the most common polymers will be examined along with a survey of associated environmental issues and current developments being made to address those issues.

Refer to the information discussed in the previous Focus section as well as Part XIII of this text and elaborate on the following focus boxes, solving any problems that appear. 
A monomer is a molecule that forms the basic unit for polymers. Monomers bind to other monomers to form repeating chain molecules through a process known as polymerization.

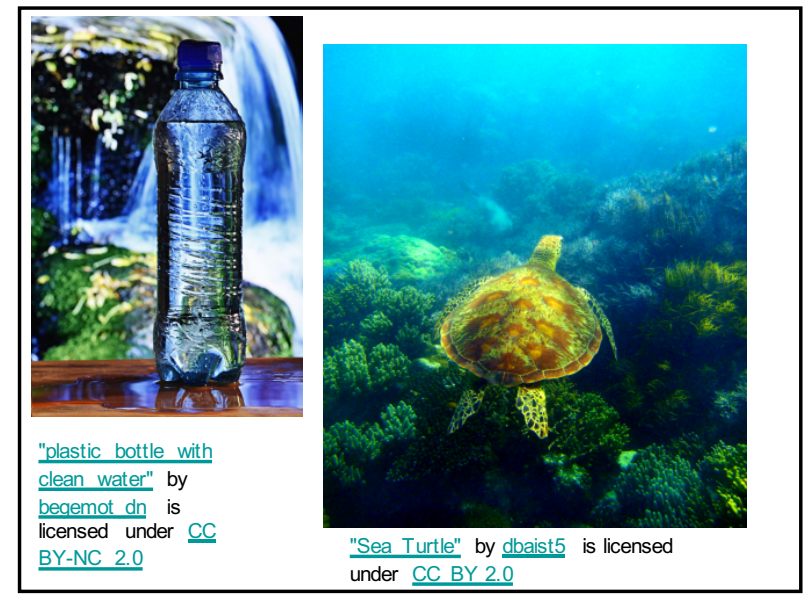

\section{Addition polymers}

Ex: Show the initiation and beginning of chain growth for the formation of polyethylene

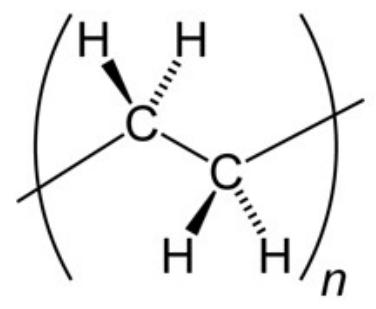




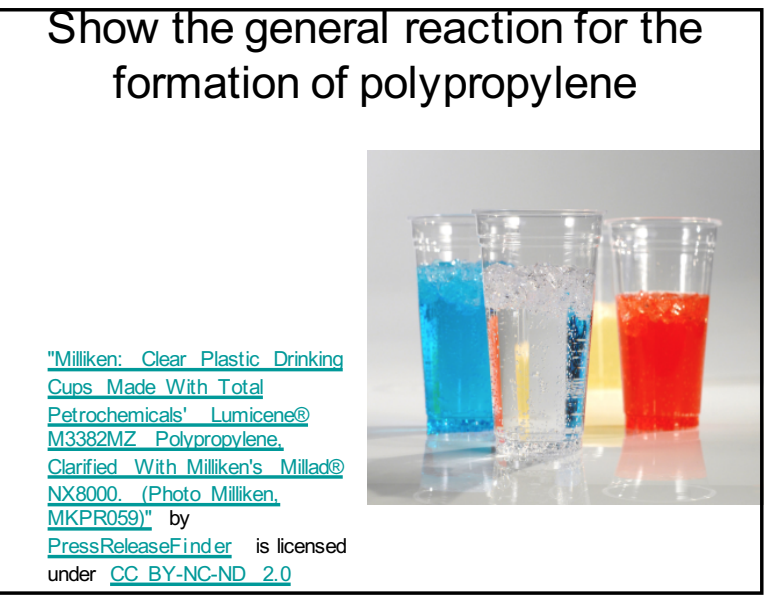

Show the general reaction for the formation of polystyrene

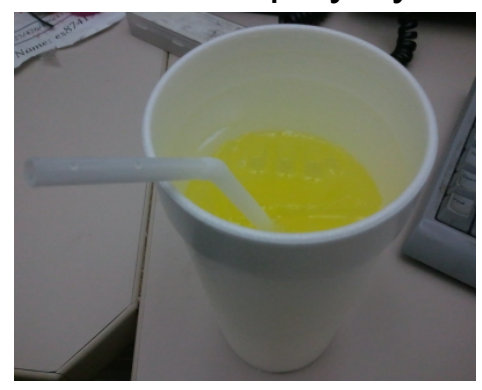

"expanded polystyrene" by Richard Masoner / Cyclelicious is licensed under CC BY-SA 2.0

Show the general reaction for the formation of Polyvinyl chloride

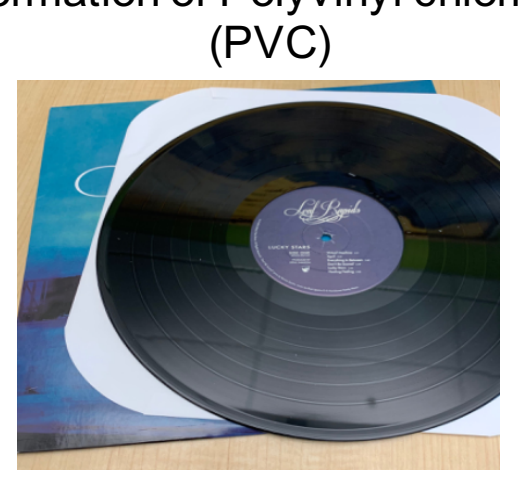


How many chloroethene (vinyl chloride) subunits are in a molecule of polyvinyl chloride with a molar mass of $3122.5 \mathrm{~g} / \mathrm{mole}$ ?

- A. 100

- B. 500

- C. 250

- D. 50

- E. 550
What is the molar mass of one molecule of polypropylene with 300 propylene subunits?

- A. 12,600

- B. 6,300

- C. 25,200

- D. 100,800

- E. 50,400

\section{Condensation Polymers}

- Monomer units join by eliminating (splitting out) a small molecule, often water.

- Ex: show the reaction for the formation of polyethylene terephthalate (PET)

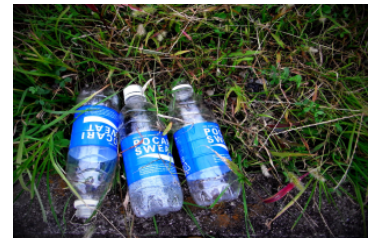

"Polyethylene Terephthalate" by chidorian is licensed under CC BY-SA 2.0 


\section{Polycarbonates}

- The main polycarbonate material is produced by the reaction of bisphenol $\mathrm{A}$ and phosgene $\mathrm{COCl} 2$.

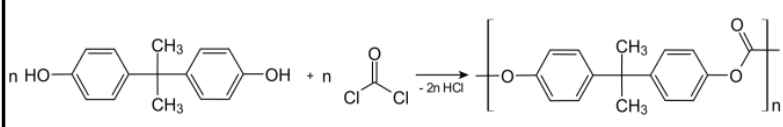

- strong, transparent

- Have a number of uses and were once used in the production of drinking bottles.

\section{Polycarbonates and bisphenol A}<smiles>CC(C)(c1ccc(O)cc1)c1ccc(O)cc1</smiles>

- Bisphenol A: estrogen-mimicking, hormone-like properties

Various studies have found a range of effects - from 'significant' to 'none'

\section{Polycarbonates and bisphenol A}<smiles>CC(C)(c1ccc(O)cc1)c1ccc(O)cc1</smiles>

- Bisphenol A: estrogen-mimicking, hormone-like properties

- Bisphenol A leachate low-dose effects (Saal and Hughes; https://ehp.niehs.nih.gov/doi/10.1289/ehp.7713)

- Industry-funded studies tend to find no significant effects

- government-funded studies tend to find significant effects 
Commercial polymers also normally have a number of other additives and processing agents

- Antioxidants, blowing agents, colorants, coupling agents, flame retardants, heat stabilisers, impact modifiers, lubricants, plasticisers, preservatives, uv stabilisers, etc.

\section{After Use?}

- Re-use, Recycle, Down-cycle.

- Incineration

- Produces CO2 and potentially other harmful compounds

- Trash - Landfill

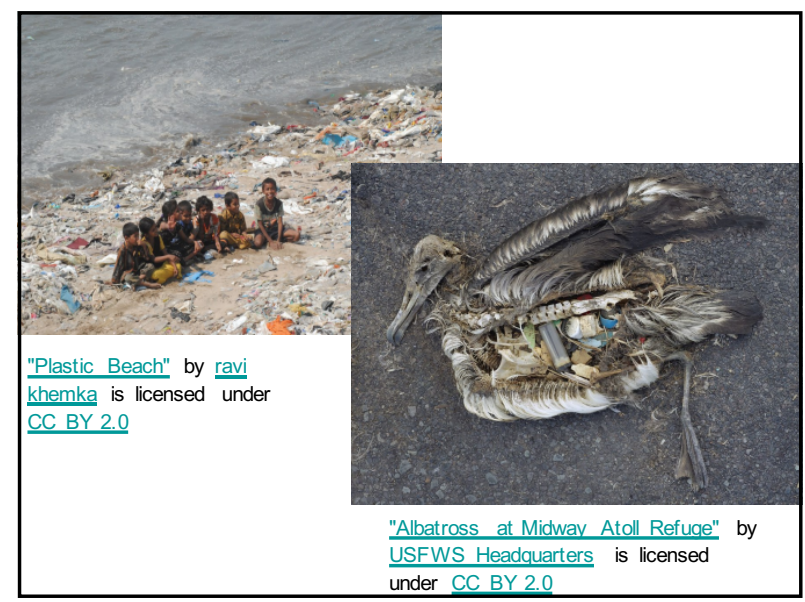




\section{National Geographic - biodegradable polymers}

https://www. nationalgeographic.com/environment 2018/11/are-bioplastics-made-from-plants-

better-for-environment-ocean-plastic/\#close

\section{After Use?}

- Re-use, Recycle, Down-cycle-ex: depolymerization

- Energy intensive, low market value.

- Incineration - high energy content, - Produces $\mathrm{CO} 2$ and potentially other harmful compounds

- Trash/Landfill

- Biodegradation - some natural polymers are degraded by worms, bacteria and fungi.

- must be designed into the polymer

- disposal sites must be redesigned to allow this. 


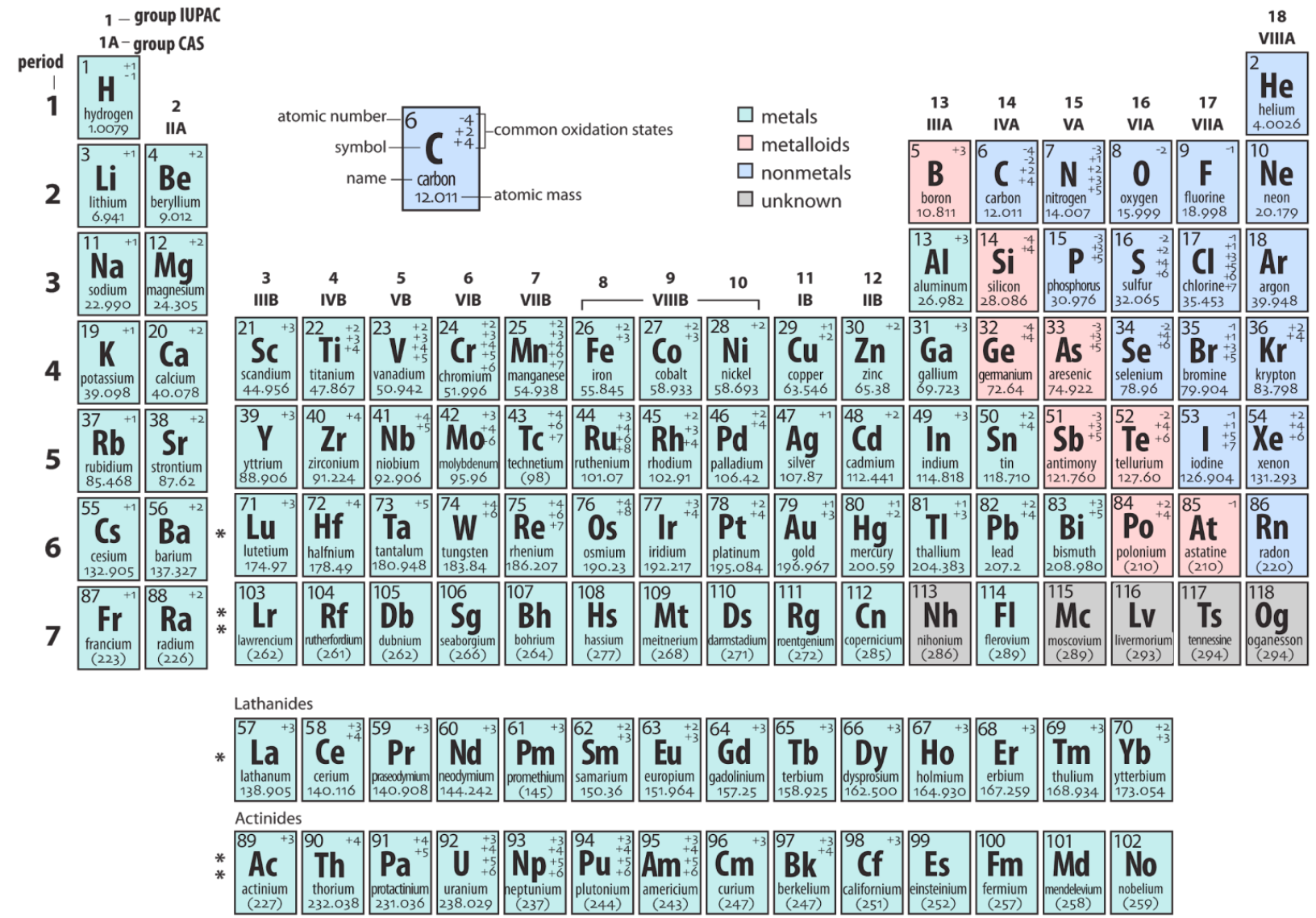

"File:Periodic table AH.png" by Ahazard.sciencewriter is licensed under CC BY-SA $\underline{4.0}$ 